Aug dem anatomischen Ingtitut der Universitát Kristiania.

\title{
UNTERSUCHUNGEN ÜBER DEN BAU DER LEBER BEI NIEDEREN WIRBELTIEREN ${ }^{1}$.
}

VON

LARS SOMMERFELT.

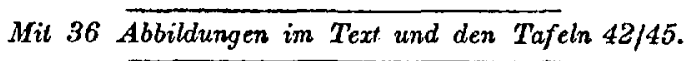

1) Die vorliegende Arbeit gibt in verkürzter Form die wichtigsten Ergebnisse einer Untersuehnng uber den Bau der Wirbeltierleber, welche als Beantwortung einer von der medizinischen Fakultat Kristiania aufgestellten Preisaufgabe am 15. April 1914 eingeliefert wurde. 
Kapitel 1.

\section{a) Einleitung und historische Übersicht.}

Mit Herings (1866) und Eberths.(1866, 1867) Arbeiten aus den Jahren 1866 bzw. 1867 beginnt ein, neuer $A b$ schnitt in der Erforschung des anatomischen Baus der Leber und ihrer phylogenetischen Entwickelung. Die früheren ebenso zahlreichen wie sich stark widersprechenden Auffassungen machten den Ergebnissen der' Arbeit dieser Forscher Platz. Die Tatsachen, die sie an deñ Tag gebracht habien, und die Bilder von Leberformen, die sie uns gegeben, haben den Grundwall für den allergrössten Teil der späteren anatomischen Leberforschung gebildet. - Besonders Herings (1866a, 1866 b) beide Arbeiten scheinen sofort die grösste Aufmerksamkeit erregt zu habien. Auf der Grundlage von Untersuchungen der Leber bei verschiedenen Amphibien, Coluber na. trix und beim Kaninchen kommt er zu dem Ergebnis; dass die. Wirbeltierleber $\mathrm{im}^{\prime}$ allgemeinen als eine netzförmige tubulöse Drüse bezeichnet werden muss: „Die Säugetierleber. im besonderen aber weicht derart ab, dass von einem eigentlichen tubulösen Bau gar nichts zu sehen ist. Alle die oft wiederholten Angaben von einem tubulösen Baue der Säugetierleber muss ich als irrig bezeichnen." - Diese Leber, meint er, ist aus Leberlobuli zusammengesetzt, die aus einer Zellmasse bestehen, welche rings um eine Centralvene angeordnet und von deren radial ausstrahlenden Capillaren durchsetzt ist. 
- Diese sind wieder durch Queräste verbunden. In bezug auf die Verbindung der Leberzellen mit den Galle- und Blutcapillaren nimmt er ein Verhältnis an, das schematisch am besten durch sein berühmtes „H e ring sches Lebermodell“ beleuchtet wird. Diestes zeigt, dass die Gallencapillaren längs der Flächen der Zellen, die Blutcapillaren längs' deren Ränder verlaufen.

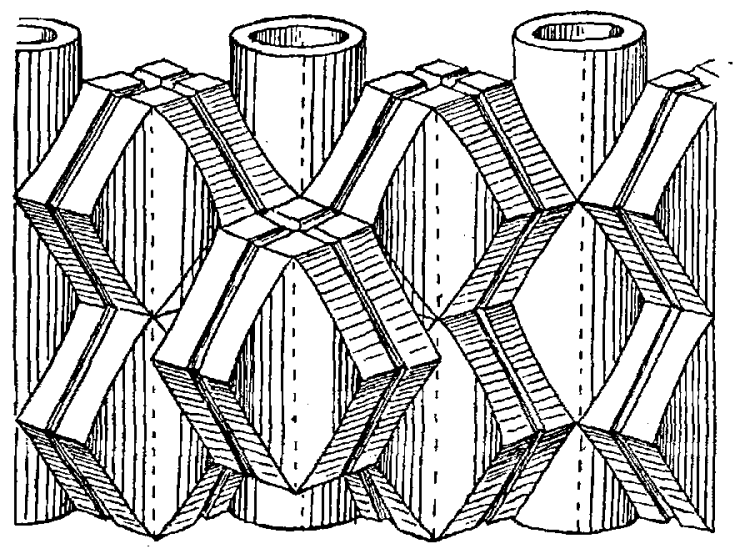

Fig. a.

Hering s Lebermodell (nach Braus, 1896).

Der Utbergang zwischen den beiden Leberformen (der allgemeinen, typischen) „Wirbeltierleber" und (der : speziellen Form) der "Säugetierleber" meint er in folgender Weise erklären zu können: „Von diesier dem' üblichen Drüsenschema genau entsprechenden Anordnung der Leberzellen bis zu derjenigen, welche dasi Säugetier zeigt, findet sich eine zusammenhängende Reihe von Übergängen. Die Zahl der Leberzellen, welche auf dem Querschnitt zur Bildung eines feinen Gallenweges zusammentreten, wird spärlicher, reduziert sich auf vier, drei und endlich auf zwei." Im letzteren Fall wird der feinste Gallengang nicht von den Ecken der Zellen gebildet, sondern dadurch, dass ihre Flächen auseinanderweichen. 
Ungefähr gleichzeitig mit Herings Arbeiten erschienen die von Eberth. Was die Leber der niederen Wirbeltiere anlangt, so kommt er in der Hauptsache zu denselben Ergebnisisen wie Hering. - Er weist ausserdem die blind endenden Äste der feinsten Gallenwege nach. - Diese, meint er, sind der erste Anfang zu dem bei den Säugetieren so reichen Netz von Gallencapillaren. - Den Unterschied zwischen der Leber der niederen Wirbeltiere und der der Säugetiere hält er für weniger wesentlich als Hering. Er besteht in der Hauptsache darin, dass die Gallencapillaren der letzteren feiner sind und reichere Verästelungen wie auch Anatomisierung aufweisen.

Das Bild, welches die beiden Verfasser von der Lebierstruktur sowohl der niederen Wirbeltiere wie der Säugetiere entworfen haben, halten wir jetzt für im wesentlichen richtig. Aber während wir dasi zugeben, können wir gleichzeitig nicht blind dafür sein, dass keine der beiden Theorien die phylogenetische Entwickelung der Leber befriedigend erklären. Herings Theorie gibt keine Erklärung dafür, woher alle die vielen rings um die Zellen der "Säugetierleber" laufenden Gallenciapillaren stammen. Nach E berth s Darstellung wird es unerklärlich, wi e die blinden, intercellulären Gallencapillaren sich vereinigen und ein Netzwerk bilden können, ohne die Blutcapillaren $\mathrm{zu}$ erreichen. - Die letztere Erscheinung, dass Gallen- und Blutcapillaren sich niemals berühren, ist durch so gut wie sämtliche Untersuchungen mit einer seltenen Einstimmigkeit bestätigt worden.

Man hat deshalb auf diesem, dem entwickelungsgeschichtlichen Punkte die wichtigsten Angriffe gegen die Theorien Herings und Eberths gerichtet.

Die nächste grössere Untersuchung auf diesem Gebiete wurde erst im Jahre 1889 von Shore. und Jones vorgenommen. Sie nahmen an, dass die Leber ursprünglich als eine 
tubulöse Drüse angelegt sei. Der tubulöse Bau sei dann während der Entwickelung verloren gegangen, dadurch, dass die Lebertubuli, denen, wie sie meinen, die Basalmembrane fehlt, sich zusammengelegt und eine einzige Zellmasse gebildet haben (wie bei Petromyzon). Von da an sollte dann wieder ein tubulöser Bau sich entwickelt haben, der dann später wiederum (bei den Säugetieren) verloren gegangen wäre. - Man dürfte kaum die Beweise, die die beiden Verfasser für ihre eigentümliche Theorie anführen, für ü'berzeugend halten.

Während Hering und Eberth. wesentlich mit künstlichen und physiologischen Injektionen gearbeitet haben, suchte G. Retzius (1892a, 1892 b) mittels der Golgimethode sich über die phylogenetische Entwickelung der Leber Klarheit zu verschaffen. Er untersuchte eine Reihe Vertreter aller Wirbeltierklassen, und zwar ausschliesslich durch Imprägnation nach Golgi. Seine Ergebnisse fasste er dahin zusammen, dass die Leber $\mathrm{k}$ e in e netzförmig-tubulöse, sondern eine verästelte tubulöse Drüse ist, und zwar wesentlich vom gleichen Typus von den niedrigsten bis zu den höchsten Wirbeltierformen. Dadurch gelang es ihm, eine Einheit zu schaffen, alle Lebern der Wirbeltiere in einer Gruppe zusammenzustellen; aber er erreichte das nur dadurch, dass er das Vorhandensein der von früheren Untersuchern nachgewiesenen Gallencapillarmaschen in Abrede stellte. Und gerade diese waren es ja, die entwickelungsgeschichtlich so grosse Schwierigkeiten verursacht hatten. - Seine Arbeit mit den umwälzenden Begriffen und Ergebnissen erregte die grösste Aufmerksamkeit - und bald auch den stärksten Widerspruch. Eine Reihe Forscher sind später mittels derselben Methode zu genau der entgegengesetzten Auffassung gelangt, da sie bei einer Menge Arten reichliche Mengen Gallencapillarmaschen gefunden haben. Besonders hat Braus (1896) sich hier bedeutende Verdienste erworben. Er hat durch verschiedene Methoden teilweise die- 
Untersuchungen über den Bau der Leher bei niederen Wirheltieren. 671

selben Arten untersucht, wie G. Retzius, und dadurch mit Kraft dessen Behauptungen widerlegt. - Retzius hat denn auch später (1898) eingeräumt, dass er bei Nachprüfung seiner Präparate gefunden habe, dass er in bezug auf die Maschenbildung zu skeptisch gewesen sei.

In seiner oben erwähnten Arbeit hat dann Braus an der Hand eines grossen Materials. die letzte grosse Untersuchung über den Bau der Leber ausigeführt. Nach umfassenden Studien über zahlreiche Arten von $\mathrm{Cyclos}$ tomen, $\mathrm{Pisces}$, A m' phibien, Reptilien and Mammalia gelangt er zu der Auffassung, dass es drei Typen von Leberstruktur gibt: Die Myxinoide-, die Amphibien- und die Säugetier leber. Von diesen weist die Myxinoideleber einen verästelttubulösen und die Amphibienleber einen wesentlich netzförmigtubulösen Bau auf. In seiner Ansicht über die „Säugetierleber" stimmt er im grossen ganzen der früheren Auffassung über dieselbe bei. Wenn er auch anderseits neue und grundlegende Beobachtungen über die Leberstruktur der niederen Säugetierformen gemacht hat. Er glaubt, ,dass die drei Typen divergente Bildungen sind. Die gemeinsame Grundform der drei Bildungsrichtungen lässt sich charakterisieren als ein Organ mit tubulöser Anordnung der Leberzellen, mit weit verästelten Centralcapillaren und gut ausgebildeten Seitencapillaren". Insbesondere leitet er die Süugetier- und Amphibienleber von der Leber einer Tierform ab, die niedriger stand, als die jetzt lebenden Amphibien, der Proamphibien.

Ausser zahlreichen Einzelheiten liefert $\mathrm{Braus}$ in seiner Arbeit einen wichtigen allgemeinen Beitrag zum Verständnis der Leberstruktur. Die Gallencapillarmaschen, die er findet, teilt er nämlich in vasozonale, diejenigen, die ein Blutcapillar umschliessen, und in cytozonale ein, die, welche nur um eine oder mehrere Leberzellen herumigehen. Er hebt hervor, dass das Vorkommen von vasozonalen Maschen nur ein Ausdruck 
für einen verä nderten tubulösen Bau ist, während die cytozonalen Maschen dagegen eine Auflösung des Baues bezeichnen, also einen Auflösungsprozess markieren.

Bra u s' Theorie gründet sich auf ein reiches und mit den Hilfsmitteln einer modernen Technik untersuchtes Material. Sie musste deshalb begreiflicherweise bedeutende Aufmerksamkeit erregen und scheint jetzt allgemein als vollständig richtig angenommen zu sein, was ja auch nicht verwundern kann. Shores' und Jones' Auffassung hat nicht vermocht, sich durchzusetzen, Braus' Theorie bleibt demnach die einzige, die eine Art Erklärung der Entwickelung liefert,. - allerdings dadurch, dass sie deren Zusammenhang verneint.

Brau s' Arbeit bildet den letzten grossen Versuch, ein erschöpfendes Gesamtbild des Baues der Wirbeltierleber zu geben. Nach seinen Ergebnissen muss $H$ e ring $s$ und $E$ ber th $\mathrm{s}$ „Wirbeltierleber"-Begriff in zwei gut charakterisierte Leberformen aufgelöst werden, den Myxinoiden- und den Amphibientypus, beide hervorgegangen aus divergenter Entwickelung eines gemeinsamen hypothetischen Typus.

Die vergleichenden Untersuchungen über den Bau der Leber bei niederen Wirbeltieren, deren Ergebnisse nachstehend mitgeteilt werden sollen, haben zum Ziel, zur weiteren Klarlegung der Frage beizutragen, ob der Bau der Wirbeltierleben grundsätzlich, wie Hering und $\mathrm{Ebertb}$ meinten, bei den niederen Wirbeltieren Einheit, oder wie von B r a u s verfochten, verschiedene Typen aufweist.

\section{b) Untersuchungsmaterial.}

Bei der Wahl meines Materials habe ich vorzugsweise die Arten benutzt, diè früher in dieser Verbindung nicht bearbeitet worden sind. Dafür habe ich die Befriedigung, wenigstens einzelne, bisher noch nicht beschriebene Leberarten zu bereits bekannten hinzugefügt zu haben. - Ich' habe durchgängig 
eine Art aus jeder Ordnung gewählt, die mir zugänglich war. Ein derartig begrenztes Material, meine ich, ist zum Studium des grundsätzlichen Leberbaus der in Betracht kommenden Tierklassen hinreichend.

Als die am primitivsten gebaute Chordatleber wird gewöhnlich die blindsackförmige Ausbuchtung der Darmröhre bei A mphioxus angeführt. Man hat auch gemeint, dass ihre Zellen eine Galle absondern. Dieses Anhängsel an die Darmröhre zeigt indessen ganz denselben feineren Bau wie diese selbst. Ich habe deshalb geglaubt, dass es ohne Interesse für die Frage sei, die in der vorliegenden Arbeit behandelt werden soll, diese Amphioxusleber in meine Untersuchung einzubeziehen.

Eine mehr entwickelte Leber trifft man erst bei den $\mathrm{Cy}$ clostomen an. Da die Myxine glutinosas-Leber einen der von $\mathrm{Br}$ aus angenommenen drei grundsätzlich verschiedenen Lebertypen darstellt, wählte ich sie zum Gegenstand meiner Untersuchung. Entscheidend für meine Wahl war auch die eigentümliche Veränderung, welche die Petromyzontidaes-Leber bei der Verwandlung von Ammocoetes zu Petromyzon durchmacht. Hierdurch wird diese etwas ausserhalb der allgemeinen Lebertypen gestellt.

Unter den. Knorpelfischen wählte ich Spinax niger, von welcher Art ich ohne Schwierigkeit mir sowohl vollständig entwickelte Individuen, wie auch Embryonalstadien verschaffen konnte. Die letzteren müssen nämlich bei den Knorpelfischen einer etwaigen Untersuchung zugrunde gelegt werden wegen des ungeheuren Fettreichtums der Leber in dieser extrauterinen Lebensperiode. - Ich weise des näheren hierüber auf den speziellen Teil hin.

Von Knochenfischen habe ich besonders mit Syngnathus rostellatus gearbeitet, dessen Leber durch ihre 
auffallende Fettlosigkeit ein in vieler Hinsicht gutes Material darstellt.

Unter den Anura wählte ich Bufocinereus und von den Urodela die Art Triton punctatus. Keine von diesen Leberarten ist früher bearbeitet worden. Shore und Jones (1889) führen nur ,newt (triton) “ an, ohne die Art näher anzugeben.

Bei den früheren Arbeiten über den Bau der Leber hat. man, soweit die "Wirbeltierleber" in Betracht kommt, nur eine einzelne Seite derselben studiert. Man hat so gut wie ausschliesslich sich auf die Erörterung der Frage nach dem gegenseitigen Verhältnis zwischen Gallencapillaren, Leberzellen und Blutcapillaren beschränkt. Bei einigen Einzeluntersuchungen findet man allerdings verstreute Bemerkungen über die Anordnung des gröberen Teils des Gefässsystems der Leber und der Gallengänge und von $\mathrm{Hyrtls}$ (1864) Hand stammt eine in ihrer Art einzig dastehende Arbeit, in der gerade diese Dinge eingehend bei Fischen und Amphibien bchandelt werden. Aber sämtliche Arbeiten, die die grossen Linien in der Erörterung über die phylogenetische Entwickelung der Leber angegeben haben, nehmen nur Rücksicht auf die Parenchymstruktur. Shore und Jones (1889) haben zwar bei einzelnen der von ihnen untersuchten Leberarten das Verhältnis der Gefässe und Gallengünge behandelt, aber sehr wenig eingehend und mittels Arbeitsmethoden, die ihren Befunden zum grössten Teil nur geringen Wert verleihen.

Indem die früheren Verfasser ihre Arbeit auf die Untersuchung der Anordnung des Leberparenchyms konzentrieren, haben sie zwar sclbstverständlich an sich etwas von dem Centralen im Bau der Leber herausgegriffen, etwas, das vielleicht in besonderem Grade ihr die einzigartige Stellung gibt, die sie unter den Drüsenorganen einnimmt. $\Delta$ ber ist wohl eigentlich der Gegenstand durch das 
Studium dieser eigentümlichen Parenchymstruktur erschöpft worden? Hat man dadurch entscheidend und vollständig die Charakteristik der Leber gegebien? Was wir über die „Süugetierleber": wissen, sagt uns, dass dies nicht der Fall ist. Gerade hier sehen wir, wie auch die grösseren Gefässe, die Gallenausführgänge und das Bindegewebe innig und charakteristisch mit dem ganzen eigentümlichen Bau der Leber verbunden sind. Wie gerade sie auch dazu beitragen, dieser ihr eigenartiges Gepräge zu geben.

Wenn dies aber bei der „Säugetierleber" der Fall ist, so erscheint es mir als eine ausserordentlich interessante und naheliegende Aufgabe, zu untersuchen, ob etwas Ähnliches auch für die Leber der niederen Wirbeltiere gilt. Vielleicht ist das Bild, das wir uns von dieser gemacht haben, nicht völlig erschöpfend? Vielleicht ist sie etwas mehr, als bloss eine netzförmig-tubulöse Drüse mit einem zweiten Netz von Blutcapillaren, das in dem Netzwerk der Tubuli drinliegt, und mit einigen cytozonalen Maschen ?

Was in vergleichend-anatomischer Hinsicht bei den Gallengängen von Interesse ist, ist wesentlich der in der Leber drinliegende Teil. Sowohl weil wir wissen, welchen äusserst charakteristischen Bestandteil gerade dieser Teil bei den am höch'sten stehenden Leberformen darstellt, wie auch weil der andere, ausserhalb der Leber liegende Teil keine homologe Bildung ist (Gegenbaur, 1901).

Ich will mich deshalb bei meiner Arbeit auf die Unter. suchung des strukturellen Verhältnisses des Leberparenchyms sowie auf das Studium von Gefässen und des in der Leber, selbst liegenden Teils der gröberen Gallengänge beschränken. Um meine Arbeit in angemessenen Grenzen zu halten, lasse ich die vielen anderen Fragen unberührt. Ich beabsichtige also z. B. nicht, das Studium des cytologischen Teils des mikroskopischen Baues der Leber aufzunehmen. 


\section{c) Technik.}

Die Imprägnierung nach $\mathrm{G}$ olg is Methode ist mein Hauptmittel gewesen beim Studium des Verhältnisses der Gallencapillaren. Ich bin im allgemeinen nach Stöhrs'(1910) Anweisung vorgegangen, wobei ich jedoch natürlich für die einzelnen Gegenstände das Verfahren empirisch etwas variieren musste.

Die Schnitte habe ich in der gewöhnlichen Weise auf der Unterseite von Deckgläsern angebracht und sie in Kanadabalsam eingeschlossen. Sie werden dadurch einer Immersionsuntersuchung zugänglich, und mittels dieser kann man die topographischen Verhältnisse der Gallencapillaren in Schnitten von passender Dicke mit Leichtigkeit verfolgen. Die Dicke der Schnitte wird für jede Art empirisch bestimmt. Man benutzt die Schnitte, die so dick sind, dass sie die Möglichkeit geben, die Gallencapillaren ein Stück zu verfolgen, und gleichzeitig dünn genug sind, um ihren Verlauf durch Immersionslinsen kontrollieren zu können.

Das gewöhnliche Schwärzen nach Golgi habe ich am häufigsten von allen Verfahren zu Leberuntersuchungen angewendet. Es gibt auch schöne und lehrreiche Bilder.

Eine Modifikation ist die Imprägnation mit nachfolgender Kernfärbung. Wenn diese gut gelungen ist, erzielt man mit ihr womöglich noch schönere Ergebnisse, da sie eine klare Orientierung über das gegenseitige Verhältnis der Leberzellen und Gallencapillaren gestattet. - Auch hierbei habe ich Stöhrs Anweisung bei Behandlung mit Chlornatrium' befolgt. Diese Modifikation ist, soweit ich sehen kann, bisher bei Leberuntersuchungen bei niederen Wirbeltieren nicht angewandt worden.

Ich will deshalb kurz erwähnen, dass ich unter den Kernfärbestoffen eine ganze Reihe:versucht habe (Safranin, Bismarckbraun, Boraxkarmin, Alaunkarmin und verschiedene Häma- 
toxyline), von denen ich Gren a chers Alaunkarmin den Vorzug geben muss. Delafield s Hämatoxylin lieferte ebenfalls gute Ergebnisse; aber die blaue Farbe unterscheidet sich nicht so scharf von der schwarzen Farbe der geschwärzten Gallencapillaren, wie die rote Karminfarbe.

Um die Vorteile der Imprägnation und Injektion unmittelbar zu verbinden, habe ich auch das Golgische Verfahren an im voraus gefässinjizierten Lebern versucht; aber leider ohne brauchbare Ergebnisse zu erzielen.

Die klassische Technik beim Studium von Gallencapillaren ist die Injektion von Farbstoffen, direkt und physiologisch. Mit vollem Recht ist sie jetzt durch das Golgi verfahren verdrängt worden. Insbesondere lässt sich von der direkten Injektion nicht behaupten, dasis sie in sonderlichem Grad mehr leistet als G ol g is Methode, und sie hat in ihren ,Extravasaten“" eine Fehlerquelle, die sich schwer, wenn überhaupt, nachprüfen lässt. - Einen gemeinsamen Zug haben beide Formen von Injektionen in ihrer schweren, ja mitunter undurchführbaren Technik. Und allein das gibt der technisch leichten, wenn auch launenvollen Grolg i methode einen Vorzug.

In der Hoffnung, dass sie für meine Arbeit Ergebnisse von einiger Bedeutung liefern könnten, habe ich indesisen bei mehreren Gegenständen beide Formen von Injektion der Gallencapillaren angewendet. Ich muss allerdings zugeben, mit wenig befriedigendem Ergebnis'.

Gewisse Züge der Anordnung der Gallencapillaren kommen selbstverständlich sehr schön zum Vorschein in auf gewöhnliche Weise fixierten und gefärbten Präparaten. Besonders beim Detailstudium wird man auf diese Weise oft wertvolle und lehrreiche Bilder finden können. Unter den besten, Fixierungsflüssigkeiten zu diesem $Z$ weck steht die von $\mathrm{Z}$ e $\mathrm{n} \mathrm{k}$ e $\mathrm{r}$ in einer besonderen Klasse für sich. Nach meiner Erfahrung kann keine der anderen, die ich angewendet habe, gegen diese 
aufkommen, was sichere und gute. Fixierung betrifft. Aber ich habe auch mit 10\% Formalin häufig gute, bisweilen ausgezeichnete Ergebnisse erzielt. - Eine ganze Reihe anderer, darunter der von Braus (1896) rempfohlene Sublimat-Eisessig, lieferte bei mir weniger gute Ergebnisse. Ganz schlechte erhielt ich mit absolutem Alkohol.

Unter den benutzten Färbungen finde ich am befriedigendsten die gewöhnliche Hämatoxylion-Eosin-, B i on d is s Triacidund Heidenhains Hämatoxylin.Färbing. Die letztere für dünne Schnitte.

Beim Studium des intrahepatischen Gefässsystems und der Gallengänge habe ich mich Serienschnitte in erster Linie bedient. Entweder Serien durch das ganze Tier, oder durch seine Abdominalorgane im Situs. Wenn die anatomischen Verhältnisse so grob sind, wie hier, bietet die Arbeit mit solchen Serien keine Schwierigk'eiten und liefert auch vollständig zuverlässige Ergebnisse. Einzelne Male habe ich auch Injektionen mit gefärbten Flüssigkeiten angewandt.

Hiermit gehe ich zu dem speziellen Teil über. Über die mehr speziellen Verfahren und zahlreichen Einzelheiten wird man in den folgenden Abschnitten verstreut bei Besprechung der einzelnen Untersuchungen Genaueres angegeben finden.

Kapitel 2.

\section{Beschreibung der Befunde.}

a) Cyclostomen.

Myxine glutinosa.

Die Myx in e-Leber ist früher viermal untersucht worden, und zwar von G. Retzius, Braus, Holm und Cole. 
Untersuchungen über den Bau der Leber bei niederen Wirbeltieren. 679

Von bedeutendem Interesse für uns sind auch die eingehenden Studien über die Gefässversorgung der Leber, die besonders schwedische Forscher angestellt haben. - Schon im Jahre 1822 hat A. Retzius diese Frage behandelt. Leider ist seine Arbeit mir nicht zugänglich gewesen; aber da I. M üll e r (1839) anführt, er sei zu denselben, Ergebnissen gelangt wie A. Retzius, so habe ich gemeint, mich mit dem Studium seiner Arbeit begnügen zu können. : Er findet, dass die beiden Leberlappen mit Blut durch V. portae, einem Zweig nach jedem Lappen, versehen werden. Ferner beschreibt er eine A. hepatica, die von A. coeliaca ausgeht. - Das Blut wird in zwei Venae hepaticae, einer von jedem Lappen ausgehend, gesammelt.

$\mathrm{K}$ linckow ström (1890) bestätigt in allem wesentlichen diese früheren Untersuchungen. Er findet ebenfalls zu jedem Leberlappen eine $V$. portae, deren $Z$ weige in der Tiefe der Leber verlaufen. Vom vorderen Leberlappen hat er mitunter (wie A. Retzius) zwei, bisweilen (wie I. Mülle r) aber auch nur eine $V$. hepatica gefunden. ',Von 'den hinteren Leberlappen aber kommen ohne Ausnahme zwei Venae hepaticae, eine von der inneren, die andere von der äusseren.Seite." Sowohl A. Retzius wie I. Müller haben diese letztere Vene gekannt, die, wie sie finden, sich unmittelbar an der caudalen Spitze der Leber auflöst. Hier hat indessen K li n ck ow s tr ö m: durch seine Injektionen eine ausserordentlich interessante Beobachtung gemacht. „In Wirklichkeit verläuft sie ganz an der Oberfläche der Leber, nur von 'dem' Peritoneum bedeckt, bis zur hinteren Spitze der Leber, um dort am Rande des Liggmentum suspensorium der Leber verlaufend, die untere Seite des Darmes zu erreichen ......"

Von späteren Forschern haben Holm (1897) und Cole (1913) dieselben Fragen behandelt. Ich komme später hiorauf zurück bei der Besprechung ihrer Arbeit im übrigen. 
Wie bei allen seinen Leberstudien arbeitet $G$. Ret $z$ i u s (1892 b) nur mit dem Golgi-Verfahren. Er bespricht die M y $\mathrm{x}$ in e-Leber als eine tubulöse, verästelte Drüse mit dicken Gallencapillaren, die kurze Seitenäste haben. Irgendwelche Maschenbildung hat er nie gesehen. Im Jahre 1898 nimmt er von neuem die Frage an der Hand seiner alten Präparate auf und kommt zu dem gleichen Ergebnis.

Braus (1896) misslang die Imprägnation nach Golgis Verfahren stets vollständig. Er hat Injektionen nicht versucht und erwähnt auch nicht die Anwendung von Serienschnitten. Im grossen ganzen kommt er zu demselben Ergebnis wie G. Retzius: „Es scheint mir daher sicher, dass Myxine eine verästelte tubulöse Leber besitzt." Er meint, dass es sich erst durch Rekonstruktion, Imprägnation oder Injektionen sicher nachweisen lässt, ob trotzdem vereinzelte vasozonale. Maschen in dieser verästelten tubulösen Leber doch vorkommen. Und er fährt fort: „Für wahrscheinlich thalte ich das Vorkommen vasozonaler Netze nicht." Dagegen hat er ein seltenes Mal cytozonale Maschen gesehen, die dadurch gebildet waren, dass das centrale Gallencapillar sich in zwei Äste teilt, die sich bald wieder vereinigen. Sie finden sich an den Verzweigungsstellen der Tubuli. Eine derartige Masche umschliesst nicht eine einzelne Zelle, sondern immer nur kleinere Abschnitte mehrerer Zellen. Er meint, sie haben eine andere Genese als die cytozonalen Maschen der höheren Leberformen, aber misst ihnen trotzdem grosse Bedeutung bei. Sie sind ein Zeichen dafür, dass der tubulöse Bau schon bei den niedrigsten Formen anfängt, sich aufzulösen. - Er betont auch stark, dass die intercellularen Sekretcapillaren immer längs der Ränder der Zellen laufen und nicht nach ihren' Flächen. Mit Recht hebt er hervor, dass nur Querschnitte der Gallencapillaren zur Entscheidung der Frage führen können, ob sie längs der Zellenflächen oder längs der Zellränder liegen. Längenschnitte ermöglichen nämlich keine klare Orientierung über diese Frage. 
Untersuchungen über den Bau der Jeher bei niederen Wirbeltieren. 681

Die eingehendste Arbeit über den Bau der Myxineleber verdanken wir Holm (1897). Seine Schrift erschien also ungefähr gleichzeitig mit Braus' Abhandlung, und augenscheinlich haben beide von den Untersuchungen des anderen nichts gewusst. - Es ist sehr zu bedauern, dass er auch die älteren ausgezeichneten Arbeiten über die Gefässversorgung der Leber nicht gekannt hat. Holm ist zu seinen Ergebnissen ohne das Gro l g i - Verfahren gelangt, „da schon R e tzi u s die Resultate dieser Methode publiziert hat". Er hat Sublimatfixierung und später-verschiedene Färbungsmethoden benutzt, sowie Injektionen durch V. portae. - Ich will hier sofort bemerken, dass seine Technik (Fixierung mit Sublimat) nicht über jede Kritik erhoben ist. - In der wichtigen Frage nach der Struktur des Leberparenchyms' stimmt er mit G. Retzius überein. Neu ist dagegen seine Behauptung, dass die intercellularen Äste, die von dem centralen Gallencapillar ausgehen, bis ganz un die Peripherie der Tubuli heranreichen können. Er meint auch, dass die zuführenden Gefässe dicht unter der Leberkapsel liegen, während die abführenden central verlaufen. Über Gefässe und Gallengänge sagt er ferner noch: „Die in der Leber vorkommenden grösseren Blutgefässe bestehen aus einer sehr dünnen Intima, von einer Schicht längslaufender glatter Muskelfasern umgeben. Zwischen diesen Muskelfasern oder dicht ausserhalb der Schicht sind kleinere oder grössere Gallengänge in grosser Anzahl vorhanden. Ein jeder dieser Gänge ist von einer bindegewebigen Kapsel umgeben. Diese Kapsel liegt aber den Gallengängen nicht dicht an, sondern bildet ein äušseres Rohr, in welchem der Gallengang freiliegt." Die Gallengänge nehmen die Gallencapillaren in sich auf. Der Utbergang ist gradweise, das Epithel nimmt langsam an Höhe ab. Hierdurch erhält das Übergangsstück ein kegelförmiges Aussehen.

Die letzte Untersuchung der Myxineleber ist von Cole (1913) vorgenommen worden. Er hat eine bedeutende Arbeit 
auf das Studium der Blutversorgung der Leber verwendet, sowie auf die intrahepatische Anordnung der Lebergefässe. Aus seiner eingehenden Beschreibung des Verhältnisses der Lebergefässe geht hervor, dass er sich der alten Auffassung anschliesst, "die ein Ergebnis der Arbeiten von A. Retzius, I. Müller und teilweise auch der von Klinckowström ist. Die vom Letztgenannten beschriebene Vene, die yom Darm nach der Caudalspitze des hinteren Leberlappens geht, teilt. sich, wie Cole zeigt, in zwei Äste. Der eine setzt sich als V: hepatica fort, während sich der andere auf der Dorsalseite des Lappens zwischen den Tubuli verliert. Also bringt auch Klinckowströms Vene Blut nach der Leber; sie ist nicht bloss ein reines abführendes Gefäss. Ausser diesem neuen Moment bringt Coles Arbeit nichts wesentlich Neues über die Blutversorgung der Leber.

Die Pfortader und die Gallengänge haben einen gemeinsamen centralen Verlauf, den er sehr genau beschrcibt, und, sagt er, ,near the point of exit from the liver we encounter the usual portal canals consisting of one more branches of the portal vein, hepatic artery and hepatic duct enclosed in the connective tissue sheath of Francis Glisson".

Bei den mikroskopischen Untersuchungen findet er die Leber sehr gefässreich. Sie hat grosse, unregelmässige Blutsinusse ,only partially filled with blood“, die ,at first appear to have no definite walls“ - ,other blood-spaces have an obvious connective-tissue wall. The former are associated with the sub-instestinal and hepatic vein, the latter with the portal vein. In serial sections $I$ have been able to trace a direct continuity between the two types of spaces". Und an einer späteren Stelle spricht er als seine Auffassung aus, dass ,a coarse vascular network is disclosed which penetrates everywhere beween the liver tubules and constitutes not an capillary system, but a reticular sinus". 
In der Frage nach der Struktur des Parenchyms stimmen alle früheren Forscher überein. Sie finden sämtlich, dass sie verästelt-tubulös ist. Aber hiermit hört die Einigkeit auf. A. Retzius, I. Müller und Klinckowström finden, dass die zuführende Vene in die dorsale Fiäche der Leber einmündet. Die übrigen Gefässe sind abführend. Den genannten Untersuchern hat sich später auch $\mathrm{Col}$ e angeschlossen. Hol m dagegen huldigt genau der entgegengesetzten Auffassung. Er meint, dass es die abführende Vene ist, die auf der Dorsalseite die Leberlappen verlüsst. Aber die Uneinigkeit erstreckt sich noch weiter. Sie umfasst nicht nur den Verlauf der Gefässe, sondern auch ihren Bau; ja bis hinaus zu ihren allerfeinsten Verästelungen erstreckt sie sich, bis.zu der Frage, ob „Blutsinus“ oder "Blutcapillaren".

Die Myxine glutinosas-Leber besteht aus zwei vollständig getrennten Lappen, die der Ventralfläche des Darmes anliegen, unmittelbar caudal vom Ubergang desı Kiemendarms in den verdauenden Darm. Von jedem Leberlappen führt ein Gallengang nach der gemeinsamen Gallenblase; von dieser zweigt der gemeinsame Gallengang $a b$, der in den Darmkanal ausmündet.

Um uns über den Bau der Leber Klarheit zu verschaffen, wollen wir zuerst einen Schnitt durch den Mittelteil des einen Lappens betrachten (Fig. 1).

Innerhalb der dünnen Bindegewebekapsel sieht man Querschnitte, Längsschnitte und Schrägschnitte durch ,die in allen Richtungen ohne irgendwelche Regelmässigkeit verlaufenden Tubulis, deren Querschnitt in der Regel 4 bis 6 Zellen aufweist. - Unmittelbar unter der "Kapsel liegen 3 bis 4 grosse blutgefüllte Hohlräume, von denen zahlreiche Blutcapillaren ausgehen. Diese buchten sich dann ${ }_{i} z w i s c h e n$ die Tubuli hinein. 
- In den mittleren Teilen bemerkt man ebenfalls grosse Gefässe und Gallengänge von abwechselnder Weite.

Wenn wir nunmehr versuchen, in den Bau dieses Organs einzudringen, wollen wir mit dem, Gefässsystem beginnen. Um mir, soweit möglich; eine objektive Meinung über die Frage zu bilder, entschloss ich mich, ein Wach s modell anzufertigen, das die Leberlappen mit den zu- und abführenden Gefässen umfasste, sowie deren Verbindung mit dem Gefässsystem im übrigen .und den umliegenden Organen. Das Modell zeigt, dass V. portae von dem Pfortaderherz ausgeht. Nach einem kurzen Verlauf teilt sie sich in zwei Äste, je einen nach jedem Leberlappen. Beide münden auf der Dorsalfläche in den Lappen ein, und $z$ war ungefähr auf deren Mitte. Dası Blut sammelt sich wieder in den Venae hepaticae. In diesem Falle fand ich zwei vom vorderen Leberlappen und einen vom hinteren. Alle münden zusammen mit den Venen vom Darm in den Sinus venosus.

Verfolgt man die abführende Vene vom hinteren Leberlappen aus, so sieht man, dass sie unmittelbar vor dessen vorderen Spitze durch Zusammenlauf zweier ungefähr gleichstarken Stämme gebildet wird, von denen der eine von der Dorsal-, der andere von der Ventralfläche ausgeht. Das Modell zeigt auch, dass von der caudalen Spitze des hinteren. Leberlappens ein Gefäss ausgeht. Auf meinem Wachsmodell würde man vergeblich eine A. he p a tic a suchen. Aber in Wirklichkeit findet sich dennoch eine, wovon ich mich durch Injektionen sowohI unmittelbar von der Aorta aus, wie von der Herzkammer vi a die Kiemenarterien habe überzeugen können. Sie verläuft zusammen mit der Pfortader und den Gallengängen, aber ihr Lumen ist sehr klein, und die Arterie spielt sicherlich nur eine unbedeutende Rolle bei der Blutversorgung der Leber. Aus den Injektionen geht hervor, dass ihre Capillaren in die übrigen der Leber ausmünden. 
Untersuchungen über den Bau der Leber bei niederen Wirbeltieren. $\mathbf{6 8 5}$

Verfolgen wir jetzt in einer Serie die grossen Gefässstämme, so sehen wir, dass eine unbedeutende Vene vom Venenplexus ides Darmes aus in die caudale Spitze des hinteren Leberlappens übergeht, indem sie am ı̈ussersten Rande des dünnen Bandes hinläuft, das diesen ıLappen mit dem Darm verbindet.

Sofort nach ihrer Einmündung in die Leber teilt sie sich in zwei Äste, einen längs der Mjtte der Ventral- und einen anderen längs der Mitte der Dorsalfläche. Der letztere löst sich bald in Capillaren auf, die zwischen die Tubuli hineingehen. Der erste geht nach 'vorn, nimmt Capillaren und kleine Venenstämme auf und nimmt allmählich an Mächtigkeit zu. Zum Schluss verlässt er die Leber ।an der vorderen Spitze des Lappens, und hier vereinigt er sich mit einer anderen Vene von ungefähr gleicher Grösse, die auf der vorderen Hälfte, ungefähr in der Mittellinie der Dorsalfläche des hinteren Leberlappens liegt. Vereinigt münden sie darauf in den Sinus venosus aus.

Die abführenden Gefässe des vorderen Leberlappens findet man als eine wechselnde Anzahl Venenstämme, die jeder einzeln in den Sinus venosus ausmündet. In 4 Serien habe ich eine etwas verschiedene Anzahl gefunden, und zwar von 2 bis 4 .

Wie man sieht, bin ich hier im wesentlichen zu dem gleichen Ergebnis gelangt, wie die früheren Untersucher, mit Ausnahme von Holm. Nur in Einzelheiten besteht ein gewisser Unterschied.

Charakteristisch für dieses ganze abführende Gefässsystem ist, dass seine Hauptäste völlig peripher verlaufen, unmittel. bar unter der Leberkapsel (Fig. 1 und 2). Ein seltenes Mal kann man einen grösseren Ast drin in der Lebersubstanz sehen; aber .verfolgt man ihn, so findet man, dass es sich sehr bald in Capillaren auflöst. 
Dic Äste der Pfortader haben im Gegensatz hierzu eine ausgesprochen centrale Lage. Sie verlaufen hier in der ersten Zeit nach ihrer Einmündung zusammen mit den Gallengängen (Fig. 1 und 3). Eine unmittelbare Verbindung zwischen zuund abführenden Venenästen habe ich'nicht beobachten können.

Untersuchen wir jetzt den Bau der innerhalb der Leberkapsel liegenden Gefässe genauer, 'so finden wir bald, dass hier ein ausgesprochener Unterschied zwischen den ganz kleinen und den grösseren Individuen besteht.

Wenn ich die Äste der V. hepatica in Serien durch kleine (10 bis $12 \mathrm{~cm}$ lange) Tiere verfolgte, so fand ich, dass ihre Wände nur aus einer dünnen Endothelschicht bestanden. Bei einem mittelgrossen (20 cm langen) Individuum sah ich dagegen unregelmässig verlaufende; spärliche Bindegewebefasern aussen auf dem Endothel. Und in einzelnen Schnitten durch längere (bis zu $37 \mathrm{~cm}$ langen) Tiere fand ich dieses Bindegewebe ziemlich reichlich.

Verfolgte ich dann die V. portae und die Gallengänge von ihrer Einmündung an weiter einwärts, so waren auch hier Verschiedenheiten im Bau augenfällig, je nach der Grösse der untersuchten Individuen.

Ein gemeinsamer Zug für sie alle war, dass Gefäss- und Gallengänge von Bindegewebe begleitet waren, dasi sich im wesentlichen rings um die Gallengänge ansammelte. - Bei den ganz kleinen Tieren (10 und $12 \mathrm{~cm}$ langen) war das Bindegewebe ziemlich spärlich und umgab oft nicht das ganze Gefäss, aber nahm bei den anderen Exemplaren proportional mit der Länge des Tieres zu, bis es bei den grössten Individuen verhältnismässig reichlich auftrat. Verfolgt man dann dieses Bindegewebe weiter, so sieht man, dass es bei den kle in sten Individue $n$ an die Gallengänge gebunden ist. Wenn diese nach einem kurzen Verlauf sich in Gallencapillaren aufgelöst haben, verschwindet auch das Bindegewebe sehr rasch; wäh- 
rend die centralen Gefässe sich als endothelbekleidete Röhren fortsetzen, bis sie sich gegen die obere und untere Spitze hin vollständig auflösen. - Bei einer $20 \mathrm{~cm}$ langen Myxine setzte sich ein Teil längsverlaufender. Bindegewebefasern indessen noch ein gutes Stück längs der mittleren Gefässe selbst nach dem Verschwinden der Gallengänge fort. --- Dasselbe war auch der Fall bei grösseron Tieren, wo das Bindegewebe etwas reichlicher vorhanden war. Diese längsverlaufenden Fasern waren anfangs soweit zahlreich, dass sie in einer Weise eine Gefässwand aussen auf dem Endothel bildeten. Allmählich wurden sie jedoch immer dünner, so dass die sie umschliessenden Lebertubuli unmittelbar dem Endothel anlagen, und zwar oft auf verhältnismässig grossen Teilen der Gefässwand. Recht häufig stah ich auch, dass ein oder ein paar Tubuli sich zwischen die Bindegewebefasern hineindrängten, so dass deren Querschnitl vollständig von. Bindegewebe umschlossen war. Dasselbe fand ich übrigens auch ab und zu, wemn ich den Verlauf der Äste der V. hepatica verfolgte.

Es ist dieses Bindegewebe rings um die mittleren Gefüsse und die Gallengänge, das Holm (1897) als Muskulatur beschrieben hat. Schon meine hämatoxylin-eosin gefärbten tbersichtspräparate schienen deutlich zu zeigen, dass man es' mit Bindegewebe zu tun hat. Die dicken, kernarmen Fasern erinnerten in keiner Hinsicht an Muskulatur. Nach v a n Gi e s on s Verfahren gefärbte Schnitte durch die Leber von Tieren von verschiedener Länge zeigten ebenfalls kräftig rote Bindegewebefärbung (Fig. 3). Um jeden Zweifel zu beseitigen, legte ich Schnitte an, die lotrecht zur Längsachse des Tieres den Darm, die Gallenblase und centrale Teile des unteren Leberlappens trafen. Und während die Darm- und Gallenblasenwände sehr schön sowohl kräftige Gelbfärbung der Muskulatur wie auch' Rotfärbung des Bindegewebes zeigten, erstrahite das die Ge- 
fäss- und Gallengänge umgebende Bindegewebe nur in stark roter Farbe.

Um mir über die Natur dieses Bindegewebes Klarheit zu verschaffen, fürbte ich Schnitte sowohl mit We igert s Elastinfärbung, wie mit Orcein, jedoch ohne positiven Erfolg. Und wenn ich es auch für wahrscheinlich ansehen muss, dass es bloss ein gewöhnliches fibrilläres Bindegewebe ist, so durf ich dennoch nicht das Vorkommen von elastischen Fasern in Abrede stellen. Alle meine zur Nachprüfung vorgenommenen Elastinfärbungen verschiedener Organe bei Myxine fielen näm. lich negativ aus.

Wir haben gesehen, dass die Äste der V. hepatica bei den kleinsten Individuen aus endothelbekleideten Röhren bestehen, während die der Pfortader teilweise von Bindegewebe umgeben sind, so lange sie mit den Gallengängen zusammenlaufen; jedoch in der Weise; dass dieses Bindegewebe sich wesentlich rings: 'um die letzteren ansammelt. Bei den grösseren Exemplaren bekommen die Äste beider eine Bindegewebeschicht, die mit der Länge des Tieres zunimmt.

Wie sollten wir nun dieses Bindegewebe verstehen? H o l m hält es für einen Bestandteil des Gefässsystems. Er sagt nämlich, dass die Äste der centralen Gefüsse aus einer dünnen Intima bestehen, ,umgeben von einer Schicht locker gelegener, lïngslaufender glatter Muskelfasern". Und später redet er davon, dass diese Schicht die Gallengänge in sich aufnimmt. Cole (1913) dagegen bemerkt bloss, dass die Pfortader, die Leberarterie und der Gallengang, is enclosed in the connectivetissue sheath of Francis Glisson".

Ich glaube kaum, dass das Bindegewebe als Teil einer Gefässwand aufgefasst werden kann. Erstens, weil ich nicht die geringste Spur von Muskulatur habe nachweisen können. Demnächst, weil es in den mehr peripheren. Teilen das Endothel nicht vollständig umschliesst, und schliesslich, weil es ab und 
zu den Querschnitt einzelner Tubuli umschliesst, selbst wenn es nicht reichlich vorhanden ist.

Zu iden Gallengängen kann man esł auch nicht rechnen. Wir haben ja gesehen, dass das Bindegewebe den Gefüsșen lange noch, nachdem jede Spur von Gallengängen verschwunden ist, folgt. - Ich erwähne später, dass die grössten Gallengänge eine ziemlich dicke Schicht von , cirkulär gehenden Bindegewebefasern aussen auf ihrem Epithel haben, ein Bindegewebe, das sehr rasch verschwindet, wenn die Gallengänge an Grösse abnehmen. Ich erachte es' für wahrscheinlich, dass dieses Bindegewebe grundsätzlich als ein Teil der Wand des Gallenganges aufgefasst werden muss. - Das übrige Bindegewebe dagegen, glaube ich, muss als das verbindende Stützgewebe des grossen parenchymreichen Organs aufgefasst werden. Ein Gedanke, der eine positive Stütze in der Tatsache findet, dass die Myxineleber sonst sehr arm an Bindegewebe ist. Nur ein seltenes Mal kann man sehen, dass von der dünnen Leberkapsel aus Bindegewebefasern ein kurzes Stück zwischen ıdie Tubuli hineingehen.

In derselben Weise, meine ich, müsste das Bindegewebe, dass die Äste der V. hepatica begleiten, aufgefasst werden. Auch hier findet man keine Spur von Muskulatur, nur bei den grössten Tieren bildet es eine einigermassen ungebrochene Hülle aussen auf dem Endothel und bei ganz jungen Individuen findet es sich überhaupt nicht.

Ich muss deshalb annehmen, dass sowohl die zu- wie die abführenden Venenäste drin in der Myxineleber grundsiitzlich nuir aus endothelbekleideten Lumina bestehen.

Verfolgen wir nun die Gefässe weiter, so kommen wir zu dem zwischen den einzelnen Tubuli liegenden Teil, dem, den Cole als ,a reticular sinus" aufgefasst hat. Ich muss einräumen, dass dies auch mein Eindruck war, als ich meine Untersuchungen über die Myxineleber mit der Bearbeitung einer 
Serie durch ein $10 \mathrm{~cm}$ langes Individuum begann. -- Ich glaulse, dass man nach einem Blick auf Fig. 2 wird einräunen müssen, dass der Gedanke nahe lag. Hier sieht man, wie die Tubuli überall von Blut umspült werden, das in weiten Hohiräumen angesammelt ist, die einen bedeulenden, vielleicht den bedeutendsten Teil des Querschnittes des Leberlappens einnehmen. Ferner sieht man einige grössere und kleincre blutgefüllte Hohlräume, die, wenn man sie in Serien verfolgt, ohne unmittelbare Verbindung mit irgendwelchen Gefïssstämmen sind. Diese müssen als noch nicht ausgefüllte Räume in dem Blutsinus, den wir gefunden haben, aufgefasst werden, und sie stützen deshalb wesentlich unsere Auffassung an diesem Punkt. Aus der Zeichnung (Fig. 2) sieht man, dass sie mitunter von bedeutender Grösse waren.

Diese Hohlräume verschwinden rasch mit der zunehmenden Grösse des Tieres; bereits bei einem $12,5 \mathrm{~cm}$ langen Individuum liessen sie sich schwer nachweisen und kamen nur in sehr geringer Grösse vor; und bei grösseren Tieren gelang es mir nicht, sie zu finden. - Auch das mikroskopische Bild schien hier nicht für das Vorhandensein eines Blutsinus zu sprechen. Die Tubuli liegen hier weit dichter zusammen und scheinen nicht immer überall von Blut umspült zu sein. - Durch Einspritzen sowohl durch die Pfortader wie die Lebervene mit einer leicht durchdringenden flüssigkeit (schwarzer 'Tusche) erzielte ich bei einer $37 \mathrm{~cm}$ langen Myxine eine anscheinend sehr vollständig und gut gelungene Injektion. Die Blutcapillaren waren hier besonders zahlreich, aber die 'Tubuli waren jedoch an einzelnen Stellen nicht von Blut umgeben. Dasselbe Ergebnis erhielt ich durch andere Injektionen bei mittelgrossen Tieren von verschiedener Länge.

Auch hier finden wir deshalb zwischen den Individuen einen Unterschied, ider von ihrer Grösse abhängig ist. - Bei den ganz kleinen Tieren besteht der intertubulare Teil des Kreislaufes 
der Leber aus einem Blutsinus. Dieser macht dann mit dem Zunehmen des Tieres an. Länge eine Umbildung zu Blutcapillaren durch.

Hinzugefügt muss werden, dass auch diese einen gewissen Unterschied aufweisen, insofern als die kleineren (aber also nicht kleinsten) Tiere durchgüngig weitere Capillaren haben als die grösseren. Und selbst in ein und derselben Leber kann ihre Grösse wechseln. In der Regel sind sie dann am weitesten in einzelnen Abschnitten der mittleren Teile der Leberlappen, weniger hervortretend in der peripherischen; aber man findet nicht selten auch das umgekehrte Verhültnis.

Die Gallengänge begleiten in beiden Leberlappen die zuführenden Gefässe. Die grossen Gallengänge, und zwar einer von jedem Lappen aus, gehen von dem Leberlappen an derselben Stelle aus, wo die Pfortader einmündet, und sind durch Bindegewebe mit dieser verbunden. - Sie heginnen sich sofort in kleinere Äste $\mathrm{zu}$ teilen, die rasch in secernierende Tubuli ühergehen. In ihren Hauptzügen weisen sie alle denselben Bau auf. Zu innerst findet man ein einschichtiges Epithel, das mit dem Lumen des Gallenganges abnimmt von hoch cylindrisch zu kubisch. Bei den kleinsten Tieren sind die grössten Gallengänge verhältnismässig klein und haben ein niedriges, cylin. drisches Epithel. - Die Kerne sind gross, rund bis schwach oval und bastal gestellt. Das kpithel sitzt auf einer diunnen Basalmembrane und un diese herum liegt eine mehr oder minder mächtige Bindegeweheschicht, die wesentlich aus längsverlaufenden Fasern hesteht. In dieser Schicht drin haben die grössten Gallengänge eine fester gebaute, rund herumlaufende Fasernschicht (Fig. 3). Das Bindegewebe habe ich eingehends bereits oben besprochen. Nirgends konnte ich die von $\mathrm{Holm}$ beschriebenen Hohlräume finden, in dem die Gallengänge liegen sollten. Sie müssen wohl als eine Schrumpferscheinung infolge mangelhafter Fixierung (Sublimat) gedentet werden. 
Vom ersten Augenblick an fiel es mir auf, wie ausserordentlich rasch die Gallengänge in Tubuli übergingen, und wie selten diese Ubergangsstellen in den Serien anzutreffen waren. Nach dem, was wir über andere Drüsen wissen, bestand hier anscheinend ein Missverhältnis zwischen der Menge des secernierenden Epithels und dem Entwickelungsgrad der Ausführungsanlage.

Ich nahm mir deshalb zuerst vor, zu untersuchen, wie weit sich die Verästelung der centralen Gallengänge erstreckte. Wie grosse Teile der Leber keine hatten; und wie oft die Tubuli in die Gallengänge ausmündeten.

In einer Serie von $10 \mu$ dicken Schnitten durch ein $12,5 \mathrm{~cm}$ langes: Individuum bestand der vordere Lappen aus 369 Schnitten, und nur in den mittelsten 35 dieser Schnittserie fand ich |Gallengänge: Ein Übergang von Tubulus zu Gallengang fand nur in 21 Fällen statt, in sämtlichen Fällen in den centralen Teilen der Leber. Zum Vergleich führe ich an, dass ein einzelner Querschnitt durch denselben Leberlappen et w a 600 Durchschnitte von Tubuli aufwies.

Ähnliche Verhältnisse sah ich im unteren Leberlappen in derselben Serie, wo die vordersten 197 Schnitte ohne jede Spur von Gallengängen waren. Ganz entsprechende Befunde beobachtete ich auch in einer anderen Serie durch ein $10 \mathrm{~cm}$ langes Individuum. Hier liess sich nicht ein einziger Gallengang in den vordersten 121 Schnitten des vorderen Lappens feststellen.

Setzen wir den früher angenommenen verästelten tubulösen Bau der Myxineleber voraus, so bleibt es völlig unerklärlich, wie die am meisten peripherisch liegenden Teile der 'Tubuli zweckmässig ihr Sekret zu den central gelegenen Ausführungsgängen hinbringen können. Hierzu kommt noch, dass die Tubuli einen stark gewundenen Verlauf haben, wodurch die Weglänge von dem peripheren zu dem centralen Teil vervielfacht wird. 
Nur eine Erklärung ist möglich, und zwar die, 'dass sich zwischen den Tubuli Anastomosen finden, die dazu beitragen, den $\mathrm{Ab}$ stand zu verkürzen, da die Galle dann nicht die langen, gekrümmten Wege zu wählen braucht. Mit anderen Worten, dass vasozonale Maschen vorkommen, wodurch selbst von den Gallengängen fernliegenden Zellen eine kürzere, direktere Verbindung mit jiesen gesichert ist.

Ich habe früher erwähnt, dass man auf Schnitten durch die Leber ihr secernierendes Epithel in Tubuli angeordnet sieht. Diese weisen auf Querschnitten eine wechselnde Zellenanzahl von 3 bis 8 auf. Die Zellen sind gross, fast kubisch, mit einem grossen, runden Kern, der sich fast immer in der basalen Hälfte der Zelle befindet. - Die Tubuli verlaufen reich verästelt ohne irgendwelche typische Anordnung. In der Regel teilen sie sich dichotomisch; aber nicht selten stossen 3 oder 4 in einem gemeinsamen Punkt zusammen. Wenn sie in Gallengänge übergehen, werden ihre Zellen allmählich etwas niedriger, und der Übergang erfolgt in dor Regel ganz unmerklich. Nur wo ein Tubulus in einen grösseren Gallengang ausmündet, kann man eine einigermassen scharfe Grenze nachweisen.

Jeder Tubulus zeigt in sseinem Mittelpunkt ein Gallencapillar. Dieses verläuft in leichten Windungen lïngs der zusammenstossenden Ränder der Zellen und wechselt etwas in seiner Weite. Während seines Verlaufes sendet es eine Menge intercelluläre Äste von wechselnder Länge aus, die jedoch niemals die Peripherie des Tubulus erreichen. Bisweilen sieht man auch die früher von B ra us (1896) nachgewiesenen intercellulären Äste, die zu Zellen hinführen, die vom Mittelpunkt zurückgezogen sind. Da es mir niemals gelungen ist, Querschnitte zu finden, die ein Gallencapillar aufweisen, das.lüngs der Flächen der Zellen liegt, muss ich annehmen, dass die Gallen. capillaren immer längs der Zellränder verlaufen. 

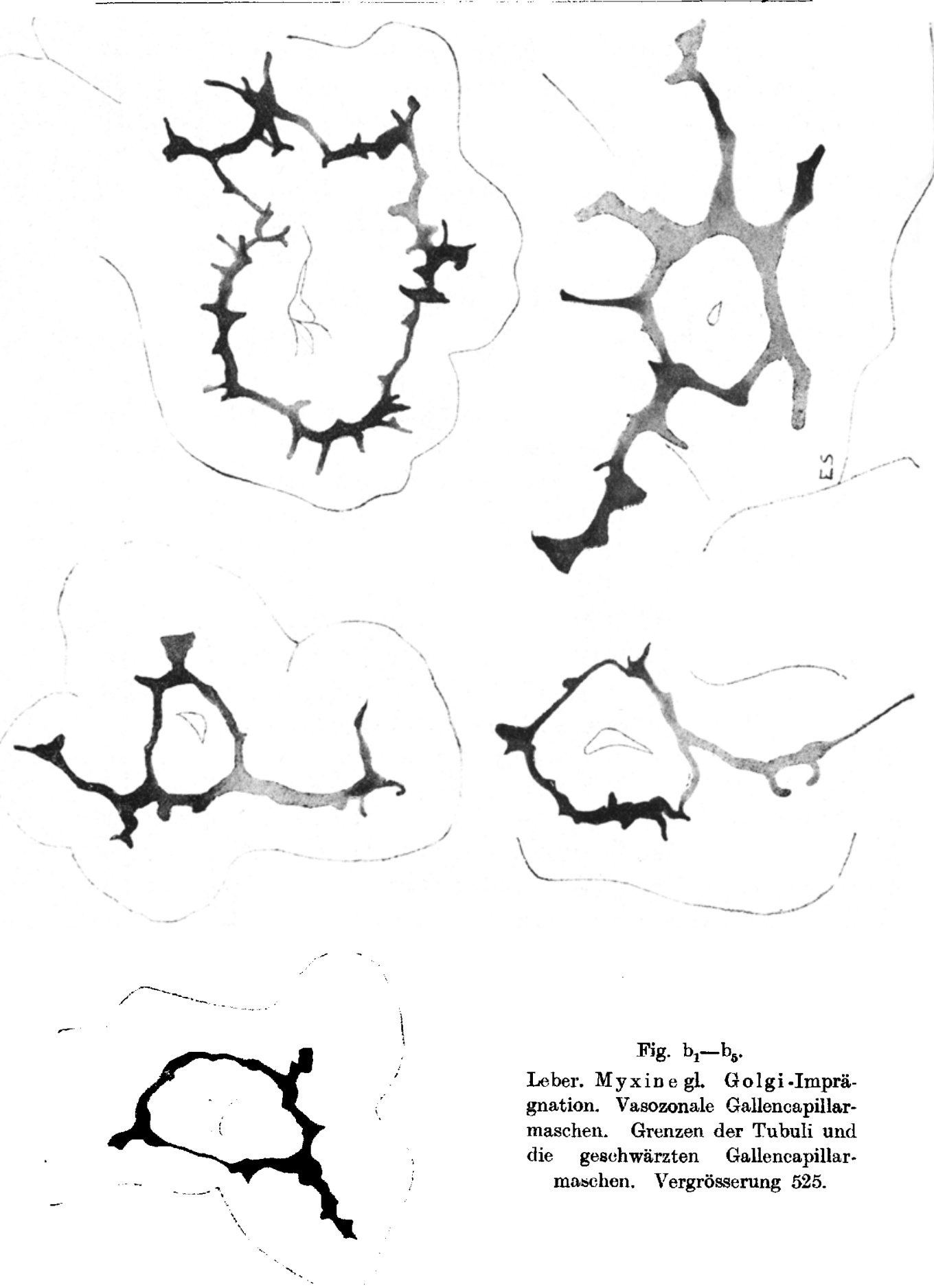

Fig. $b_{1}-b_{5}$.

Leber. Myxine gl. Golgi-Imprägnation. Vasozonale Gallencapillarmaschen. Grenzen der Tubuli und die geschwärzten Gallencapillarmaschen. Vergrösserung 525. 

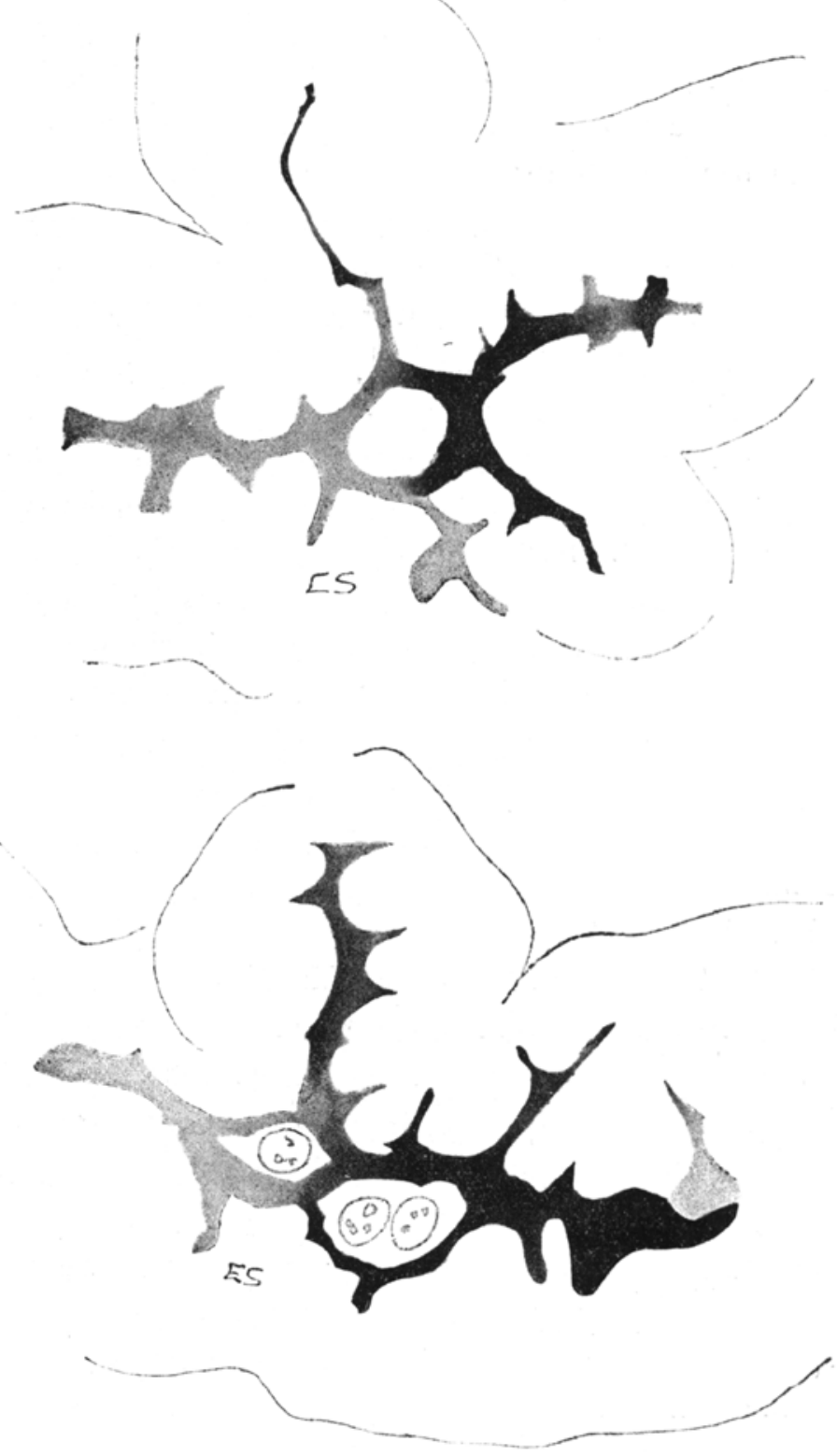

Fig. $b_{8}-b_{7}$.

Leber Myxine gl. Golgi-Imprägnation. Cytozonale Gallencapillarmaschen. Auf Fig. $b_{7}$ sind auch die Kerne eingezeichnet; die eine Masche ist uni-, die andere pluricellulär. Vergrösserung: $\mathbf{8 7 5}$. 
Das war das Wesentliche, was beim Studium gewöhnlich fixierter und gefärbter Präparate zur Beobachtung kam. Um in die Parenchymstruktur näher einzudringen und dadurch ins reine zu bringen, ob der Bau dieser ursprünglichen Leberform hiermit vollständig erklärt ist, wandte ich eine Reihe der Untersuchungsverfahren an, die oben erwähnt wurden.

Schon meine besonders gut gelungenen Grolg i-Präparate wiesen zwei Formen der Maschenbildung der Gallencapillaren auf, die vasozonale und die cytozonale.

Das Vorkommen von cytozonalen Maschen war schon früher bekannt. Dagegen war der Nachweis der vasozonalen von bedeutender theoretischer Wichtigkeit. Hierdurch war nämlich die Myxineleber aus'ihrer gänzlich vereinzelten Stellung gegenüber dem gewöhnlichen „Wirbeltiertypus" herausgerückt. Die für unsere Auffassung von der Entwickelung der Leber bedeutungsvolle Frage war dann: Ist diese primitive Leber eine verästelte tubulöse mit einzelnen netzförmigen Verbindungen, oder ist sie eine netzförmig e tu bulös e mit oder ohne blind endenden Tubuli?

Aus den Gol'gi-Präparaten ging hervor, dass die verschiedenen Teile der vasozonalen Maschen in sehr verschiedenen Ebenen lagen. Und das war unzweifelhaft der Grund, warum es mir nicht gelang, eine einzige vasozonale Masche trotz eifrigsten Suchens in gewöhnlichen Schnitten zu finden. Auf diesem Wege konnte ich deshalb der Entscheidung über die Struktur nicht näherkommen.

Um Imir hierüber Klarheit zu verschaffen, versuchte ich deshalb, in meinen Serien den Verlauf einzelner Tubuli zu verfolgen, um dadurch einen Einblick über ihr Verhältnis zu erhalten. - Das Verfahren ist einfach; aber soll es wirklich etwas leisten, so ist eine Reihe günstiger zusammentreffender Umstände erforderlich. Man muss eine Bildung finden, die wïhrend ihres Verlaufs durch die Schnilte, die man unter- 
sucht, keine Veränderung aufweist. Eine Bildung, die also einen festen Anhaltspunkt gibt. Eine eigentümliche Kontur in der Kapsel der Leber, ein im Querschnitt getroffenes Blutgefäss, $\mathrm{k}$ a $\mathrm{n} \mathrm{n}$ insofern gute Dienste leisten, aber es ist äusserst selten. Derartige Anhaltspunkte muss man deshalb sorgfältig ausfindig zu machen suchen. Die Tubuli, die man verfolgen will, müssen gut getrennt durch Blutcapillaren verlaufen; auch dürfen sie sich bei ihrer Verästelung nicht von dem "Richtungskörper", den man benutzt, entfernen. Schliesslich müssen sie dessen Umgebungen beherrschen, damit nicht andere Tubuli sich störend hereindrängen. Wenn alle diese Bedingungen vorhanden sind und gleichzeitig die Gallencapillaren gut gefärbt. sind, so kann man ohne Schwierigkeit den Verlauf der Tubuli verfolgen und damit die Verästelungen und etwaige Maschenbildung der mittleren Gallencapillaren studieren.

Das Verfahren ist selbstverständlich in hohem Grade subjektiv; aber unter den erwähnten Voraussetzungen muss ich es als brauchbar und zuverlässig bezeichnen. Seine Beweis. kraft allein wird allerdings nicht besonders gross sein; aber als ein Hilfsverfahren hat es jedenfalls seine Berechtigung. Ich habe hier dieses Verfahren soweit eingehend behandelt, da ich es auch später angewandt habe, ohne, wie in diesem Falle, die damit erzielten Ergebnisse durch eine Rekonstruktion am Wachsmodell festzustellen.

Das Ergebnis sieht man aus der nachstehenden Zeichnung (Fig. c).

Diese Zeichnung weist eine Reihe zusammenhängender vasozonaler Maschen von sehr verschiedener Grösse und Form auf, mit anderen Worten, sie zeigt, dass die Myxine-Leber eine netzförmige tubulöse Drüse ist.

Soweit war ich mit meinen ,G olg i - Präparaten und meiner Arbeit mit Serienschnitten gelangt.

Dass der befriedigendste Beweis für die Richtigkeit meiner Resultate eine Wachsrekonstruktion sein würde, die die Gallen- 
capillaren wiedergäbe, darüber war ich mir sofort klar; ebenso wie, dass diese Aufgabe technisch ausserordentlich grosse

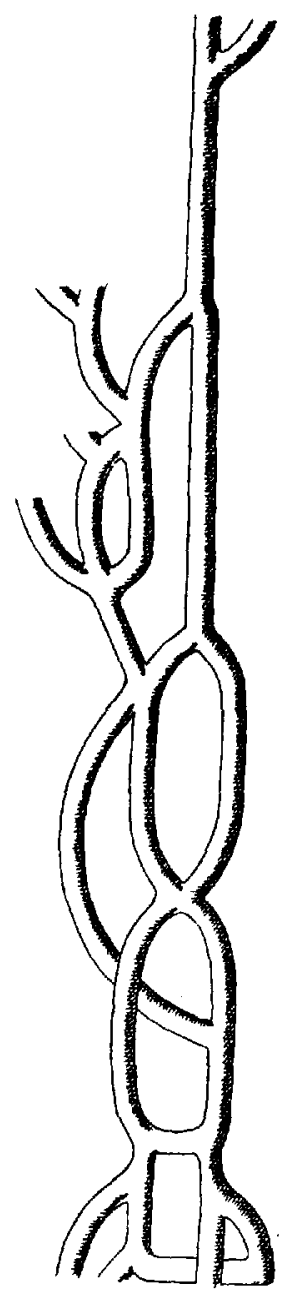

Fig. c. Schwierigkeiten bot. Aber ausserdem war sie nicht einmal unbedingt nötig. Eine Rekionstruktion der Tubuli würde zwar ein klares Bild von der Struktur der Leber geben; nur würde man dabei die intercellulären Äste und die cytozonalen Maschen der Gallencapillaren am Wachsmodell nicht mit zur Darstellung bringen können.

Nach mehreren misslungenen Versuchen gelang die Rekonstruktion von 16 Schmitten $\mathrm{zu}$ je $10 \mu$ von einem $10, \tilde{\partial} \mathrm{cm}$ Jangen Individuum. - Das Wachsmodell bestätigte in der schönsten Weise das Ergebnis, zu dem ich auf anderem Wege bereits vorher gelangt war, dass nämlich die Leber bei Myxine gl. eine netzförmige tubulöse Drüse ist. - Eine Wiedergabe des Modells im Druck erwies sich indessen leider als gänzlich unmöglich, und zwar weder photographisch noch durch Zeichnung. Die Tubuli liegen nämlich allzu dicht beieinander und decken sich teilweise gegenseitig. Ich fertigte deshalb ein neues Modell desselben Teils an und erhielt dadurch eine genaue Kopie des ersten. Auf diesem Wachsmodell entfernte ich dann alle Tubuli, die keine Verbindung mit anderen eingingen. Ferner Myxine gl. Schema. DieVerbindungderTu- nahm ich auch alle Verästelungen der Tubuli buli, durch 51 Schnitte weg, welche die freje Übersicht behinderten, verfolgt. $\mathrm{Je} 2,5 \mathrm{~mm}$ in derHöhe entspricht ein falls die Äste nicht irgend eine Verbindung Schnitt à $10 \mu . \quad$ zwischen zwei lubuli bildeten. Das übrig- 
gebliebene skelet, das bloss die Verbindungen der Tubuli, die vasozonalen Maschen, zeigte, ist auf Fig. $\mathrm{d}_{1-2}$ wiedergeben.

Das Wachsmodell wies keine blind endenden Tubuli auf. solche fand ich indessen leicht in aer oberen und unteren
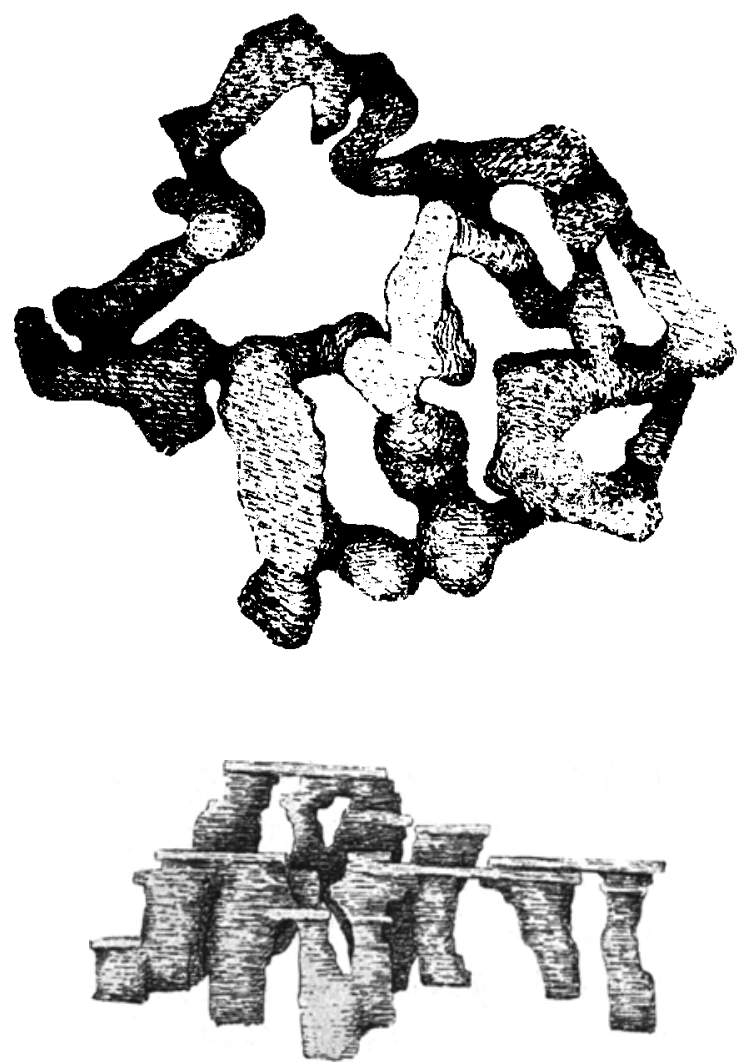

Fig. $d_{1}-d_{2}$.

Myxine g]. Wachsrekonstruktion (vgl. den T'ext).

Spitze der Leberlappen. Diese enthalten nur wenige Tubuli, die sich ohne Schwierigkeit eine kürzere Strecke verfolgen lassen. -- Mitunter kann man auch ein Bild sehen, wie es auf nachstehendem Schema' angiedeutet ist (Fig. e). 
Ein einzelner Tubulus verläuft parallel zu einem peripheren Gefäss, und zwar zwischen diesem und der Leberkapsel, fern von anderen Tubuli. Verfolgt man diesen einsamen Tubulus, so wird man nicht selten finden, dass er blind endet.

Durch die Wiedergabe im Wachsmodell war der Bau der Myxineleber in der Hauptsache entschieden. Es war festgestellt worden, dass sie netzförmig-tubulös war. Das nächste, was es nunmehr zu entscheiden galt, war, in welchem Grade dieser Bau wieder aufgelöst war, welche Züge auf die Auflösung dieser rein tubulösen Struktur hindeuteten, von der die am höchsten entwickelten Leberformen anscheinend keine Spur aufweisen. Braus (1896) hat durch seinen Befund von cytozonalen

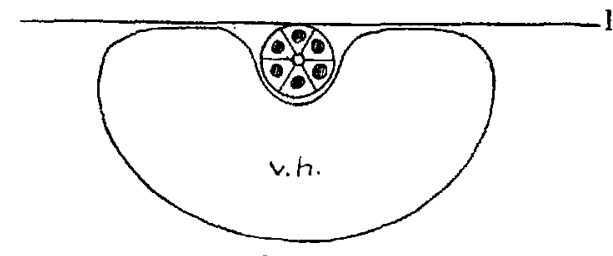

Fig. e.

Myxine gl. Schema. Querschnitt eines Tubulus, der zwischen einem Gefäss (v. h.) und der Leberkapsel (1.) liegt.

Maschen einen Auflösungsvorgang nachgewiesen. Aber bezeichnet seine Beobachtung einer einzelnen, , spärlich vorkommenden Form die Grenze dafür, wie tief.dieser Vorgang reicht?

Meine Golgi-Präparate zeigten nicht so ganz wenige cytozonale Maschen; aber erst nach einer ziemlich langwierigen Arbeit mit gewöhnlichen Präparaten gelang es mir, eine grössere Anzahl zu finden. Darin hat B ra us unzweifelhaft recht, dass diese Maschen nicht häufig sind.

Die Myxineleber zeigte $z w e i$ Formen von cytozonalen Maschen (Fig. $\mathrm{b}_{6-7}$ und Fig. 4-6), verschieden je nach ihrer Lage, und zwar solche, die am Vereinigungspunkt ron zwei oder mehreren Tubuli lagen (siehe Fig. $b_{6-7}$ und Fig. $5-6$ ) 
und verhältnismässig häufig waren, und solche, die ,,spontan“ im Verlauf eines Tubulus auftraten (Fig. 4). - Von der ersten Form gibt es unicelluläre, ja, ein einzelnes Mal sah ich zwei derartige zusammenhängende Maschen, und pluricelluläre. Die letzteren umschlossen von 2--6 Zellen. Diese Form lässt sich nur auf die im nachstehenden Schema angedeutete Weise entstanden denken, dass sich nämlich zwei (oder mehrere) Tubuli aneinander gelegt haben und das trennende Gefäss sich zurückgezogen hat. Ein Vorgang, der dadurch erleichtert wird, dass die Lebertubuli der Basalmembrane entbehren. - - Man kann
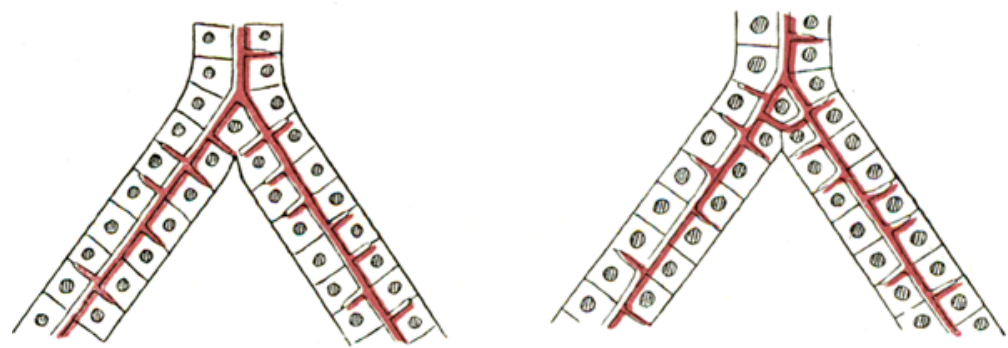

Fig. $f_{1}-f_{2}$.

Myxine gl. Schema. Bildung einer cytozonalen Masche durch Vereinigung zweier Tubuli.

dadurch alle Formen von uni- bis zu pluricellulären Maschen erhalten, je nachdem die beiden Tubuli bei ihrer Vereinigung sich auf eine kürzere oder längere Strecke gegeneinander anlegen, und je nachdem die Verbindung zwischen ihren Gallen. capillaren näher oder weiler weg von ihrem ursprünglichen Nittelpunkt erfolgt. - Für die Richtigkeit dieser Auffassung spricht, dass man nicht selten unvollständige Formen sieht, wo der Ring nicht völlig geschlossen ist.

Es erweist sich als schwieriger, zur Klarheit über die ,spontan“" auftretenden cytozonalen Maschen zu gelangen. Von solchen fand ich nur unicelluläre, und ich glaube nicht, dass pluricelluläre vorkommen. Das mittlere Gallencapillar teilt sich 
dichotomisch, und nachdem es eine Zelle umschlossen hat, vereinigen sich die beiden Äste wieder. Sie sind ausserordentlich selten. Es gelang mir überhaupt nur ein paarmal, sie in besonders ausgezeichnetem Material nachzuweisen.

Ihre Entstehung lässt sich auf zwei Weisen denken, die ich durch nachstehende schømatische Zeichnungen zu erläutern versucht habe, wo Fig. gr Querschnitt durch einen gewöhnlichen Tubulus wiedergibt, wïhrend Fig. $g_{9}$ 'und $g_{3}$ Querschnitte durch die beiden Formen von Maschen zeigen, die sich denken lassen:

Entweder kann (wie auf lextfigur $\mathrm{g}_{9}$ ) das (iallencapillar sich bloss dichotomisch geteilt haben, um sich darauf wieder zu vereinigen, nachdem es eine Zelle umschlossen hat (durch

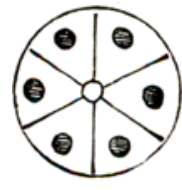

$g_{1}$

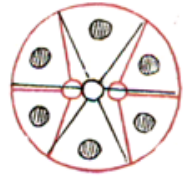

Fig. $\mathrm{g}_{1}-\mathrm{g}_{3}$.

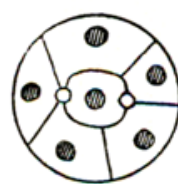

$\mathbf{g}_{3}$

My $x$ ine gl. Schema, Bildung einer eytozonalen Masche im Verlauf eines Tubulus (vgl. den Text).

eine rote Farbe dargestellt), ohne dass dadurch irgendwelche Verschiebung in der ursprünglichen Lage der Zellen im Verhältnis zur Peripherie des Tubulus entstanden ist. Oder es liesse sich auch denken, dass die Gallencapillarmasche eine Zelle umgibt, die ihre Verbindung mit der Peripherie aufgegeben hat, welch letztere von dieser weg in den Mittelpunkt des Tubulus gerückt ist und dort von allen Seiten von Leberzellen umgeben liegt (Fig. g $_{3}$ ), durch die ihre Ernährung erfolgt. Das Volumen des Tubulus wird sich dann an der betreffenden Stelle steigern, und das gegenseitige Verhältnis der Zellkerne würde sich verändern, insoweit als der Kern der Mittelzelle 
Untersuchungen über den Bau der Leber bei niederen Wirbeltieren. 703

ungefähr in eine Höhe mit der Ebene der Masche des Gallencapillars zu liegen kommt.

In den wenigen ,spontanen“ Maschen, die ich sah, konnte ich keine derartige Verdickung des Querschnittes des Tubulus finden, ebensowenig wie ich den in Betracht kommenden Zellkern in der Höhe der Ebene der Maschen liegen sah. Ich nehme deshalb an, dass diese cytozonalen Maschen auf die zuerst angedeutete Weise gebildet sind (Textfig. $\mathrm{g}_{2}$ ).

Mit Braus lege ich dem Nachweis von cytozonalen Maschen Bedeutung bei, als die erste Spur von einer Auflösung im rein tubulösen Bau. Und die Reihe von Formen, die ich fand, deuten meiner Meinung nach einen ziemlich weit vorgeschrittenen Auflösungsprozess an. Ein besonderes Gewicht messe ich dem Befund von zwei zusammenhängenden cytozonalen Maschen bei. Solche sind übrigens erst bei U rodela, also weit höher in der Wirbeltierreihe nachgewiesen worden.

Der Übersichtlichkeit halber habe ich die Parenchymstruktur der Myxineleber alsı ein Ganzes geschildert, gemeinsam für alle Individuen; geht man aber näher auf sie ein, so findet man auch hier einen Bau, der je nach der Länge desı Tieres wechselt.

Gemeinsam für alle Altersstufen ist der netzförmige tubu. löse Bau mit blind endenden Ästen der Tubuli; aber die Tubuli selbst zeigen je nach der Länge des Individuums ein wechselndes Bild. - Bei den kleinsten, 10-11 cm langen Tieren ist das mittlere Gallencapillar dicker und plumper als bei den grösseren, während die Leberzellen niedriger sind. Von dem Mittelcapillar gehen nur selten intercelluläre Äste aus, und diese erweisen sich als nur ganz kurze Spitzen, die sich zwischen die Zellen hineinschieben.

$\mathrm{Ab}$ und zu weitete sich das Mittelcapillar plötzlich stark aus, während gleichzeitig die Zellen entsprechend niedriger wurden, so dass der Tubulus in der Regel keine entsprechende 
Verdickung seines Durchmessers aufwies. Das sieht man fast ausschliesslich in den Mittelteilen der Schnitte, besonders in der Nähe der Gefässe. - Nach einem ganz kurzen Verlauf (einige wenige Schnitte) nahm das Gallencapillar seine ursprüngliche Grösse wieder ąn. Die Bedeutung dieser Ausweitungen kenne ich nicht.

Bei etwas grösseren Individuen verhalten sich die Gallencapillaren in derselben Weise; jedoch sind die intercellulären Äste hier besser entwickelt; sie sind länger und schlanker als bei den jüngsten Tieren, und die Ausweitung der Gallencapillaren verschwindet rasch mit der zunehmenden Länge des Tieres. Eine völlig geschlossene cytozonale Masche, ausser einigen einzelnen unvollständigen, fand ich bei einem $12,5 \mathrm{~cm}$ langen Individuum.

Bei den älteren Exemplaren werden dann die Gallencapillaren rasch schlanker, die Zellen verhältnismässig höher und die intercellulären Äste sehr viel zahlreicher, in der Regel auch länger und dünner. Gleichlaufend hiermit nehmen auch die cytozonalen Maschen an Anzahl und. Formenreichtum zu.

Auch hier finden wir also eine Entwickelung von der mehr plumpen und undifferenzierten Struktur der kleinsten Individuen zu grösserem Reichtum und grösserer Abwechselung im Parenchymbau der älteren. Ein Bildungsvorgang, der in seinen Hauptzügen die Entwickelung der Blutcapillaren und des Bindegewebes, die die Gefässe begleiten, folgt.

\section{Zusammenfassung.}

1. Die Leber bei Myxine glutinosa ist in der Hauptsache eine netzförmige tubulöse Drüse mit nicht selten blind endenden Ästen.

2. Die Tubuli weisen im Querschnitt eine wechselnde Anzahl Zellen auf, von 3 bis 8 . Sio haben ein centrales Gallencapillar mit zahlreichen intercellulären Ästen, die blind enden 
und niemals die Peripherie der Tubuli erreichen, sowie längs der Ränder der Zellen liegen. Sowohl das centrale Gallencapillar wie die intercellulären Äste weisen Verschiedenheiten auf, je nach der Länge des Tieres.

Nicht häufig bilden die Gallencapillaren cytozonale Maschen entweder an der Verästelung eines Tubulus (uni- und pluricelluläre) roder ohne eine solche Veranlassung (unicelluläre). Cytozonale Maschen finden sich jedoch nicht bei den kleinsten $(10-11 \mathrm{~cm}$ langen) Individuen.

3. Die Leber wird wesentlich durch V. portae mit Blut versorgt, zum geringeren Teil durch die unbedeutende $\mathrm{A}$. hepatica, die zusiammen mit der Pfortader einmündet, und durch eine kleine Vene, die vom Darm aus durch die caudale Spitze des hinteren Leberlappens einmündet. - Die Äste der Pfortader verlaufen in den mittleren Teilen der Leber. - Dasi Blut wird durch die Vv. hepaticae weggeführt. Von diesen gehen immer zwei Äste von dem hinteren Lappen aus, und zwar einer von der Dorsal- und einer von der Ventralfläche. Der letztere bildet eine Fortsetzung der Vene, die rom Darm aus an der caudalen Spitze des Lappens ausmündet. Die beiden Lebervenenäste vereinigen sich dicht vor der vorderen Spitze des Lappens. - Vom vorderen Leberlappen aus wird das Blut in einer wechselnden Anzahl von Lebervenen geleitet (ich habe 2-4 gefunden).

Dic Verbindung zwischen den Ästen der Pfortader und der Lebervenen erfolgt bei den kleinsten (10-10,5 cm langen) Individuen durch einen Blutsinus, bei den grösseren durch Blutcapillaren.

4. Die Gallengänge verlaufen zusammen mit den mittleren Gefässen (Ästen der Pfortadér). Nur sehr selten münden die Tubuli in die Gallengänge aus. - Bloss die grössten Gallengänge haben eine zirkuläre Bindegewebeschicht aussen auf dem Epithel. 
5. Das Bindegewebe der Lebier, ist nicht reichlich. Es kommt fast ausschliesslich in der dünnen Leberkapsel und zusammen mit Gefässen vor, insbesondere den mittleren, und den Gallengängen.

\section{b) Selachien.}

\section{Spinax niger.}

Aus früherer Zeit liegen mehrere Untersuchungen über die Leber der Selachier vor, von denen jedoch einzelne Arbeiten sehr wenig eingehend sind.

L e y d i g (0 p pe l, 1900) hat gröbere Gallengänge gesehen; aber die Ergebnisse, zu denen er gelangt, sind im übrigen jetzt für uns von geringem Interesse.

Pilliet (0 ppel, 1900) findet, dass die Pfortader- und Lebervenenverästelung eine unregelmässige Ausbreitung zeigt, abgesehen von einer zahlreichen jGruppierung von Pfortaderästen unter der Leberkapsel.

Uber die Scyllium-Leber findet man bei Shore und J o n es (1889) vereinzelte Bemerkungen. Sie ist ausserordentlich fettreich, jedoch nicht mehr, alst dass der tubulöse Bau nicht vollständig verdeckt wird: „Each tubule measures from $50-70 \mu$, in diameter and the anastomoses are less apparent than in the liver of the eel. The blood channels! have well defined thick walls of endothelial cells.“ - „The bile ducts -, run with the larger blood-vessels." .

Eine eingehendere Untersuchung verdanken wir Braus (1896) durch sein Material von A canthias, Raja und Chimaera. Bei erwachsenen Tieren hat er die grossen fettreichen Zellen beobachtet, die in Verbindung, mit den dünnen Gallencapillaren zu grosse Schwierigkeiten für das Studium der Leberstruktur bilden. Die intrahepatischen Blutgefässe waren ziemlich reich an Bindegewebe. Weiter kam Braus nicht 
bei seiner Arb'eit mit völlig entwickelten Tieren. Er nahm deshalb die Frage von einer anderen Seite auf, nämlich ontogenetisch, indem er Embryonalstadien verschiedener Knorpelfisch ${ }^{\circ}$ bei seinen Untersuchungen anwandte. Dies am' weitesten entwickelten Embryonen zeigten eine netzförmige tubulöse Leberstruktur. Und er fährt fort: „Da also die Leber der Haifische in frühen Entwickelungsstadien schon einen netzförmig-tubulösen Bau besitzt, und in diesem keine Änderung sich bemerkbar macht während des Beginnes und Fortschreitens der Fettanhäufung in den Leberzellen, so kann man wohl schliessen, dass das Organ des erwachsenen Tieres ebenfalls netzförmigtubulös gebraut ist."

Holm (1897) hat auch dem intrahepatischen Gefässsystem und den Gallengängen einige Aufmerk'samkeit geschenkt. Er stellt das Vorhandensein einer V. portae, einer V. hepatica und einer A. hepatica fest. Die Gallengänge begleiten die Pfortaderäste, poft eingehüllt in das Bindegewebe der Gefässe. Nach iUtersuchung von völlig entwickelten wie auch embryonalen Stadien fasst er seine Auffassung folgendermassen zusammen: „Bei den Haien endlich kommen wir, wenn auch beim ersten Anblick von einer Drüsennatur wenig $z u$ sehen ist, durch Vergleich mit embryonalen Stadien zu derselben Auffassung, zu der wir in bezug auf die Myxineleber und anderer tubulöser Drüsen gekommen sind. Der ursprüngliche Zustand der Leber ist jedenfalls der einer tubulösen Drüse gewesen."

Bei $\mathrm{Sp}$ in ax stiess auch ich in der ungeheuren Fettmenge der Leber auf eine unüberwindliche iSchwierigkeit. Der Fettreichtum der Zellen ist so überwältigend und die Gallengänge sind so fein, dass man sich keine Hoffnung machen kann, zu einer genaueren Kenntnis' der Struktur der Leber durch irgend eine jetzt bekannte Methode bei 'dem völlig entwickelten Tiere 
zu gelangen. - Um jedoch einen Eindruck vom Bau zu bekommen, habe ich, wie schon frühere Untersucher, Embryonalstadien als Material benutzt.

Aus einer Reihe von Spinaxembryonen, die in $\mathrm{Z}$ e n ckerscher Flüssigkeit fixiert waren, suchte ich das günstigste $\mathrm{Ob}$ jekt aus, die Entwickelungsstufe, bei der die Fettmenge so gross war, dass sie gerade noch genauere Untersuchung gestattete. Als Ergebnis der Proben wurden Embryonen von etwa 40 bis $42 \mathrm{~mm}$ Länge ausgewählt. Bereits hier sind die Zellen ziemlich fettreich; abier das Fett ist wesentlich im basalen Teil angesammelt, die Überbleibsel des ursprünglichen Protoplasmas liegen drin dem centralen Gallencapillar an. Dadurch entsteht längs dieses Capillars eine schmale Protoplasmazone, die das Gallencapillar hervorhebt und dessen .Verlauf sehr schön hervortreten lässt.

Bei einer Serie durch ein $41 \mathrm{~mm}$ langes Individuum habe ich die Anordnung des Gefässsystems und der Gallengänge untersucht. Die Struktur des secernierenden Parenchyms und das Verhältnis der Gallencapillaren habe ich ebenfalls versucht, mit Hilfe derselben Serie klarzulegen; ausserdem durch einzelne Schnitte durch die Lebern von Individuen von etwas wechselnder Länge. Leider misslangen alle Versuche mit Golgi-Imprägnierung. Sowohl bei Embryonen von verschiedener Länge wie bei erwachsenen Individuen versuchte ich die eigentliche Golg i - Methode mit Osmiumlösung sowohl wie das modifizierte Verfahren (nach Stöhrs Lehrbuch, 1910). Leider stets mit negativem Ergebnis.

Während der intra- wie der extrauterinen Lebensperiode ist die Leber bei Spinax niger ein voluminöses, ausserordentlich vorherrschendes Organ. Sie bildet eine H-Figur, deren vorderen beiden Arme sehr kurz sind, während die beiden hinteren 'Arme eine bedeutende Länge haben. Der Querstrich wird von einer „Brücke“ aus Lebersubstanz gebildet, die ven- 
tral vom Kiemendarm liegt. Bei dem erwachsenen Tier ist diese „Brücke“ verhältnismässig weit dünner als auf der Embryonalstufe. Die verschiedenen Teile der Leber zeigten in meiner oben erwähnten Serie die Verhältnisse, die ich durch nachstehendes Schema darzustellen versucht habe.

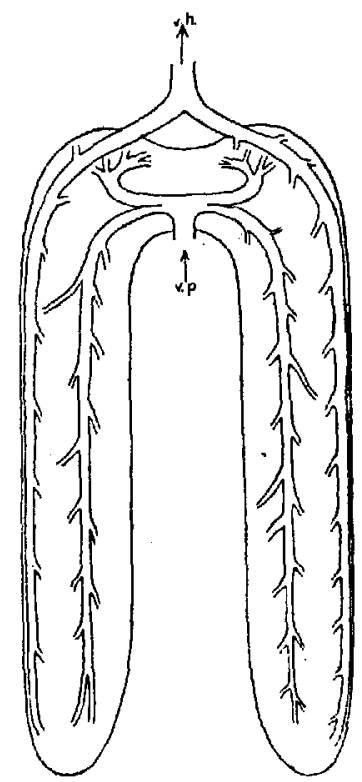

Fig. $h$.

Spinax. Schema. Die Verteilung der Lebergefässe bei einem $41 \mathrm{~mm}$ langen Embryo. $\nabla . p_{.}=$PLortader, $\nabla . h_{.}=$Lebervene. Die Leberarterie nicht gezeichnet.

In einem Übersichtspräparat (Fig. 7) findet man Verhältnisse, die denen der Myxineleber sehr gleichen: Durchschnitte aller Art von verästelten, unregelmässig verlaufenden, durch blutgefüllte Räume getrennte Tubuli, deren Querschnitt eine sehr verschiedene Zellenanzahl aufweist. Peripher und central' sieht man grosse, mit Endothel bekleidete Blutgefüsse. -Gallengänge sieht man selten und gegebenenfalls nur in der unmittelbaren 'Nähe der centralen Gefässe. 
Das Gefässsystem der Leber wird von einer grossen zuführenden Pfortader gebildet, einer unbedeutenden Leberarterie, die im Capillarnetz der Pfortader ausmündet, sowie von einer abführenden Lebervene. V. portae bricht durch die dünne Bindegewebekapsel der Leber dicht am hinteren Rande der verbindenden „Brücke“ hindurch. Sie teilt sich sofort in

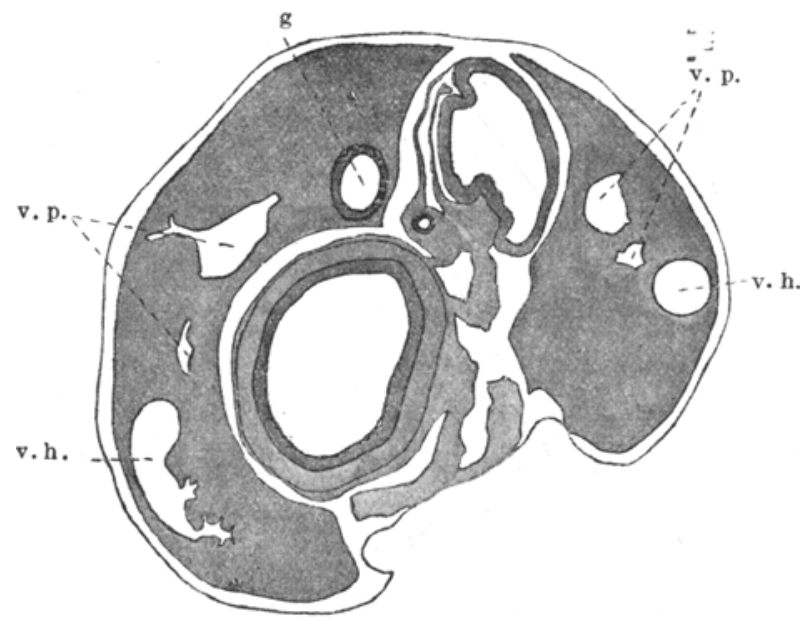

Fig. i.

Spinax. Querschnitt eines $41 \mathrm{~mm}$ langen Embryos. Leberparenchym und Blutcapillare sind durch eine graue Farbo angedeutet, nur die Gefässe sind eingezeichnet.

v. p. $=$ Zweige der Pfortader

v. h. = Zweige der Lebervene g. = grosser Gallengang.

Die Flüssigkeit von Zenker. Hämatoxylin-Eosin. Vergrösserung 16.

drei Äste (siehe Fig. h), von denen zwei rückwärts verlaufen, und zwar in der Mitte jedes hinteren Leberastes, sowie einem Ast, der in der Querrichtung des Tieres, lotrecht auf der Längsachse der Leber verläuft. Dieser letztere geht sehr rasch in zwei Stämme über, einem nach jedem der beiden vorderen Leberäste. Wie man sieht, entspricht ein Portaeast jedem der Arme in der H-Figur, die diese Leber bildet. Diese vier Gefässstämme 
verzweigen sich allmählich in kleinere Äste, die sämtlich ebenso wie die Hauptstämme im grossen ganzen central, und zwar etwas mehr in der Nähe der medialen Fläche verlaufen. Jedoch ist die centrale Lage nicht völlig so stark ausgeprägt wie bei Myxine. Bei Spinax sieht man ab und $z u$, dass einzelne Äste weit gegen die Leberkapsel herausschiessen.

Das Blut wird in einem abführenden Gefässsystem gesammelt, dessen Äste unter der Leberk'apsel liegen. Selten von dieser durch mehr als ein paar Tubuli getrennt. Sie nehmen an Grösse stark von hinten nach vorn zu und erweisen sich als zwei grosse Stämme, der eine an der Lateralseite jedes der Teile der Leber, die den beiden Längsstrichen der H-Figur entsprechen (siehe Fig. $h$ und i). Dicht caudal von den Spitzen der beiden vorderen Leberästel brechen sie durch die Lebersubstanz hindurch, gehen nach der medialen Fläche hinüber und verlassen hier die Leber. Unmittelbar darauf vereinigen sie sich zu einer V. hepatica.

Die Äste der V. hepatica sind bei den Embryonen von etwa 40 mim Länge nur mit Endothel bekleidete Röhren, während 'die Pfortaderäste, wenn sie von den Gallengängen begleitet werden, teilweise von einem nicht sehr reichlichen Bindegewebe umgeben sind.

Bei dem entwickelten Individuum sind, soweit ich es beurteilen kann, sowohl die grossen Äste der V. portae wie der $V$. hepatica von Bindegewebe eingeschlossen. Im übrigen ist die Spinaxleber arm an Bindegewebe.

Wie bei Myxine waren die Gallengänge auffallend wenig entwickelt im Verhältnis zu der Menge der secernierenden Tubuli. Uberhaupt gelang bloss der Nachweis von Gallengängen in einem verhältnismässig kleinen Teil der Leber, in 143 Schnitten zu je 7,5 $\mu=1,0725 \mathrm{~mm}$, die ganze Leber war $6,405 \mathrm{~mm}$ lang. Und nur in einem Teil der 143 Schnitte, nämlich in denen, welche die verbindende „Brücke" trafen, waren sie soweit 
zahlreich, dass sie sofort in die Augen fielen. Ein Blick auf Fig. $\mathrm{h}$ wird hiernach zeigen, in welchem bedeutenden Teil des Organs die gröberen Ausführungswege der Galle fehlen.

Typisch für den Verlauf der Gallengänge war, dass sie immer den grosisen Ästen der V. portae dicht anlagen (Fig. 7), also eine centrale und mediale Lagle im Organ hatten. Sie wurden meistens von einem Mesenchym begleitet, das jedoch nirgends' so reichlich war, dass man bei den Gefässen und Gallengängen von einem gemeinsamen Mesenchym reden konnte. Es umgab hauptsächlich die Gallengänge. Diese sammelten sich wie die Äste der Pfortader im hinteren Teil der "Brücke". Hier brachen sie mit vier grösseren Gängen aus. - Was den feineren Bau anlangt, so waren die Gallengänge wie die bei Myxine gebaut. Sie bestanden aus einem einschichtigen Epithel, das mit dem Lumen der Gallengänge von einem niedrig cylindrischen bis zu kubischem abnahm. Den kleinsten Gallengängen fehlte Mesenchym, wenigstens in den mehr peripherisch gelegenen Teilen der Verästelung der Gallengänge drin in der Leber. Die grössten wiesen dagegen eine verhältnismässig mächtige Schicht auf. Zwischen diesen beiden äussersten Fällen fanden sich Übergänge aller Art.

Eine Sonderstellung nahm ein grosser Gallengang ein, der auf der Ventralseite des grossen quergehenden Astes der V. portae in dem medialen Teil des einen Leberlappens lag (Fig. i).

Er wurde durch Zusammenlaufen mehrerer gewöhnlicher Gallengänge gebildet. Unmittelbar darauf bekam er eine dichte Schicht Mesenchym, das bereits teilweise zu rund herumgehendem faserigen Bindegewebe ausdifferenziert war. Von diesem Augenblick an nahm er keine weiteren Gallengänge in sich auf und begann sich bald darauf auszudehnen. Sein Lumen wurde etwa 10 mal so gross wie irgend eins der anderen Gallengänge. Nach einem kurzen Verlauf endete er dann blind. Vermutlich stellt er die Anlage zu der Gallenblase dar. 
Wenn Tubuli in die Gallengänge ausmünden, nimmt das secernierende Epithel gradweise an Höhe ab, so.dass der Ubergang ganz unmerkbar wird.

Die Tubuli sind reich verästelt und haben einen unregtelmässigen Verlauf. Auf Querschnitten weisen sie 3-7 Zellen auf mit grossen, runden, basal gestellten Kernen. Wie bereits erwähnt, erhielten sie bedeutende Fettmengen, die wesentlich in den basalen Teilen der Zellen angesammelt waren, während die Überbleibsel des ursprünglichen Protoplasmas sich in der Nähe des centralen Gallencapillars angesammelt hatten; dieses ist von sehr wechselnder Weite, in der Regel von verhältnismässig grossem Durchschnitt und verläuft leicht gewunden längs der Ränder der Zellen. Während seines Verlaufs sendet das centrale Gallencapillar zahlreiche intercelluläre Äste von wechselnder Länge aus, die jedoch niemals die Peripherie der Tubuli erreichen; die Querschnitte der Gallencapillaren zeigen, dass sowohl das centrale Gallencapillar wie die intercellulären Äste immer längs der Ränder der Leberzellen verlaufen.

Nach den Untersuchungen von B raus (1896) ist es unzweifelhaft, dass die Struktur der Leber netzförmig-tubulös ist. Vasozonale Maschen liessen sich ebenfalls unschwer nachweisen, wenn ich einzelne Tubuli in meiner Serie verfolgte. Dagegen gelang es mir nicht, sie selbst in $15-20 \mu$ dicken, nach Bi on di gefärbten Schnitten nachzuweisen. - Ausser den netzförmig anastomosierenden Tubuli finden sich ziemlich häufig solche, die blind enden.

Finden sich nun hier, wie bei der Myxineleber, Anzeichen, die auf eine Auflösung in dem rein schematischen tubulösen Bau hindeuten? Nach früheren Untersuchungen finden sich keine. Man hat zwar früher schon die intercellulären Gallencapillaren beobachtet, aber irgendwelche intratubuläre Maschenbildung ist niemals zur Beobachtung gekommen. 
Schon zu einem sehr frühen Zeitpunkt in meinen Untersuchungen bekam ich einen Verdacht. von ihrem Vorkommen. Man sieht nämlich nicht selten ein Bild, wie es Fig. 8 wiedergibt. Sie zeigt eine nicht völlig geschlossene cytozonale Masche an der Verästelungsstelle von miehreren Tubuli. Mitunter konnten diese Maschen eine einzelne, bisweilen auch mehrere Zellen umschliessen. Auch bei dem gewöhnlichen Verlauf der Tubuli waren solche unvollständige Maschen keine Seltenheit; aber erst nach einer sehr langwierigen Arbeit gelang es mir, eine einzelne, vollständig cytozonale Masche zu finden (Fig. 9). Aus der Zeichnung ersieht mian, dass sie ganz klein ist, kleiner als die Kerne der Leberzellen. Also kann sie nur einen kleinen Teil einer Zelle umschliessen. Ferner sieht man, dass sie nicht an der Verzweigungsstelle von zwei Tubuli liegt.

Soweit ich mich davon habe überzeugen können, sind also die vollständig geschlossenen cytozonalen Maschen sehr selten bei Embryonen von Spinax auf der von mir untersuchten Entwickelungsstufe. Man muss sich indessen vor Augen halten, dass mein Material aus einem sehr jungen embryologischen Stadium besteht. Deshalb erscheint mir die Annahme nicht unwahrscheinlich, dass eine Reihe der unvollständigen cytozonalen Maschen nicht ganz fertige Entwickelungsstufen der vollständigen Maschen darstellt.

\section{Zusammenfassung.}

1. 'Die Leber des untersuchten Embryonalstadiums ist von netzförmig-tubulösem Bau mit nicht wenigen blind endenden Tubuli. In jedem Tubulus läuft ein centrales Gallencapillar längs der Ränder der Zellen. Dieses sendet blind endende, intercelluläre 'Äste aus, die jedoch niemals die Peripherie der Tubuli erreichen. Verhältnismässig häufig sieht man unvollständige, sehr selten vollständige cytozonale Maschen. 
2. Die Blutversorgung geht wesentlich durch die V. portae vor sich, deren Äste in den centralen und medialen Teilen: laufen. 'Es findet sich eine überaus unbedeutende A. hepatica. - Die Äste der Lebervene liegen peripherisch in der Nähe der Leberkapsel auf der Lateralseite der Leberäste.

3. Die Gallengänge kommen nur in geringen Mengen vor und nur in einem kleinen Teil der Leber. Sie begleiten die Äste der Pfortader.

Das Bild, das wir aus unserem Material erhalten haben, leidet an einer nicht unbedeutenden Schwäche. Es kann ja nämlich zweifelhaft sein, ob es sich ohne weiteres auf die Leber des völlig entwickelten Tieres überführen lässt. - Ich muss mich indessen mit $\mathrm{Braus}$ 'Auffassung einig erklären. Wie ich erwähnt habe, zeigen die Zellen einen starken Fettreichtum. Sie haben also bereits dasselbe Gepräge anzunehmen begonnen wie das des völlig entwickelten Individuums. Es ist deshalb, wie ich meine, kaum wahrscheinlich, dass die Leber dieser Embryonen später einen von dem von mir bearbeiteten Stadiums grundsätzlich verschiedenen Bau aufweisen sollte.

Wie man sieht, zeigt die Sp in ax-Leber in der Hauptsache denselben Bau wie die der Myxine. Dass sie in einzelnen Punkten primitiver $z u$ sein scheint als diese, findet unzweifelhaft seine Erklärung teils darin, dass ich mit Embryonen gearbeitet habe, teils auch darin, dass die Myxine-Leber sich weit leichter untersuchen und studieren lässt.

Nachdem ich meine Arbeit im April 1914 als' Beantwortung einer aufgestellten Preisaufgabe eingereicht hatte, ist später im März 1915 eine interessante Arbeit von S c a m m on (1915) erschienen.

Wenn wir unser Untersuchungsmaterial auch von etwas verschiedenen Gesichtspunkten ansehen, wird es dennoch natür- 
lich Gebiete geben, wo unsere Untersuchungen zusammenfallen. Und mit grosser Freude habe ich viele meiner Befunde bestätigt gesehen durch eine von der meinen vollständig unabj hängigen Untersuchung. S c ammon sagt u. a. : ,The differentiation of hepatic cylinders into bile ducts ar very closely associated with their relation to the blood ressels. Bile ducts ar only formed from cylinders, which ar in contact with the main trunks of the hepatic-portal veins or their larger and more definite branches." (In Wirklichkeit begleiten sie n u r die Äste der Pfortader.) - "The development of the minor ducts is extremely small in proportion to the amount of the hepatic cylinders, smaller, I think, then in any other group of vertebrates."

Zwei seiner Zeichnungen haben auch für uns ein besonderes Interesse, nämlich seine Textfigur $11 \mathrm{C}$ und die Textfigur 5 . Die erstere (S. 283) beleuchtet die Gefässverhältnisse bei einem $41 \mathrm{~mm}$ langen. Acanthiasembryo und weist eine bedeutende Übereinstimmung mit meiner schematischen Fig. $h$ vom Verhältnis der Blutgefässe bei einem Spinaxembryo von derselben Länge. Noch interessanter ist jedoch seine Textfigur 5 (S. 272), die einen kleinen Gallengang mit einigen daranstossenden Tubuli und deren Gallencapillaren bei einem $37 \mathrm{~mm}$ langen Acanthiasembryo wiedergibt. Uns zeigt diese Zeichnung eine deutliche pluricelluläre Masche, die er, soweit ich finden kann, im Text nicht berührt. Ich kann überhaupt nicht sehen, dass er das intratubuläre Verhältnis erwähnt, was ja auch in der Peripherie seiner Untersuchungen liegen muss.

Der Leser wird sich daran erinnern, dass ich eine einzige kleine unicelluläre cytozonale Masche bei einem Spinaxembryo von $41 \mathrm{~mm}$ Länge gefunden habe. Deshalb bestätigt seine Zeichnung in der schönsten Weise unser Ergebnis, dass man schon im Embryonalleben bei den Selachiern ky tozonale Maschen 
findet, die ersten Anzeigen für Auflösung des schematisch tubulösen Baugrundsatzes.

\section{c) Teleostien.}

Syngnathus rostellatus.

Die Leber der höherstehenden Fische ist im Gegensatz zu der der Knorpelfische zum Gegenstand ziemlich vieler, mehr oder weniger eingehender Untersuchungen gemacht worden.

Eine einzigartige Stellung unter den Leberarbeiten nimmt die Studie H y rtls (1864) ein: „Uber das Verhältnis der Leberarterie zur Pfortader ber Amphibien und Fischen." Es ist dies die erste - und letzte Arbeit, die sich eingehend (nach der Technik der damaligen Zeit) mit der Blutversorgung der Leber und dem Verhältnis der Gefässe in der Leber beschäftigt. Ausser der Pfortader und der Leberarterie behandelt $\mathrm{Hyrtl}$ nämlich auch die Anordnung der Lebervenen und "Gallengefässe".

Er hat mit dem Stör und verschiedenen Knochenfischen gearbeitet, ohne aber näher anzugeben mit welchen Arten. Beim Stör findet er eine A. hepatica, eine V. portae und eine V. hepatica. Das eigentliche zuführende Gefäss ist die Pfortader. A. hepatica begleitet diese und "mündet mit ihren letzten Reiserchen nur in den Pfortaderbezirk der Lebercapillaren ein". Ihre Äste laufen nicht nur auf der einwärts dem Darm zugekehrten Fläche (in der Weise, wie er das. Verhältnis bei den Amphibien gefunden hat), sondern auch im Inneren der Lebier, ja sogar auf der Aussenfläche der Leber. Ähnliche Verhältnisse gelten auch für die Knochenfische.

Eberth. (1866 und 1867) kommt in seinen bedeutungsvollen Arbeiten zu der Auffassung, dass die Fischleber rein tubulös ist. Es kommen jedoch einzelne Anastomosen zwischen den central liegenden Gallencapillaren vor. Blind endende intercelluläre Ästo hat er nicht gesehen. 
Shore und Jones (1889) fanden bei Muraena einen netzförmig-tubulösten Bau. Die Tubuli zeigten bisweilen „a roughly radiating arrangement round a large blood-vesisel". Ohne sicher zu sein, nehmen sie an, dass diese Gefässe dem. Gebiet der V. hepatica zugehören. - Bei Ple uronectes finden sie in der Hauptsache denselben Bau. Einige der Blutgefässe haben dicke muskulöse Wändde. Andere haben keine solche, und da die Gallengänge die letzteren begleiten, halten die Verfasser sie für Portaeäste.

Die nächste Untersuchung stammt von $R$ e $t z$ i u s (1872 b), der in seinen Golgi-Präparaten von Anquilla niemals Maschen sah, d. h. Zeichen einer netzförmigen (tubulösen) Struktur. Dagegen stellte er das Vorhandensein von blinden Seitenästen fest, die von den Centralcapillaren ausgingen.

Die Leber der Anquilla war auch das von Braus (1896) benutzte Material. Durch verschiedene Methoden, u. a. Imprägnierung nach Golgi, kam er zu dem Ergebnis, dass die Struktur netzförmig-tubulös war. „Die Leberschläucha bilden ein Balkenwerk, durch dessen Maschen wir uns das Gerüst der Blutgefässe hindurchgesteckt denken müssen, so dass das eine Netzwerk die Lück'en des anderen ausfüllt." Er hat auch knospen- oder pilzförmige intercelluläre Äste von dem axialen Centralgallencapillar ausgehen sehen.

Braus hatte im Gegensatz zu Retzius das Vorhandensein won vasozonalen Maschen festgestellt. Cytozonale Maschen wies zuerst Bluntschli (1903) durch seine Studien über Ceratodus und Acipenser ruthenus und Sommerlebern biei Anquilla und Barbus nach. Er sieht in einer Anhäufung lymphatischen Gewebes die Ursache zum Entstehen dieser Maschen. - Die Blutgefässe bestehen aus V. hepatica, V. portae, mit welch letzterer die Äste der Leberarterie und die Ausführungsgänge gemeinsam verlaufen. Die Gallengänge zeichnen sich durch "Schaltstücke“ aus, die sich zwischen 
die grossen Gallengänge und die Gallencapillaren der secernierenden Tubuli hinunterschieben.

Eine spätere Arbeit über die Tele ostie r-Leber schreibt sich von Eva Segerstraale (1910) her. Sie hat die Winter. leber verschiedener Arten benutzt, und obwohl die Arbeit wesentlich das Leberbindegewebc umfasst, hat sie doch auch

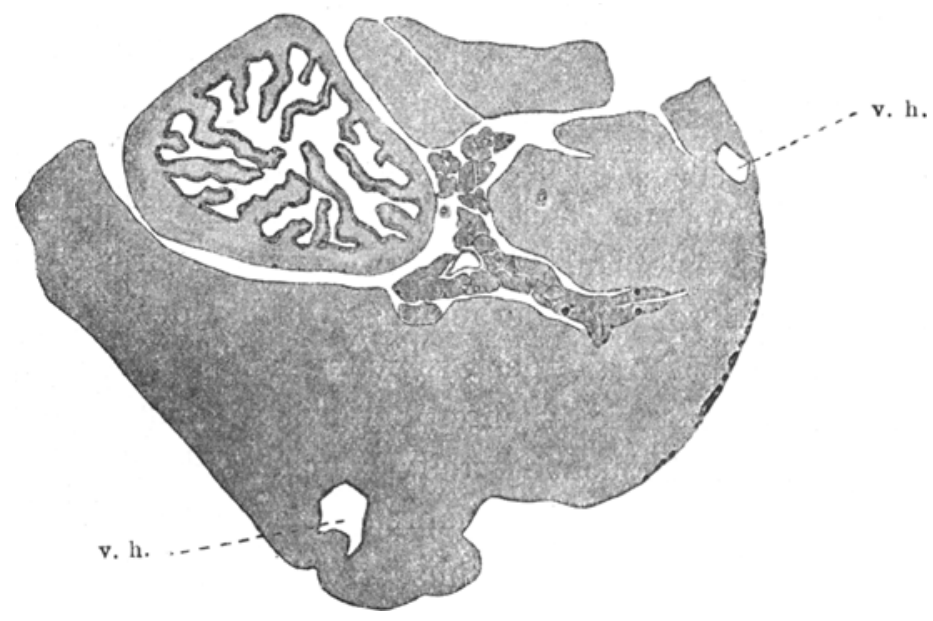

Fig. $k$.

Syngnathus rost. Querschnitt von Leber und Darm. Leberparenchym und Blutcapillare sind durch eine graue Farbe angedeutet. Der Pankreas. stamm mit einem Zweig hinein in die Leber. Im Stamm selbst ein Pfortaderzweig; durch die Spitze des Pankreas.Pfortaderzweigs steht die Pfortader in Verbindung mit einer der Blutcapillaren der Leber. Dorsal in der Leber. substanz ein Gallengang (Qucrschnitt). v. h. $=$ Zweige der Lebervene. Die

Flüssigkeit von Zenker. Hämatoxylin-Eosin. Vergrösserung 35.

der Parenchymstruktur Aufmerksamkeit geschenkt. Sie findet, dass der netzförmig-tubulöse Bau unverkennbar ist, und die Tubuli häufig radiär rings um ein grösseres Gefäss angeordnet sind. Einzelne Arten haben auch cytozonale Maschen. Bluntschlis Auffassung von „Schaltstücken" hält sie für wenig berechtigt. Und entscheidend scheint mir ihre Einwen- 
dung gegen seine Theorie von der Bedeutung des lymphatischen Gewebes für das Entstehen der cytozonalen Maschen zu sein. Bei Cottus gelang es ihr nämlich, solche Maschen nachzuweisen, während sich keine Andeutung von irgendwelcher Aufhäufung des lymphatischen Gewebes fanid.

Ein Schnitt durch die Leber von Syngnathus rostell a tus gibt ein höchst eigentümliches Bild.

Drin in der Lebersubstanz, die sich durch ihre klaren, ziemlich grossen Zellen und dünnen Gallencapillaren auszeichnet, liegen "Inseln“ von Pankreasgewebe. Eine genauere Untersuchung ergibt, dass diese Inseln die abgeschnittenen Teile der Pankreasäste sind, die sich in das Leberparenchym hineinschieben. Diese innige Verbindung zwischen den beiden grossen Verdauungsdrüsen gibt der Syngnathusleber ein Sondergepräge; andererseits hat sie in ihrer Fettlosigkeit einen wesentlichen Vorzug als Untersuchungsstoff, da man dadurch mit Leichtigkeit nach dem Golgi-Verfahren arbeiten kann.

Die Leber bei Syngnathus rostellatus ist ein nicht besonders voluminüses Organ von lïi.g.icher Form, das in der Hauptsache veintral zur Darm:öhre liegt. Auf der dorsalen Fläche der Leber zwischen dieser und dem Darm liegt dann der ,Pankreasstamm“, von dem aus die genannten Äste sich in die Lebcrsubstinz hincindrüngen. Diese Äste bestehen aus P'nilkreassulsstanz, die ein ziemlich grosses Blutgefüss mit einer dünnen Biidegewebewand umschlicsst. Ferner werden sie von Drüseniuusführungswegen, mit Epithel bekleideten Röhren, begle:tel. - Die Pankreasiiste zeigen in der Leber ein sehr wechselndes Verhältnis. Oft sind sie ohne Verüstelung, bisweilen aber verüsteln sie sich stark, ebenso wie die einzelnen Äste auch von sehr verschiedener Länge sind. Die meisten reichen von der Dorsalfläche der Leber aus nicht weiter, als bis mitten in die Lebersubstanz hinein. Einzelne gehen noch etwas tiefer, 
mehr ventral, aber niemals erreichen sie die Ventralfläche der Leber. - Alle weisen sie die oben erwähnte Anordnung auf, und oft sieht man, dass die mittleren Gefässe mit kleinen Gefässstämmen und Capillaren in Verbindung stehen (Fig. k). Durch diese Gefässe geht nämlich die Blutversorgung der Leber vor sich. Sie stellen den wesentlichen Teil des zuführenden Systems dar, V. portae. - Es findet sich auch eine kleine Arterie, die zusammen mit Pankreasästen verläuft. Leider misslangen die Injektionen durch das Arteriensystem, und in Serien liess sich kein unmittelbarer Ubergang zwischen den Ästen der Arterie und den Blutcapillaren der Leber nachweisen. Nach den Präparaten zu urteilen, scheint diese kleine Arterie am ehesten die Pankreasäste mit Blut zu versehen. Ausschliessen darf man jedoch nicht die Möglichkeit, dass sie ebenfalls an der Blutversiorgung der Leber teilnimmt. Bei anderen Fischen, Pleuronectes, zeigten jedenfalls die Injektionen, dass es eine A. hepatica gibt. Die Äste der Arterie verlaufen hier zusammen mit der Pfortader; oft sind die Venenäste von zwei kleinen Arterien begleitet, je eine auf jeder Seite. Das Blut der Syngnathusleber sammelt sich in Venenstämmen, die hauptsächlich parallel zur Längsseite der Leber verlaufen, und die an der Ventralseite liegen, in der Nähe der Bindegewebekapsel (Fig. k), mit ëinzelnen kleineren $Z$ weigen, die etwas in die Tiefe herabreichen; sie vereinigen sich $z u$ einer grossen $V$. hepatica.

Den Ästen der Pfortader im Pankreas fehlt jede Muskulatur und ebenso haben sie fast keine Bindegewebefasern. Die allergrössten Äste der Lebervene haben dagegen eine etwas dickere Gefässwand, wo einzelne Fasern Gelbfärbung bei va n Gi e s on zeigten. Die kleineren Äste haben dünne Bindegewebewände und die allerkleinsten sind nur mit Endothel bekleidete Röhrchen, die bloss durch ihre Grösse sich von den Blutcapillaren unterscheiden. 
Die Gallengänge sind von der gewöhnlichen Art mit niedrig kubischem Epithel, das auf einer Schicht von rund herumlaufendem Bindegewebe aufsitzt. Das letztere ist überaus spärlich; ebenso wie der Leber, abgesehen von den Fasern der Leberkapsel und der Lebervenen, fast vollständig jedes Bindegewebe fehlt. Die Gallengänge einzelner gehen drin in der Leber in die Pankreasäste über; die meisten verlassen indessen die Lebersubstanz auf der Dorsalfläche der Leber und gehen, an Zahl nur wenige, ein kürzeres oder längeres Stück längs dieser hin. - Bei Pleuronectes begleiten die Gallengänge die Äste der V. portae. - In, der Syngnathusleber drin gehen die Gallengänge rasch in Tubuli über und verschwinden nach kurzer Zeit gänzlich. Sie sind deshalb im Leberbilde sehr wenig hervortretend. Im wesentlichen halten sie sich an die centralen und dorsalen Teile der Leber und erreichen niemals vollständig die gegenüberliegende Ventralfläche. In den Schnitten durch den Mittelteil der Leber konnte ich nur bis zu vier Gallengänge nachwoisen, obwohl die Schnitte nach van Giesons Verfahren gefärbt waren, um ihr Bindegewebe leichter nachweisen zu können. Ähnlich war das Verhältnis in der Leber im übrigen. Dio Anzahl der Lebertubuli in einem' solchen Schnitt gelang es mir aber leider nicht festzustellen, da die Abgrenzung zwischen den einzelnen Tubuli immer schwierig, oft sogar ganz unmöglich ist. - Diese letztere Eigenschaft macht die Arbeit mit gewöhnlichen Präparaten wenig befriedigend. Sie lassen nur das Leberepithel, angeordnet in Tubuli, erkennen, deren Zellenzahl sich auf Querschnitten nicht immer entscheiden lässt, die aber in der Regel 4-6 Zellen aufweisen. Die Golg i-Präparate mit und ohne Kernfärbung gestatteten dagegen ein genaues Studium der Struktur des Leberparenchyms. In reichlicher Menge zeigten sie vasozonale Maschen, ja mehrmals sogar zwei zusammenhängende. Cytozonale Maschen fanden sich ebenfalls häufig vor, aber wesentlich unicelluläre, weit seltener pluricelluläre. 
Am häufigsten waren die, welche an der Verästelungsstelle der Tubuli lagen. Ein einzelnes Mal 'zeigten die Präparate sogar zwei zusammenhängende unicelluläre Maschen dieser Form. Bisweilen lag eine monocytische Masche, soweit sich das entscheiden liess, auch in dem gewöhnlichen Verlauf eines Tubulus' die unicellulären cytozonalen Maschen waren im allgemeinen ganz klein, kleiner als der Umkreis einer Leberzelle, ja mitunter auch kleiner als die Kerne der Leberzellen. Sie umschliessen deshalb unzweifelhaft in der Regel nur einen Teil dèr Zelle.

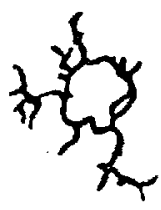

$l_{1}$

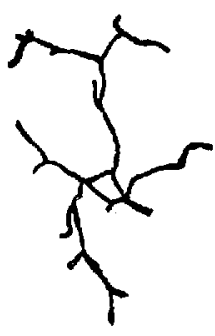

$\mathbf{l}_{\mathbf{s}}$

Fig. $\mathrm{l}_{\mathbf{1}}-\mathrm{l}_{\mathbf{2}}$.

Leber. Syngnathus rost. Golgi-Imprägnation $l_{1}$ eine vasozonale, $l_{2}$ eine cytozonale Gallencapillarmasche. Vergrösserung $l_{1}: 335, l_{a}: 700$.

Die Golgi-Präparate zeigten an vielen Stellen in grossen Mengen die knospen- oder pilzförmigen Seitenäste, die von dem Centralcapillar ausgehen und von Braus (1896) beschrieben worden sind als seiner Meinung nach intercelluläre Seitencapillaren. Ob dies zutrifft, lässt sich nach den GolgiPräparaten nicht mit Sicherheit unterscheiden, da diese ja nicht die nötige Übersicht über die Abgrenzung der einzelnen Zellen ermöglichen. Nach meinem Eindruck bin ich jedoch geneigt, $\mathrm{B} r$ a u s in seiner Auffassung recht zu geben. - Andere Knochenfische haben jedenfalls intercelluläre Seitenäste, die vom Centralcapillar ausgehen, wovon ich mich bei Pleuronectes über- 
zeugen konnte. Sie sind ja auch früher schon bei anderen Arten nachgewiesen worden.

Bei Syngnathus gelang es nicht, den Verlauf der einzelnen Tubuli in Serienschnitten $z u$ verfolgen, da, wie erwähnt, eine Abgrenzung zwischen den Tubuli oft ganz unmöglich ist. Bei Pleuronectes kann man indessen, besonders in den Spitzen der Organe, die Tubuli ein kürzeres oder längeres Stück verfolgen, und hier gelingt auch bisweilen der Nachweis von blind endenden Tubuli.

\section{$\mathrm{Z}$ usammenfassung.}

1. Die Leber der Knochenfische, studiert an Material von Syngnathus und Pleuronectes, erweist sich als eine netzförmig-tubulöse Drüse, jedoch auch mit einzelnen blind endenden Tubuli. Jeder Tubulus hat ein centrales Gallencapillar, das intercelluläre Seitenäste aussendet.

Cytozonale Maschen sieht man oft, am häufigsten unicelluläre. Sie finden sich sowohl an der Teilungsstelle der Tubuli, wie währen'd ihres gewöhnlichen Verlaufs.

2. Die Blutversorgung erfolgt durch $V$. portae und teilweise durch eine A. hepatica. - Bei S yng nathus laufen die Äste der Pfortader drin in der Pankreassubstanz, wesentlich in den Mittelteilen der Leber, aber auch im dorsalen Teil. Das Blut sammelt sich in den Verästelungen der Lebervene, die auf der Ventralfläche verlaufen, unmittelbar unter der Leberkapsel.

3. Die Anzahl der Gallengänge ist gering. Sie münden bei Syng nathus auf der dorsalen Fläche der Leber verstreut in diese ein und gehen rasch in Gallencapillaren über. Ihr Epithel ist niedrig' kubisch und während ihres Verlaufs von spärlichem, ringförmig verlaufendem Bindegewebe umgeben. - Bei Pleuronectes verlaufen sie zusammen mit den Ästen der V. portae. 
Fassen wir nunmehr die Ergebnisse unserer Arbeit mit Spinax- und den untersuchten Knochenfischen zusammen, so sehen wir, dass die Leber der Fische eine netzförmig-tubulöso Drüse ist, jedoch mit einzelnen blind endenden Tubuli. Das centrale Gallencapillar ist bei dem entwickelten Individuum dünn und fein und sendet intercelluläre Seitenäste von wechselnder Form und Länge aus; sie erreichen indessen niemals die Peripherie der Tubuli. - Cytozonale Maschen kommen sowohl an der Trennungsstelle der Tubuli vor, wie auch ,spontan" in ihrem Verlauf.

Die Blutversorgung der Leber geht durch die Äste der Pfortader sowie durch die A. hepatica vor sich. - Bei den Knorpelfischen werden sie von den Gallengängen begleitet, dasselbe ist bei den Knochenfischen (Pleuronectes) der Fall. Nur wo besondere Verhältnisse eintreffen (Syngnathus) trennen sie sich; aber selbst hier behalten sie gemeinsame Züge in ihrem weiteren Verlauf bei, bei ihrer Einmündung auf der Dorsalflüche der Leber und in ihrer intrahepatischen Lage wesentlich in den centralen und dorsalen Teilen der Leber.

Die intrahepatischen Gefüsse sind entweder nur mit Endothel bekleidete Röhren, oder es' liegt aussen auf dem Endothel eine mehr oder weniger dicke Bindegewebeschicht, bei Knochenfischen auch mit etwas Muskulatur.

Die Gallengänge sind nach dem gewöhnlichen Typus gebaut und wie bei Myxine anscheinend wenig entwickelt, verglichen mit der Menge des secernierenden Parenchyms.

\section{d) Amphibien.}

Die Amphibienleber ist bei Leberarbeiten immer ein Lieblingsgegenstand gewesen, und zahlreiche Arten sind im Laufe der Zeit zum Gegenstand mehr oder weniger eingehender Studien gemacht worden. 
Hyrtl hat im Jahre 1864 seine Arbeit über das Gefässsystem der Leber bei Amphibien und Fischen veröffentlicht. Unter den ersteren hat er eine Reihe von Vertretern für U ro dela untersucht, und durch seine Injektionen nachgewiesen, dass das intrahepatische Gefässsystem aller dieser Arten in den Hauptpunkten dasselbe Gepräge hat. - Die Pfortader ist ein oberflächliches Gefäss, das auf der inneren Leberfläche verläuft. Die grössten Äste behalten diese oberflächliche Lage, und keiner der Pfortaderäste reicht bis zu der äusseren Leberfläche hinüber. - Auf dieser liegt die V. hepatica. Dieses Gefäss weist ebenfalls einen ausgesprochen oberflächlichen Verlauf auf, und seine Äste zeigen dieselbe Gesetzmässigkeit in ihrer Ausbreitung, wie die Äste der Pfortader, da auch sie nich $t$ bis zu der entgegengesetzten Leberfläche hinüberreichen. V. portae und deren Verästelungen werden von einer A. hepatica begleitet, deren sämtliche Capillaren schliesslich in die der Pfortader ausmünden.

Trotz der technischen Schwierigkeiten gelang es $\mathrm{Hyrtl}$, auch wohlgelungene Injektionen IderGallencapillaren zu erhalten. Diese bilden vollständig geschlossene Netze. - „Um einen Vergleich zu machen, denke man sich ein feinstes Drahtgitter durch die Lücken von massiven Eisenstäben durchflochten. Was zwischen Draht und Eisenstäben offen bleibt..... denke man sich .... durch ein Zellmosaik ausgefüllt, und man hat die rechte Idee vom Verhältnis der. Gallenwege zu den Blutwegen in der Amphibienleber."

Hering (1866) sah Tubuli, die im allgemeinen im Querschnitt 3-4 Zellen aufwiesen. Jedoch meint er, in einem einzelnen Fall, den er abbildet, nur zwei Zellen gesehen zu haben, ohne dass er indessen einen Irrtum ausschliessen will. Über Hyrtls frühere Untersuchungen sagt er: „Im übrigen aber ist sein Vergleich der beiden durcheinander gesteckten Netze der Capillaren einerseits und der Gallengänge andererseits mit 
einem im Raume ausgebreiteten Gitterwerk von Eisenstäben, durch dessen Lücken ein feines Drahtgitter durchgeflochten ist, ganz treffend, wenn man noch hinzufügt, dass Draht und Eisenstäbe überall um den Durchmesser einer Leberzelle voneinander abstehen, sich aber nirgends berühren."

Die meisten späteren Arbeiten stützen diese Auffassung von der netzförmig-tubulösen Struktur der Amphibienleber. Als einen neuen Zug hebt Eberth (1867) hervor, dass die Amphibienleber wahrscheinlich ebenfalls blind endende Leberzell. balken habe.

Shore und Jones (1889) haben Rana, Caecilia und Triton untersucht und bei ihnen allen anastomisierende Tubuli gefunden. Triton zeigt auch ausser den typischen Tubuli : „here and there a short idouble row of cells". Sie haben auch den Gefässen und Gallengängen einige Aufmerksamkeit gewidmet, jedoch ohne näher auf deren Verhältnis einzugehen. Bei ihrer Beschreibung der Ran a-Leber sagen sie, dass ,small bile ducts are found running near the larger bloodvessels and have the usual structure". Ebenso kurzgefasst äussern sie sich über 'die Gefässe und Gallengänge der C a e cili a - Leber: „The larger vessels have very thick walls and are situated with the bile ducts in the margin of the lobe." Das ist alles, was sie über diese Züge im Bau der Amphibienleber zu bemerken haben.

G. Retzius (1892 b) nimmt das Vorhandensein von zahlreichen blind endenden Seitencapillaren an, während er im übrigen keine völlig sicheren Gallencapillarmaschen in seinen Golg i-Präparaten findet.

Eine eingehende und überausı wertvolle Untersuchung über die Amphibienleber verdanken wir Braus' (1896). Er zeigt, dass trotz vieler gemeinsamer Züge ein bedeutender Unterschied zwischen der Anura-und der Urodela-Leber besteht, insofern als die erstere auf einer primitiveren Entwickelungs- 
stufe näher der niederen Leberformen steht. Sie ist in der Hauptsache eine netzförmig-tubulöse Drüse, während die Urodelaleber grössere Abweichungen von dieser Form zeigt. Es ist denn auch die letztere, der er augenscheinlich seine grösste Arbeit geopfert hat und wo seine Befunde vom grössten Interesse sind. - Seine Ergebnisse fasst er dahin zusammen, dass die Amphibienleber keine rein tubulöse Drüse ist. Die Leberbalken sind nicht überall gleich dick. „Es kommen Verschmälerungen vor, einmal durch Abnahme der Zahl der Zellen, welche den Quers'chnitt eines Balkens zusammensetzen, ferner durch Auseinanderweichen der Zellen zu Platten. - Vergleichen wir die Leber mit einem Gerüst, so ist dies aus Balken und Brettern gezimmert." Die Bildung von Zellplatten, meint er, ist eine Folge einer Anhäufung von häufig pigmentierten Leucocyten in grossen Haufen. Die Frage, ob die Leberzellen aktiv oder passiv an der Umbildung vom gewöhnlichen Tubulus zu Zellplatten teilnehmen, lässt er offenstehen. Einen wichtigen Beweis hierfür findet er bei den $\mathrm{S}$ a l a ma nd e r n, deren Sommerleber stark pigmenthaltig ist, während der Winterleber das Pigment fehlt; und ,in der Pigmentleber war nämlich an Stellen, wo zwischen zwei Pigmentinseln die Leberzellen einreihig lagen, die centralen Gallencapillaren flächenständig. In der Winterleber dagegen fanden sich nur typische, kantenständige Centralcapillaren".

Die Gallencapillaren bestehen aus einem centralen Capillar und von dort ausgehenden intercellulären Seitencapillaren. Oft läuft das centrale Gallencapillar über die Flüchen der Zellen und ist häufig von den Blutcapillaren nur durch einen halben Zellquerschnitt getrennt.

Trotz dieser strukturellen Veränderungen behält die Amphibienleber dennoch das Gepräge einer netzförmig-tubulösen Drüse, wo auch cytozonale Maschen sich häufig in den Zellplatten finden. Durch seine Untersuchungen von Larvenstadien 
von Salamandra maculos a findet. er, dass sie entwickelungsgeschichtlich durch Verschmelzung von Seitencapillaren gebildet werden. - Ich habe mich hier nur an die grossen Hauptlinien in seiner Arbeit gehalten; später komme ich auf sie und zahlreiche Einzelheiten zurück.

Aus obiger kurzgefasster geschichtlicher tobersicht wird man ersehen, dass die Amphibienleber fleissig bearbeitet worden ist, und zwar nicht nur hinsichtlich der Züge, bei denen ich oben verweilt habe. Schon seit Eberths Arbeit (1867) hat man bedeutendes Gewicht darauf gelegt, dass die Amphibienleber „zweierlei Substanzen“ enthält. Dass sich aussér Leberparenchym auch Haufen von Zellen vorfanden, die nach oppels Arbieiten (1900) für Leucocyten angesehen werden müssen, ein Ergebnis, das $B$ raus nach eingehenden Untersuchungen bestätigt. $\mathrm{Da}$ das Studium dieser Zellen ausserhalb der Aufgabe liegt, die ich mir gestellt habe, habe ich über Arbeiten auf diesem Felde nichts berichtet.

\section{a) Andra.}

Bufo cinereus.

Die Leber bei $\mathrm{Bufo}$ c in ere us ist ein grosses klumpiges Organ. Ein Längenschnitt in der Frontalebene zeigt eine plumpe H-Form bei kleinen Tieren. Bei grösseren teilt sie sich in mehrere Leberlappen, ohne jedoch ihre ursprüngliche Form ganz zu verlieren.

Eine Serie durch ein ganz junges Tier zeigt, dass die Leber ausser durch die unbedeutende A. hepatica wesentlich durch die Pfortader mit Blut versorgt wird. Diese mündet auf der Ventralseite ein, ziemlich. weit hinten auf der „Brücke", die die zwei Längsstriche dler H-Figur vereinigt. Sie ist hier mit den Gallengängen und der Leberarterie verbunden. Die Portaeäste nehmen bei ihrem Eintreten die mitt- 
leren Teile ein und verzweigen sich allmählich weiter nach der dorsalen und medialen Fläche der Leber hin. Die Lebervene bricht vorn an der „Brücke ${ }^{\text {" }}$ hervor. Ihre Hauptäste sieht man auch, dicht bevor die Vene die Lebber verlässt; in den centralen Teilen. Sie werden hier durch Vereinigung
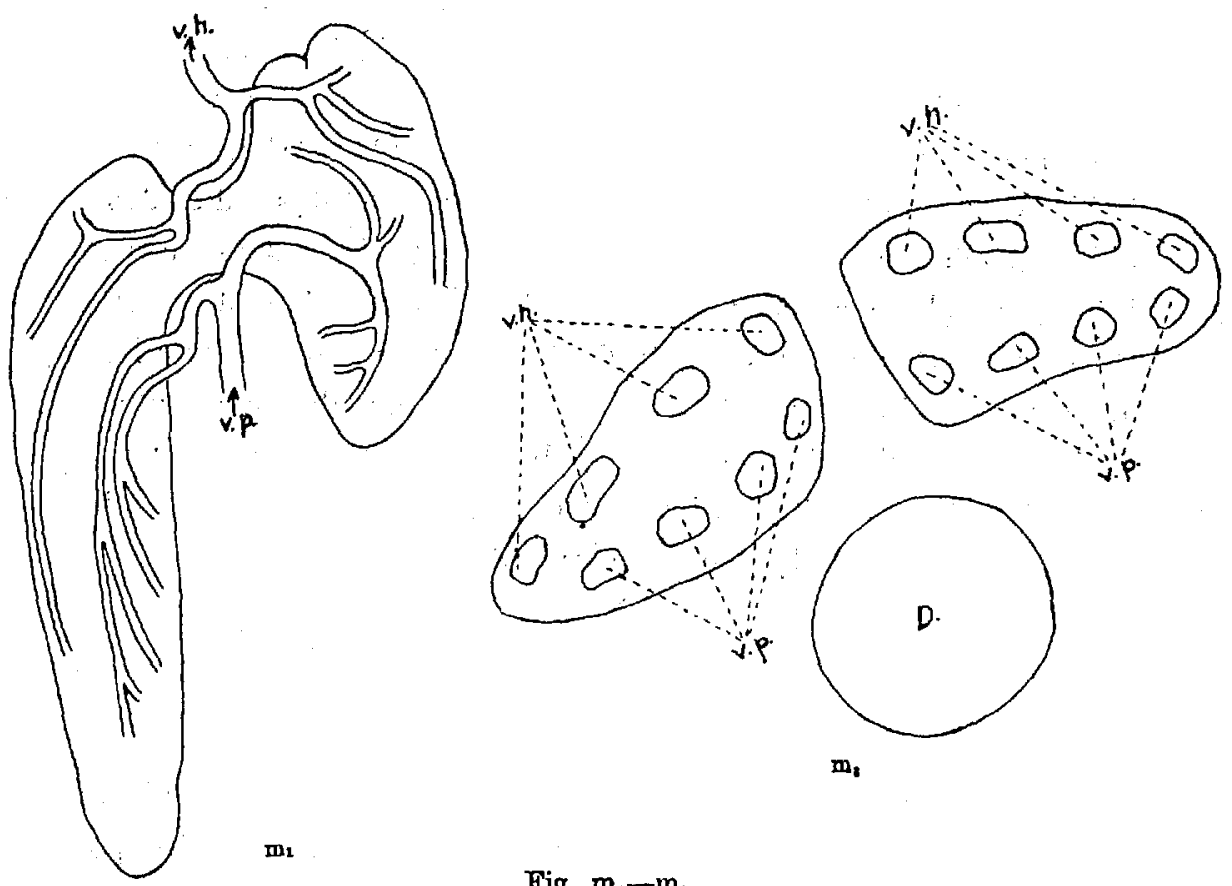

Fig. $m_{1}-m_{2}$.

Bufo cinereus. $m_{1}$ halbschematischer Längenschnitt, $m_{2}$ schematischer Querschnitt durch die Leber bei einem jungen $\mathbf{2 , 5} \mathrm{cm}$ langen Individuum. Verlauf der Lebergefässe. Die Leberarterie nicht gezeichnet. v. p. Pfortader, v. h. Lebervene, D. = Darm.

von Gefässen gebildet, die als Ganzes im ventralen und ventrolateralen Teilen der Leber liegen ( $\mathrm{s}$. Fig. $\mathrm{m}_{\mathbf{1}^{-2} \mathrm{z}}$ ).

Sowohl für die Äste der Pfortader wie der Lebervenen gilt als Regel, dass sie nicht unmittelbar unter der Leberkapsel verlaufen, da sie von dieser durch einige Tubuli getrennt sind. Jedoch haben sie im grossen ganzen eine periphere Lage, und 
zwar besonders die Äste der Lebervene. Einzelne Äste laufen indessen kürzere oder längere Strecken doch unmittelbar unter der Leberkapsel.

Die Äste der Lebervene sind wesentlich mit Endothel bekleidete Röhren, von denen die grösseren mit einem sehr spärlichen Bindegewebe versehen sind. Die Äste der Pfortader verlaufen zusammen mit den Gallengängen, in den Lebern der kleineren Tiere mit einem isehr spärlichien, in denen der grösseren mit einem reichlicheren Bindegewebe. Jedoch zeigt die Wand der Äste 'der V, portae wenigstens unmittelbar nach ihrer Einmündung einzelne, nach $\mathrm{van} G$ ieson gelbgefärbte Fasern und einige spulenförmige Kerne. Abgesehen von der die Leber umgebenden Kapsel ist die Bufoleber sehr arm an Bindegewebefasern.

In ider Leber der nicht ganz kleinen Individuen sieht man die Äste der Pfortader teilweise umgeben von Leucocythaufen, die indessen wesentlich die Gallengänge umschliessen, namentlich die grösseren. Die Seiten der Gefässwände, in deren Nähe sich kein Gallengang befindet, sind meist gänzlich frei von Leucocythaufen (Fig. 10).

Die Gallengänge werden aus einem kubischen Epithel aufgebaut, das auf einer dünnen Basalmembrane sitzt. Ihre Anzahl ist gering im Vergleich zu der mächtigen Parenchymmenge des Organs, und den Übergang von Tubulus zum Gallengang sieht man verhältnismässig sehr selten. - Trotz ìhrer geringen Anzahl kommen sie nicht sehr ausgebreitet im Organ vor. In einer Serie durch eine Leber von 312 Schnitten zu je $10 \mu$ zeigten die vordersten 79 Schnitte nicht einen einzigen Gallengang. Und auch in den hinteren 166 Schnitten fehlten sie gänzlich. Also fanden sich Gallengänge nur in wenig mehr als der Hälfte der Länge der Leber. Und bloss in einem' verhältnismässig kleinen Mittelteil kamen sie in so grosser Menge vor, dass sie sofort in die Augen fielen. 
Auf den ersten Blick wird ein gewöhnlich gefärbter Schnitt von einer $\mathrm{Bufo} \mathrm{c}$ inereus-Leber dasselbe Bild aufweisen, das wir von den niederen Wirbeltierformen her kennen. Man sieht durchgeschnittene Tubuli, in deren Mittelpunkt das centrale dünne Gallencapillar mit kleinen, aber ganz scharfen $\mathrm{Ab}$ biegungen längs der Ränder der ziemlich grossen Zellen hinläuft. Dass die Gallencapillaren "kantenständig" sind, davon kann man sich überzeugen auf den zahlreichen Querschnitten von Tubuli, die durchgehends 3-6 Zellen aufweisen. - Vom Centralcapillar gehen blind endende intercelluläre Äste aus, die niemals bis an die Peripherie von Tubuli heranreichen. Man wird ferner grössere Gefässstämme sehen, vón denen einzelne von Gallengängen begleitet sind. Nur wenn man eine grössere Anzahl Schnitte sorgfältig durcharbeitet, wird man ein seltenes Mal auf das aufmerksam werden, was dieser Leber eine Sonderstellung gegenüber den niederen Typen verleiht. Mitunter wird man dann Tubuli sehen, deren Querschnitt nur zwei Zellen aufweisen, und ein zwischen diesen liegendes centrales Gallencapillar sehen lassen. Ich werde später näher auf diese zu sprechen kommen.

Weiter kommt man kaum mittels gewöhnlicher Präparate infolge der Feinheit der Gallencapillaren. Wie gewöhnlich griff ich deshalb zum Golgi-Verfahren. Ausserdem wandte ich physiologische Injektion mit Indigokarmin an und versuchte auch unmittelbare Injektion durch die Gallengänge, ohne jedoch hier mehr als durch die Imprägnierung zu erreichen.

Dass die Leber von netzförmig-tubulösem Bau war, ging aus der grossen Menge vasozonaler Maschen hervor, die die GoIg i - Präparate erkennen liessen. Ein Blick auf die Fig. $n_{1}$ wird jeden davon überzeugen. Neben diesen anastomosierenden Tubuli finden sich auch blind endende. Jedoch zeigen die Serien sie nicht in grösserer Menge. 
Ein besonderes Interesse erhielten die Golgi-Schnitte durch die grosse Menge cytozonaler Maschen, die sie aufwiesen: sowohl uni- wie pluricelluläre, und sowohl an der Vereinigungsstelle vou Tubuli wie ohne einen solchen Anlass. In beiden rällen traten sogar wiederholt zwei zusammenhängende unicelluläre Maschen auf. Ein Verhältnis, das vielleicht mehr als eine grosse Anzahl auf eine weit vorgeschrittene Auflösung des schematisch tubulösen Baues hindeutet.

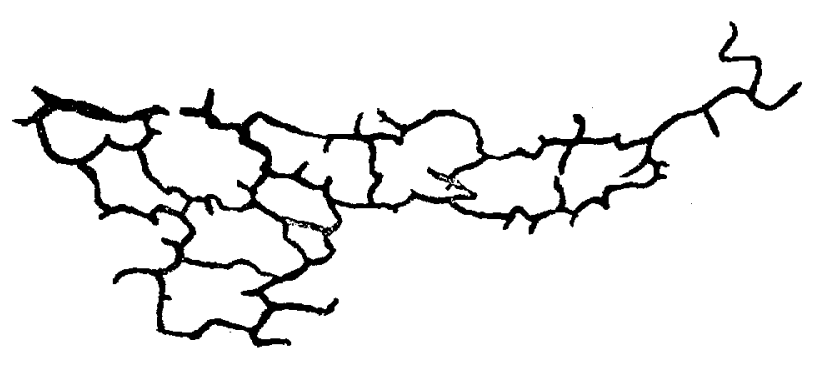

$\mathbf{n}_{3}$

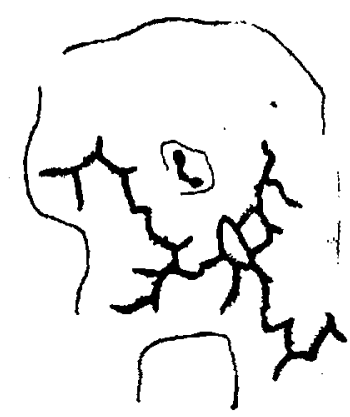

dy

Leber. Bufo cinereus. Golgi-Imprägnation. $n_{1}$ : acht zusammenhängende vasozonale Gallencapillarmaschen. $\mathrm{n}_{2}$ : zwei zusammenhängende cytozonale an der Vereinigungsstelle zweicr Tubuli; auch pilzförmigc intracelluläre Seiten. wege sind sichtbar. Vergrösserung 335.

Intracelluläre Gallenwege sieht man in reichlicher Menge sowohl in den Golg i-Präparaten, wie in den Schnitten durch Lebern von Tieren, wo physiologisch Injektion mit Indigokarmin vorgenommen war. Teils kommen sie als kleine pilzförmige Ausläufer der Gallencapillaren vor (s. Fig. $\mathbf{n}_{2}$ ), teils zeigten besonders die Golgi-Präparate sie als ein zusammenhängendes feines, drahtartiges Netzwerk.

\section{Zusammenfassung.}

1. Die $B$ u f o-Leber hat eine plumpe H-Form. Sie ist eine netzförmig-tubulöse Drüse, deren Tubuli in Querschnitten von 
2-6 Zellen aufweisen. Nehmen nur zwei Zellen an der Bildung der Querschnitte teil, so verläuft das Gallencapillar zwischen den zusammenstossenden Flächen der Zellen. Im übrigen läuft es längs der Ränder der Zellen. Von den Centralcapillaren gehen intercelluläre Äste aus, und sowohl von der ersteren wie den letzteren intracelluläre Gallengänge.

Häufig bilden die Gallencapillaren cytozonale Maschen, sowohl uni- wie pluricelluläre. Sie finden sich sowohl an der Verzweigungsstelle der Tubuli wie in deren allgemeinem Verlauf. In beiden Fällen sieht man nicht selten zwei zusammenhängende-und dann unicelluläre Maschen.

2. Die Blutversorgung geht durch die unbedeutende Leberarterie und die mächtige Pfortader vor sich. Die Pfortader dringt zusammen mit der Leberarterie und den Gallengängen ventral und rückwärtsı der „Brücke“ in die Leber hinein. Die Lebervene verlässt die Leber weiter vorwärts auf dieser „Brücke“. In Serien durch kleine Tiere zeigte es sich, dass die Äste beider anfangs einen centralen Verlauf haben; aber bald gehen die der Pfortader in den dorsalen und medialen Teil der Leber, die der Lebervene in den ventral- und ventnolateralen Teil über. Die Äste beider verlaufen hier im grossen ganzen peripher in der Lebersubstanz. - Die Gefässe sind in der Leber mit Endothel bekleidete Röhren; bei grösseren Individuen umgeben von einem siehr spärlichen Bindegewebe, in dem man unmittelbar nach der Einmündung der Pfortader einzelne Muskelfasern sieht. Längs der Pfortaderäste sieht man oft, wo diese von Gallengängen begleitet werden, Leucocythaufen.

3. Die Galleng:änge sind nach dem gewöhnlichen Typus gebaut. Sie folgen den Ästen der V. portae und sind wenig entwickelt im Vergleich zu der Menge des secernierenden Paren. chyms. 


\section{в) Urodela.}

Triton punctatus.

Die Triton-Leber ist ein längliches Organ, das wesentlich ventral zum Darmkanal mit seiner Längsachse parallel zu diesem liegt.

Sie wird durch die grosse Pfortader und die kleine Leberarterie mit Blat versehen. Die lelztere begleitet die V. portae, und die Capillaren der Leberurterie münden in die der Pfortader ein.

Sie dringen unmittelbar an der hinteren Spitze der Leber auf der Ventralfläche in die Ieber hinein; durchbrechen rasch die Lebersubstanz und gehen darauf nach vorn ungefähr mitten auf der Dorsalfläche der Leber (Fig. o). Die ganze Zeit verlaufen sie parallel zur Längsachse der Leber, peripherisch, entweder unmittelbar unter oder in der Nähe der Leberkapsel.

Die Pfortader sendet zahlreiche Äste aus. Die grösseren halten sich sämtlich an die Dorsalfläche der Leber, während kleinere Zweige kürzer oder länger nach der Ventralseite hinübergchen, aher diese selbst niemals erreichen; nur äusserst selten gehen sie weiter als bis zu den centralen Teilen der Leber.

Nachdem das Blut die oft ziemlich weiten Capillaren durchströmt hat, sammelt es sich wieder in den Ästen der Lebervene. Diese $\ddot{A}$ ste sieht man im caudalen Teil als kleine Stïmme auftreten, die parallel zur Längsachse der Leber verlaufen. Weiter nach vorn nehmen sie bedeutend an Mächtigkeit zu und werden allmählich wesentlich in zwei grosse Venen gesiammelt, die beide oberflächlich in der Lebersubstanz liegen, Leilweise unmittelbar unter der dünnen Bindegewebekapsel der Leber. Die eine dieser Venen verläuft ungefähr mitten auf der ventralen Fläche der Leber, die andere auch auf der Ventralfläche, und zwar rechts, wenn man das Tier von hinten 
und oben betrachtet, nach dem Ubergang hin zwischen der ventralen und dorsalen Leberfläche. Sie behalten die ganze Zeit im wesentlichen ihre ursprüngliche Lage; schliesslich verlassen sie die Leber nahe bei deren vorderen Spitze. Ausserdem sieht man auch kleinere $Z$ weige der Lebervene in der Nähe der Leberkapsel.

In allem Wesentlichen stimmen also meine Ergebnisse mit den von $\mathrm{Hyrtl}$ (1864) veröffentlichten überein. - Während

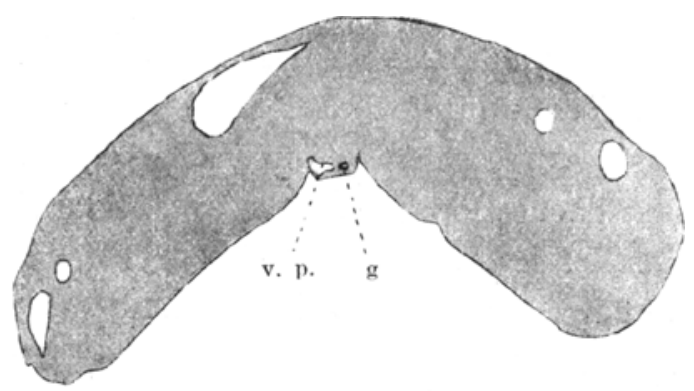

Fig. o.

Leber. Triton punct. Querschnitt durch den kranialen Teil der Leber. Leberparenchym und Blutcapillare sind durch eine graue Farbe angedentet. v. p. $=$ Pfortaderzweig g. = Gallengang.

Die ïbrigen Gefässe sind Lebervenenzweige. Die Flüssigkeit von Zenker. Hämatoxylin-Eosin. Vergrösserung 16.

ihres intrahepatischen Verlaufes haben die Gefässe eine schmale (iefüsswand, mit Endothel innen, und aussen auf diesem mit. einem nicht besonders reichlichem Bindegewebe. Muskulatur konnte ich nicht nachweisen.

Die intrahepatischen Gallengänge folgen den Ästen der Pfortader, besonders den grösseren Ästen. Ihre Anzahl ist gering, und verhältnismässig selten sieht man einen Tubulus in einen Gallengang ausmünden. Sie sind in der Regel von klèinen Haufen Leucocyten hegleitet, die sie ganz oder teilweise um- 
geben. - Diese Leucocyten sieht man in der Regel nur bei Schnitten durch die grösseren Gallengänge.

Die geringe Anzahl der Gallengänge im Vergleich $z u$ der Menge des Parenchyms geht daraus hervor, dass die vorderen 98 Schnitte zu je $10 \mu$ keinen einzigen Gallengang aufwiesen, und zwar in einer Leher, die im ganzen aus 391 Schnitten bestand. Das will sagen, dass das vordere Viertel des Organs ohne jede Verbindung mit dem gröberen Teil des Ausführungssystems der Drüse war. In den übrigen $3 / 4$ sind die Gallenwege chenfalls sehr spärlich.

Dass die Verbindung zwischen dem Parenchym und den Ausführungsgängen gering ist, geht auch daraus hervor, dass die Gallengänge, wie erwähnt, die ganze Zeit sich dicht an den Hauptstamm der V. portae und deren grössten Äste halten, also wesentlich oberflächlich in den dorsalen Teilen der Leber yerlaufen. Indessen sieht man auch $a b$ und zu Gallengänge, die zusammen mit kleineren Pfortaderästen ein Slück hinein ins Parenchym dringen.

Die Gallengänge bestehen aus einem Epithel, das je nach deren Lumen von niedrig cylindrisch bis $z u$ niedrig kubisch wechselt und grosse Kerne aufweist. Nach aussen wird das Epithel von nicht reichlichem rundumlaufenden Bindegewebe umgeben, das ebenfalls an Menge mit der Weite der Gallen. gïnge wechselt.

In einem Schnitt durch die Tritonleber wird man sofort einen schmalen Gürtel von leucocytähnlichen Zellen gewahr, ler unmittelbar unter der dünnen Leberkapsel liegt. Was indessen unser Interesse besonders erregt, ist die Struktur des Leberparenchyms selbst, und zwar wegen des neuen Gepräges, das sie hat, im Vergleich zu der der niederen I,eberformen.

Wohl findet man auch hier Tubuli mit von $2-5$ Zellen auf lem Querschnitt, sowie einem centralen Gallencapillar. Der wesentliche Teil der Leberzellen ist jerloch in anderer Weise 


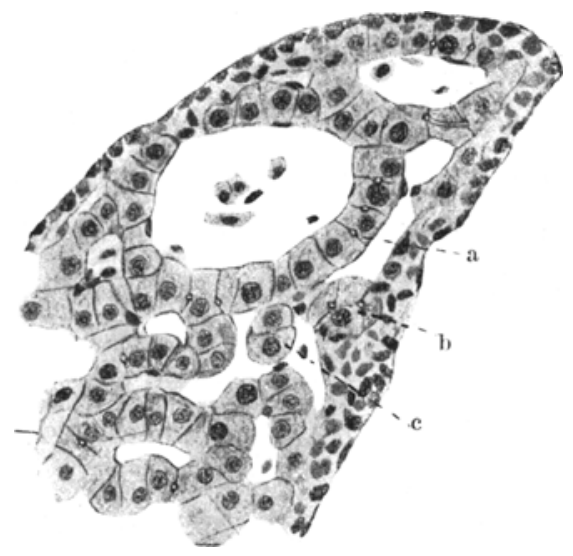

Fig. p.

Leber. Triton punct. Das Leberparenchym ist teilweise in einreihigen Zellreihen (a), teils in Tubuli angeordnet. Sowohl ,zweizelliger" Tubulus mit Gallencapillaren zwischen den Flächen der Zellen (c), wie gewöhnlicber „mehrzelliger" Tubulus (b). In dem letzteren sieht man den Querschnitt des Gallenrapillars, indem er eine cytozonale Masche bildet. Unmittelbar innerhalb der Leberkapsel liegt eine schmale Zone von leukozytähnlichen Zellen. Die Flïssigkeit von Z enker. Hämatoxylin-Ehosin. Vergrösserung 200.

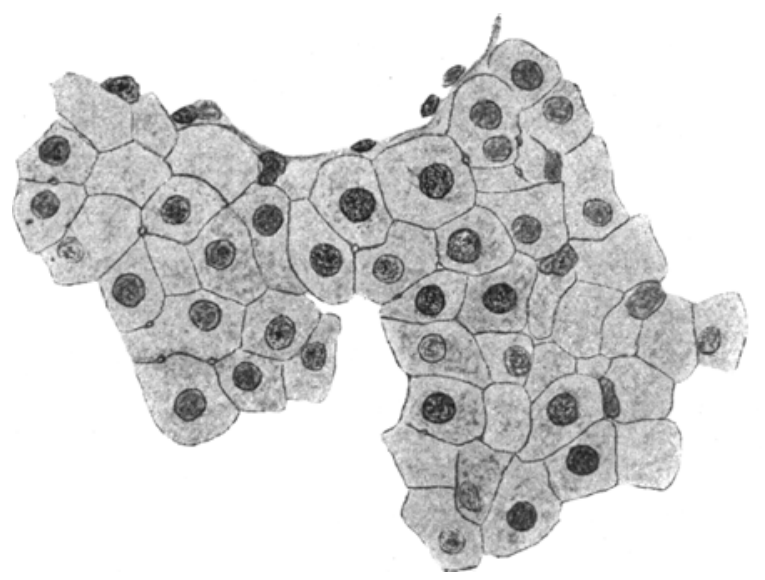

Fig. q.

Leber. Triton punot. Zellplatte, Flächensehnitt. Die ,kanten“" und „flächenständigen“ Gallencapillaren. Die Flüssigkeit von Zenker. Häma. toxylin-Eosin. Vergrösserung 590. 
angeondnet; in den Schnitten sieht man sie in grösseren und kleineren zusammenhängenden Flächen gesammelt (Fig. q), teilweise treten sie in einreihiglen Zellenreihen auf (Fig. p).

Die Leberzellen sind ungewöhnlich gross. Die Giallencapillaren sind dünn und liegen je nach den Verhältnissen längs (ler Ränder der Zellen oder längs: deren zusammenstossenden Flächen. In den Tubuli mit zwei Zellen auf dem Querschnitt und in den einreihigen Zellenreihen sind sie ,flächenständig“, in den Tubuli sonst ,kantenständig“. In den zusammenhängenden Zellflächon sieht ma,n beide Fornen. -- Mitunter sicht Inan auch ein Bild, wio das hier wiedergegebene:

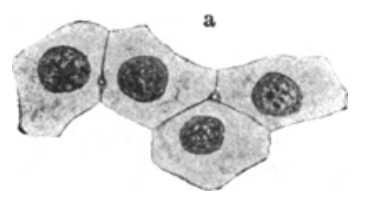

Fig. r.

Luber. 'Triton punct. Die Flüssigkeit von Zenker. Hämatoxylin-Eosin. Vergrösserung 590.

Man sieht eine Zelle (a), the in Verbindung mit zwei liallencapillaren steht, von denen das eine "flächenständig“, das andere ,kantenstïndig" ist. Gleichzeitig steht die Zelle in Verbindung sowohi mit einem, ,mehrzelligen“ Tubulus und einer einreihigen Zellenreihe. Sie bildet ein Verbindungsglied zwischen diesen beiden formen von Parenchymstruktur.

Ringsherum im Leberparenchym sieht man Ansammlungen von Pigment; wie ich sofort betonen will, ohne Verbindung mit dem Vorhandensein von einreihigen Zellreihen.

Indem man einzelne Tubuli in Serien verfolgt, sieht man, dass wenigstens einzelne unzweifelhaft blind enden.

Bei dem weiteren Eindringen in das Studium der Anordnung des Leberparenchyms war die Grolg i - Imprägnierung das 
wertvollste Hilfsmittel. Besonders einige sehr gul gelungene kerngefärbte Präparate (mit ( $\mathrm{r}$ e $n$ a $\mathrm{c}$ h e r s Alaunkarmin) gaben ansgezeichnet klare und übersichtliche Bilder. Sie zeigten schematisch gesehen zwei liormen der Leberstruktur.

Sie zeigten, dass auch diese Leber eine netzförmig-tubußose Drüse ist. Häulig sieht man nämlich, wie die Gillencipillaren visozomale Maschen bilden.

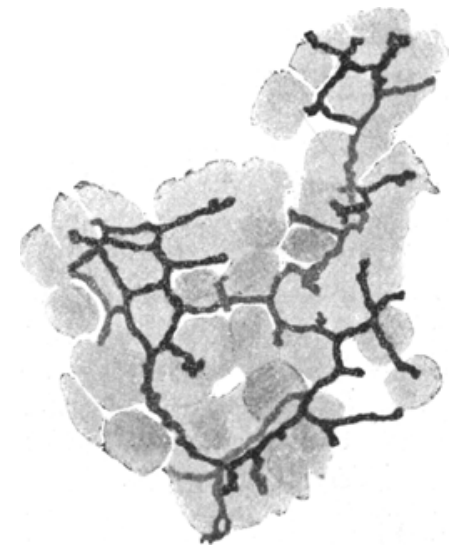

Fig. s

Leber. Triton punct. Golgi-Imprägnation. Vasozonale Hasche in Verbindung mit cytozonaler (cine kleine Zellplatte). Vergrösserung 430.

1)ass der Auflösungsprozess des reinen tubulïsen Baucs, der durch dic cytozonalen Waschen gekennzeichnet wurde, ebenfalls weit vorgeschritten war, erwies die Menge solcher Mischen, die ich beobachtetc. Sie waren wesentlich unicellulär, und kamen sowohl an dor Vereinigungsstelle der T'ubuli vor, wic auch "spontan“ in ihrem Verlauf. In beiden liallen sah ich häufig zwei zusammenhängende cytozonale Maschen. Also im grossen ganzen ein Bild, das von den niederen Leberformen her wohlbekannt ist. 
Völlig neu wirkte die andere Form von Leberstruktur. B ra u s gebührt das Verdienst, ein klares Bild dieser Bauart durch seinen Vergleich mit einem „Gerüst. . . aus Balken und Brettern gezimmert", gegeben zu haben.

Es sind diese „Bretter", die das Neue in der Struktur bezeichnen. Wie erwähnt, sind sie auch in gewöhnlichen Präpraraten zu sehen. Ind meine Golgi-Präparate zeigten sie in ciner Menge und Ausdehnung, die keinen Augenblick irgend-

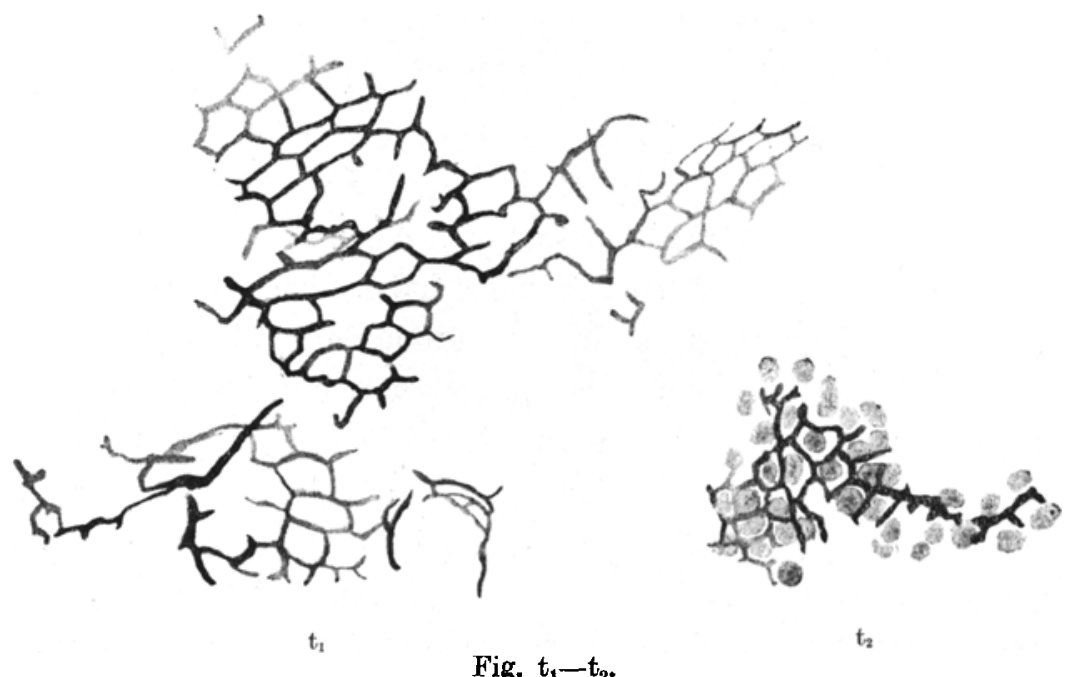

Leber. Triton punct. Golg i-Imprägnation. Zusammenhängende eytozonale Gallencapillarmaschen, in $t_{2}$ mit Kernfärbung (Grenachers Alaunkurmin). Vergrösserung 430.

welchen 'Zweifel aufkommen liessen, dass sie einen sehr wesentlichen Teil des Leberparenchyms bilden. Sie treten als grössere oder kleinere Flächen zusammenhängender cytozonaler Maschen auf, die zum grössten Teil unicellulär sind (Fig. $t_{1-z}$ ).

Zweifellos waren die einreihigen Zellenreihen, die man in gewöhnlichen Schnitten beobachten kann, Querschnitte der Zellplatten, welche in ihnen sowohl wie in den G olgi-Präparaten 
so schön zum Vorschein kamen, in den letzteren als die erwähnten Flächen von cytozonalen Maschen. - Diese Platten weisen fast keine Blutcapillaren zwischen den einzelnen Zellen auf, also verlaufen die Blutcapillaren hier wesentlich parallel und nicht lotrecht zu der Ebene, die die Zellplatte darstellt. $\Lambda$ ber erweisen sich nun auch alle Zellplatten nur als ,einzellige" auf Querschnitten? Finden sich nicht anch Zellplalten, deren Durchschnitt von zwei oder mehr Zellen gebildet werden? Dass solche vorkommen, kann ich nicht in Abrede stellen; aber häufig sind sie sicher nicht, dazu sind die sicheren einzelligen Reihen allzu vorherrschend im Leberbilde.

Wemn wir uns nun über die (ienese dieser Zellplatten eine Meinung bilden wollen, so muss ich den Leser auf $\mathrm{S}$. 746-752 verweisen, wo ich in einer Übersicht die Frage nach den ,,flächenständigen" Gallencapillaren behandelt habe. Ich verfechte dort als meine Auffassung, dass die Wanderung der Gallencapillaren von den Zellrändern nach den Zellplatten ein Ausdruck für die gesteigerten Lebensprozesse in den Zellen ist. In diesen lag die Ursache zu den zweizelligen Tubuli der Anuraleber. - Je mehr die Tätigkeit der Zellen sich steigert, und damit ihr Drang nach vergrösserter Aufnahme- und Ausscheidungsfliche, wird nummehr eine Strukturveränderung in zwei Richtungen erfolgen. Die ,mehrzelligen" Tubuli werden abnehmen zugunsten der Entwickelung von ,zweizelligen". Und die ,zweizelligen“ werden sich, wie auf nachstehendem Schema (Fig. $u_{1}$ und $u_{2}$ ) gezeigt, zusammenlegen, wodurch sie eine grössere Ausscheidungsfläche erhalten, indem gleichzeitig die ursprünglichen Centralcapillaren sich durch Seitencapillaren miteinander verbinden werden. Hierdurch entstehen die zahlreichen cytozonalen Maschen der Leberzellplatten.

Eine weitere Entwickelung desselben Grundsatzes zeigt Textfigur v, wo man sieht, wie mehrere einreihige Zellplatten 
durch ihre Vereinigung eine Zellplatte bilden. Also ein Prozess, entsprechend dem, der bei der Bildung cytozonaler haschen

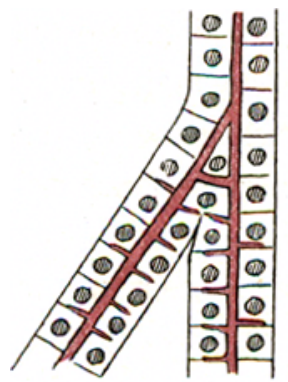

$\mathrm{u}_{1}$

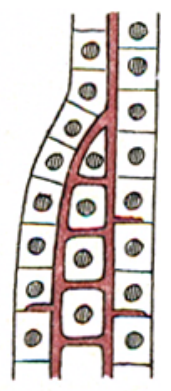

$\mathbf{u}_{2}$

Fig. $u_{1}-u_{2}$.

'Tritou. Schema. Bildung ciner Zellplatte aus „zweizelligen" 'T'ubuli.

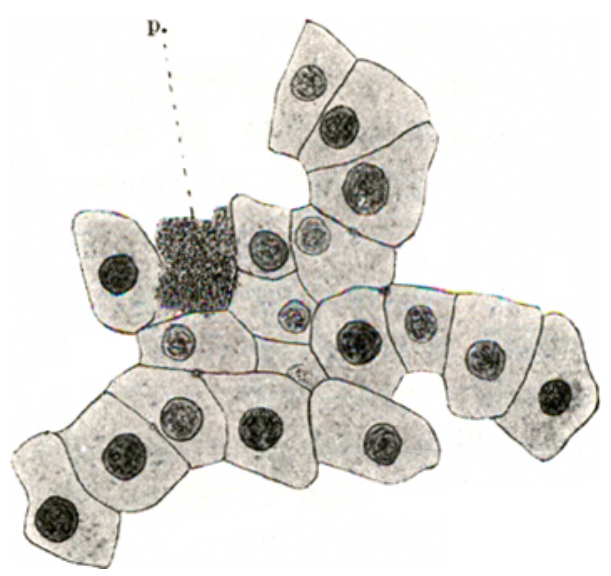

Fig. $v$.

Leber. Triton punct. Mebrere Zellplatten stossicn zusammen und scheinen dadurch an der Bildung einer neven Zellplatte teilzunehmen. $p_{1}=$ pigmenthaltige Loukocyten. Die Flüssigkeit von Zenker. Hämatoxylin-Eosin. Vergrösserung 590 .

an der Veromigungsstelle gewöhnlicher ,mehrzelliger" 'Tubuli ror sich geht (s. Fig. $f_{1-2}$ ). 
Gestützt wird diese Auffassung dadurch, dass den T'ubuli sicherlich eine begrenzende Basalmembrane fehlt, die den oben besprochenen Vorgang verhindern könnte. Und verfolgt man „Zweizellige“ Tubuli in Querschnitten, so sieht man, dass sie sehr häufig mit ihrem einen Ende mit einer Zellplatte in Verbindung stehen. - Braus hat gemeint, dass die Zellplatten durch ein Abflachen gewöhnlicher „mehrzelliger" Tubuli gebildet 'würden. Dasss dies vorkommt, kann selbstverständlich nicht in Abrede gestellt werden, jedoch zeigen die Verhältnisse in der Tritonleber, dass hier zum mindlesten einige Zellplatten auf andere Weise gebildet sein müssen. Die Figuren $p, q$ und $t_{1}$ lassen hier keinen $Z$ weifel übrig. Die Tubuli der T'ritonleber zeigen bis zu 5 Zellen auf Querschnitten und ihnen fehlt deshalb einfach die nötige Anzahl Zellen, um Zellplatten von der Ausdehnung zu bilden, wie sie diese Zeichnungen erkennen lassen.

Ungeachtet verschiedener Auffassungen über die Genese der Zellplatten, steht doch soviel fest, dass sie eine Auflösung des tubulösen Baus bezeichnen. Mit der grossen Menge zusammenhüngender cytozonaler Maschen ist jede Spur eines centralen Gallencapillars und damit auch von irgendwelchem tubulösen Bau verschwunden. Da sie unzweifelhaft aus 'Tubuli gebildet sind, vermutlich durch Verschmelzung mehrerer, so bezeichnen sie also eine Änderung in der tubulösen Struktur dest Parenchyms.

Betrachtet man die Struktur, so kann ich demnach das Ergehnis, zu dem Braus gelangte, nur bestätigen: dass Tubuli, die in der Regel 3-5 Zellen im Querschnitl aufweisen, mitunter sich bis zu zwei Zellen verschmälern können. Dafür weiten sie sich häufig zu grossen „Zellplatten“ wieder aus. In diesen sind alle oder wenigstens fast alle Zellen von einer Gallencapillarmasche umgeben. - Die G o 1 g i - Präparate zeigen, 
diass auch die Zellplatten an der Bildung der vasozonalen Maschen leilnehmen, dass also selbst da, wo der tubulöse Bau sich aufgelöst hat, das Leberparenchym so lange als möglich eine netzförmige Anordnung beibehält (s. Fig. s).

\section{Zusammenfassung.}

1. Die Triton-Leber ist eine netzförmig-tubulöse Drüse, die zwei verschiedene Formen von Parenchymstruktur aufweist. - Tubuli mit 2-5 Zellen im Querschnitt und mit einem centralen Gallencapillar, das je nach der Anzahl der Zellen der Tubuli im Querschnitt längs der Flächen oder deren Ründer verläuft. Von diesem Gallencapillar gehen intercelluläre Seitencapillaren aus. Häufig bilden die Gallencapillaren sowohl vasowie cytozonale Maschen, die letzteren sind in der Regel unicellulïr. - Cytozonale Maschen sind sowohl während des gewöhnlichen Verlaufs der Tubuli, wie an deren Vereinigungsstellen zu sehen, und in beiden Fïllen sieht man oft zwei zusammenhängende. Blind endende Tubuli kommen ebenfalls vor.

IÏufig sicht man dic andere Form: Grössere oder kleinere Zellplatten, denen jedes tubulöse Gepriige fehlt. In diesen Plallen liegon die Gallencapillaren längs der Fläichen der Zellen oder längs deren Ränder, und so gut wie jede Zelle ist von einer cylozonalen Masche umigeben. Die Zellplatten stehen in Verbindung mil Tubuli, deren centrales Gallencapillar in ein Netzwerk aus cytozonalen Maschen übergeht und hierdurch das Geprïge eines Centralcapillars verliert. Die Blutcapillaren, die die Zellen der Platten versorgen, laufen im wesentlichen parallel zu der Oberfliiche der Zellplatten.

2. Die Blutversorgung erfolgt durch die unbedeutende Leberarterie sowie durch die Pfortader. Diese treten hinein ungefähr an der hinteren Spitze der Leber auf der Ventralfläche; gehen auf die Dorsalfliiche über und verlaufen dort peripherisch 
unterhalb der Leberkapsel in dem Mittelteil der dorsalen Leberfläche. Die grössten Äste der Pfortader halten sich ebenfalls unterhalb der Kapsel. Die beiden Hauptüste der Lebervene verlaufen ebenfalls oberflächlich unterhalb der Kapsel auf der Ventralfläche der Leber; der eine Ast ungefähr mitten auf dieser, der andere gegen der Übergangsstelle zwischen der Dorsal- und Ventralfläche der Leber hin.

3. Die Gallengänge folgen den Ästen der Pfortader. Sie halten sich besonders längs der Hauptstämme und entfernen sich zusammen mit den kleineren Portaezweigen nur ein kurzes Stück von ihnen. Sic sind wenig entwickelt im Vergleich zu der Menge des Leberparenchyms, und einen. Übergang von Gallencapillar zu Gallengang sieht man verhältnismässig selten.

Bei unserer Arbeit mit der A mphibien-Leber sind wir auf eine neue Erscheinung gestossen. Wir haben zum erstenmal Gallencapillaren geséhen, die zwischen den zusammenstossenden Flächen der Zellen verlaufen, während sie bei den niederen Wirbeltierformen immer längs der Zellründer gelegen haben. -- Wir habjen diese ,flächenständigen "Gallencapillaren teils in T'ubuli gefunden, deren Querschnitt von nur zwei Zellen gebildet wurde, teils auch in den beschriebenen Zellplatten.

Welche Bedeutung soll man nun dieser Wanderung der Gallencapillaren im Verhältnis zur Oberfläche der Zellen beimessen? Bezeichnen sie ein neues Bauprinzip in der Parenchymstruklur, oder stellen sie nur eine Änderung in der Struktur dar, die wir von früher kennen und bei allen niederen Formen von der Myxineleber an nachgewiesen haben?

Blicken wir zurück, so finden wir, dass schon $\mathrm{Hering}$ $(1866 \mathrm{~b})$ auf die ,zweizelligen“ Tubuli aufmerksam geworden war, ohne dass er jedoch darin etwas sah, das von den ,mehrzelligen“"grundverschieden war. Er sagt im Gegenteil, da er 
diese neue Anordnung der Gallencapillaren längs der Zellflächen nur von der Säugetierleber her kennt: ,Von der dem üblichen Drüsienschema genaú entsprechenden Anordnung der Leberzellen bis zu derjenigen, welche das Säugetier zeigt, findet sich eine zusammenhängende Reihe von Übergängen. Die Zahl der Leberzellen, welche auf dem Querschnitt zur Bildung eines feinsten Gallenweges zusammentreten, wird spärlicher, reduziert sich auf vier, drei und endlich zwei." Im letzteren Fall rückt das Gallencapillar von der Zellkante nach der Zellfläche hin. - Wie man sieht, sieht er nicht nur keinen grundsätzlichen Unterschied zwischen den ,zwei“- und ,mehrzelligen“ Tubuli, sondern er findet im Gegenteil, dass ,eine zusammenhängende Reihe von Übergängen" besteht. Und ferner sagt er von der Säugetierleber: „Entsprechend ist auch die Zahl der Gallenwege relativ zur Zahl der Leberzellen viel grösser, weil jede Zelle nicht bloss nach einer Seite, sondern nach vielen Seiten hin von Gallenwegen umzogen ist. Die gesamten Gallenwege eines Stückchens Kaninchenleber würden z. B. ... die GeSamtlänge der Gallenwege eines gleichgrossen Stückes Froschleber ganz ausserordentlich an Länge übertreffen." Eine Kusserung, die zeigt, dass ihm die vermehrte Ausscheidungsfläche, die dadurch für jede einzelne Zelle entsteht, nicht entgangen ist. Er sagt jedoch nichts darüber, welches Gewicht er diesem Umstand beigelegt hat als Ursache zur Wanderung der Gallencapillaren von den Zellräindern nach den Zellflächen. - Anders beurteilt Braus (1896) dieses Verhältnis. Und seine Auffassung. verdient um so grössere Aufmerksamkeit, als er der erste war, der Zellreihen (bei Urodela) init Gallencapillaren zwischen den zusammenstossenden Fliichen nachgewiesen und genau studiert hat. Also die weitere Entwickelung des ,zweizelligen" Tubuliprinzips. -- Sowohl bei Amphibien wie bei Säugetieren sieht er im Blut- und Lymphgefässsystem die Ursache zu den Veränderungen, die man dort im Bau findet. In 
der Amphibienleber meint er, den eigentlichen Grund zu den Veränderungen in den stark entwickelten Lymphgefässen mit Haufen von Pigmentzellen suchen zu müssen. Das Verhältnis zwischen dem Leberparenchym und dem Gefässsystem denkt er sich in der Weise, ,dass durch die hohe Entwickelung und Verzweigung der Gallenabfuhrkanäle die Leberbalken gleichsam in einem labilen Gleichgewicht sich befinden, und dass das Auftreten an sich so zarter Gebilde, wie der mit „Pigmientzellen" gefüllten Lymphsäcke, genügt, um das gleichmässige Balkenwerk der Leberzellen in ein Gerüst von dicken und dünnen Platten umzumodeln“." „Nach dem Befund bei der Leber der Anura (wo er nämlich nur ,zwei"-- und „mehrzellige“ Tubuli, also keine Zellreihen gefunden hat) scheint nach dem Verschwinden der Lymphsäcke die tubulöse Form der Leber, wenn auch nicht überall, sich wiederherstellen zu können. Dafür spricht auch der Vergleich melanotischer und unpigmentierter Lebern solcher Urodelen, welche eine ausgeprägte Periodizität der Melanose aufweisen (Salamandra)."

Diese Theorie von B ra us leidet an nicht unbedentenden Schwächen. Bei mehreren Amphibien finden wir nicht nur „Zweizellige" Tubuli, sondern auch Zellplatten in den Lebern, die keine besiondere Aufhäufung der "Pigmentzellen " erkennen lassen, und die, jedenfalls bei Triton, Zellplatten entfernt von irgendwelchem Haufen von Pigmentzellen haben; also anscheinend gänzlich unabhängig von diesen. Braus erklürt das als übriggebliebene Formen, die nicht beim Verschwinden der "Pigmentzellen" wieder zu mehrzelligen Tubuli umgebildet worden sind.

Aber wesh all b sind nun diese nicht zurückgebildet worden, wenn diese Umbildung in vielen anderen Amphibienlebern vor sich geht? Und noch dazu bei so nahestehenden Arten? Braus meint, dass bei Salamandra eine solche Umbil- 
Untersuchungen über den Bau der Leber bei niederen Wirbeltieren. $\mathbf{7 4 9}$

dung stattfindet. Nun habe ich bei Trito n Mengen von Zellplatten beobachtet, aber wenigstens in einzelnen Lebern so gut wie keine Pigmentzellen in der Lebersubstanz. Weshalb geht diese Umbildung bei Salamandra vor sich und nicht bei dessen nahen Verwandten Triton? Auf diese Frage gibt B r a u s' Theorie mir keine Antwort.

Und wie verhält es sich nun mit dieser Änderung des Parenchyms, die von dem Auftreten und Verschwinden der Leucocythaufen abhängig sein sollte? - B r a u s sagt über Salamandra: „In der Pigmentleber war nïmlich an Stellen, wo zwischen zwei Pigmentinseln die Leberzellen einreihig hintereinander lagen, die centralen (Gallencapillaren flächenstïndig. In der Winterleber dagegen fanden sich nur typische kantenständige Centralcapillaren." Und spüter: „Beweisender noch ist das Verhalten der Salamanderleber, die vor Fintritt. der Melanose nur mehrzellige Schliinche und Platten mit kantenständigen Centralcapillaren aufwies...." Leider ist es mir unmöglich gewesen, ein genügendes Material ron Winter- und Sommerlebern von Salamandra herbeizuschaffen. Jedoch zeigt ein Studium von Brau s' Abbildungen, dass er in seiner oben angeführten Darstellung das Verhältnis etwas schematisch geschildert hat. Seine Zeichnung Taf. XXVII, Fig. 16: „Salamandra maculosa, Winterleber von ausgewachsenem Tier. Zellplatte mit unregelmässig verteilten Gallencapillaren" - zeigt nämlich ausser ,kantenständigen“ auch Querschnitt eines Gallencapillars, das zwischen zwei zusammenstossenden Zellflächen liegt. - Selbst habe ich beide unsere einheimischen Tritonarten ( $T$. punctatus und T. cristatus) untersucht, um einen etwaigen Wechsel in der Parenchymstruktur festzustellen. Von der Mitte des Januar bis in die Mitte des Mai habe ich den Leberbau bei beiden Arten einmal monatlich untersucht. Irgendwelche grundsätzliche Veränderung war nicht zu sehen; sämtliche Lebern zeigten das Leberparenchym teils in Zellplatten, 
teils in zwei- oder mehrzelligen Tubuli angeordnet, und in allen Schnitten die verschiedenen Bildungen in einigermassen gleicher Menge.

Fassen wir kurz die früheren Ergebnisse zusammen, so sehen wir, dass „kanten“- und „flüchenständige“ Gallencapillaren in sämtlichen untersuchten Amphibienlebern vermischt vorkommen; und dass bei einer $A$ rt die „,kantenständigen“", bei einer anderen die ,flächenstïndigen " im Leberbild am meisten vorherrschen. Möglicherweise geht auch bei einzelnen Arten eine periodische Veränderung in dor Weise vor sich, dass die Gallencapillaren von den Zellrändern nach den Zellflïchen wandern, und umgekehrt ( $\mathrm{Br}$ a $1 \mathrm{~s})$. Beides gibt einen deutlichen Fingerzeig dafür, dass ein $\mathrm{grunds}$ it $\mathrm{zli}$ cher Unterschied nicht bestehen kann; die neuen, lïngs der Flïchen der Zellen verlaufenden Gallencapillaren können nur eine $\ddot{A} n d$ erung des von den niederen Wirbeltierformen her bekannten Bauprinzips bezeichnẹn.

Erinnern wir uns nun an die Bilder, die wir beim Studium. der Parenchymstruktur der Amphibienleber gesehen haben, so müssen wir sagen, dass sie alle in dieselbe Richtung zeigen. Während die meisten Zellen ihr Sekret in Kanäle ausleerten, die entweder längs ihrer zusammenstossenden Flächen oder längs ihrer Ränder verliefen, nahmen andere Zellen eine $Z$ wischenstellung ein (Fig. r). Sie standen nämlich auf der einen Seite in Verbindung mit einem ,kantenständigen“, auf der anderen mit cinem „flächenständigen" Gallencapillar. Sie bildeten eine sichtliche, sozusagen handgreifliche Verbindung zwischen den beiden Formen. Sie zeigten besser als irgendwelche Schlussfolgerung, dass- die Anordnung der Gallencapillaren längs der Zellflächen keinen unbedingten neuen Bauprinzip bezeichnete.

Aber woher kommt nun diese Wanderung der Gallencapil- 
Untersuchungen über den Bau der Leber hei niederen Wirbeltieren. $\mathbf{7 5 1}$

laren von den Zellrändern nach deren Flächen? Nach meiner Meinung ist das Verhältnis folgendes:

Die Gallencapillaren sind hohle Röhren, Ausbuchtungen, Rinnen in dem Ectoplasma der Zellen, und zwei oder mehrere entsprechende bilden zusammengekittet ein einziges Gallencapillar. Besteht der Querschnitt der Tubuli aus drei oder mehreren Zellen, so läuft das Centralcapillar lïngs den zusammenstossenden Rändern der Zellen, da es dadurch am leichtesten mit sämtlichen Zellen in Verbindung kommt. Auf dieselbe Weise verhält es sich mit den Seitenästen. Durch eine Anordnung lïngs der Zellründer kommen auch sie in Verbindung mit der grössten Anzahl Zellen. Nun ist es ein aus. nahmfreies Gesetz, empirisch gefunden und bestitigt, dass die Gallencapillaren niemals die Blutbahnen berühren. Wenn nun der Querschnitt der Tubuli von bloss zwei Zellen gebildet wird, so können die Blutcapillaren deshalb nur an einer Stelle liegen, und das ist längs der zusammenstossenden Flichen der Zollen. Morphologisch ist diese Anordnung also nur eine Zweckmissigkeitsveranstaltung. In keiner Hinsicht grundstiłzlich verschieden von der Anordnung der Gallencapillaren längs der Ränder der Zellen. - Natürlich ist diese Zweckmässigkeitsveranstaltung nur ein Ausdruck einer tieferen Ursache (die B ra us in Veränderungen im Blat- und Lymphgefässsystem suchte) für eine mehr oder weniger eingreifende $\mathrm{b}$ i o log is $\mathrm{ch} \mathrm{e}$ Verïnderung. Und will man diese suchen, so hat man drei bekannte Faktoren, mit denen man arbeiten kann. In erster Linie bekommen die zwei Zellen dadurch dieselbe Ausscheidungsfläche, die drei oder mehrere Zellen vorher gemeinsam hatten. Demnächst bekommen sie eine weit grössere freie Oberfläche, wodurch auch der Zugang und die Verbindung mit den Blutbahnen um so viel grösser werden. - Die Zellen bekommen also eine vergrösserte Aufnahme- und Ausscheidungsfläche. Ferner kommen diese längs der Zellflächen verlaufenden Gallencapillaren bei 
den höher und am höchsten organisierten Wirbeltieren, vor, wo die Lebensprozesse mit der grössten Raschheit und Intensität vor sich gehen. Und bei 'diesen kommen sie in steigender Menge vor, je höher man in die Tierreihe hinaufkommt. Bei den niedrigstehenden Wirbeltieren sind sie überhaupt noch nicht nachgewiesen worden. - Alle Momente deuten in dieselbe Richtung. Sie deuten auf die gesteigerten Lebensprozesse in den Zellen hin und den damit verbundenen Drang zu gesteigerter Aufnahme- und Ausscheidungsfläche und lassen schliessen, dass hier der tiefere Grund zu der Wanderung der Gallencapillaren von den Rändern der Zellen zu ihren Flächen liegt.

Die Auffassung, der ich hier das Wort rede, eröffnet die Möglichkeit, den Unterschied in der Parenchymstruktur, den wir bei den verschiedenen Amphibien finden, unter einen gemeinsamen Gesichtswinkel zu bringen. Wir kennen ja von dieser Struktur eine ganze Reihe von Formen mit allen Utbergängen in dor Menge der ,flächenständigen“ Gallencapillaren, und zwar von den verhältnismässig' seltenen zweizelligen 'Tubuli der typischen Anura-Leber bis zu den ,Zellplatten“ von Proteus ( $\mathrm{Bras}$ ) und Triton, sowie ein eventuelles Wechseln zwischen diesen und den mehrzelligen Tubuli der Salamander-Leber (Braus). Nur wenn man sich eine solche Veränderlichkeit im Bau der Amphibienleber vor Augen hält, dass also ihre verschiedenen Strukturformen der Stärke der biologischen Prozesse abgepasst sind, nur dann bekommt man das Verständnis für seine grundsätzliche Einheit.

Kapitel 3 .

Gesamte Ergebnisse der Untersuchung.

Nachdem wir die Untersuchungen abgeschlossen haben, wollen wir in aller Kürze versuchen, die Ergebnisse zusammen- 
Untersuchungen über den Bau der Leber bei niederen Wirbeltieren. 753

zustellen, sehen, welches Bild wir von dem Leberbau der niederen Wirbeltiere bekommen haben.

Erst aber möchte ich hier einschieben, dass ich von der charakteristischen Teilung in Lobuli, die wir in den Säuge. tierlebern finden, in der Leber der niederen Wirbeltiere keine Spur gesehen habe. Sie werden im Gegenteil, von einer einzigen grossen bindegewebearmen Parenchymmasse gebildet.

Früher wurde die Myxineleber als ein Typus für sich aufgestellt, mit einem verästelt-tubulösen Bau (Retzius [1892], B rau s [1896], Hol m [1897]). Ihre cytozonalen Maschen waren selten, umschlossen immer kleinere Teile mehrerer Zellen und lagen immer an der Vereinigungsstelle von Tubuli (B ra us [1896]).

Als der andere Typus wurde die netzförmig-tubulöse Leber aufgestellt. Rein kam diese nach Braus (1896) bei den Fischen vor; während die zahlreichen cytozonalen Maschen bei den Amphibien und die Zellplatten der UrodellaLeber, eine Auflösung der reinen tubulösen Struktur bezeichneten. Später haben Bluntschli (1903) und Segerstra a I (1910) cytozonale Maschen auch bei den Knochenfischen nachgewiesen.

Der dritte Typus, die Säugeti er leber, lag ausserhalb des Rahmens meiner Arbeit.

Diese drei Typen wurden als divergentel Bildungen angesehen, ausgehend von einer, jetzt nicht mehr vorhandenen Grundform (Braus).

Das Wesentliche bei dieser Auffassung, was ihr ihren Charakter gab, war das Aufgeben des Gedankens von einer zusammenhüngenden Entwickelung.

Deshalb sohe ich auch das bedeutendste Ergebnis meiner Arbeit darin, dass es mir gelungen ist, die grundsätzlich gleiche Parenchymstruktur in allen von mir untersuchten Tierklassen 
festzustellen. Sämtliche von mir untersuchten Leberformen haben in der Hauptsache dasselbe Gepräge.

Die My $\mathrm{x}$ in e-Leber erwies sich als eine verhältnismässig hoch organisierte Form. Nicht von der rein primitiven Art, wie man früher annahm. Sie ist eine netzförmig-tubulöse Drüse, jedoch mit nicht wenigen blind endenden Tubuli. - Die Gallencapillaren bestehen aus Centralcapillaren und intercellulären

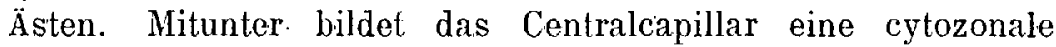
Masche, unicellulär oder pluricellulär. Fin einzelnes Mal sah ich sogar zwei zusammenhängende unicelluläre solche Maschen. - Die cytozonalen Maschen finden sich sowohl an der Vereinigungsstelle der Tubuli wie in deren gewöhnlichem Verlauf.

Mit dem Nachweis dieses Baues war die Myxineleber nicht nur aus ihrer einzig dastehenden Stellung herausgerissen und der anderen netzförmig-tubulösen Art zugeordnet. Durch ihre cytozonalen Maschen zeigte die Myxineleber ausserdem eine so weit vorgeschrittene Auflösung der tabulösen Anordnung, dass sie dadurch anscheinend eine entwickeltere Stufe bezeichnet als die Leber der Knorpelfische: Nach früheren Untersuchungen hatten ja die $\mathrm{S}$ e l a c hi e r eine rein netzförmig-tubulöse Leber; jedoch fand ich bei ihnen mit Leichtigkeit blind endende Tubuli.

Indessen gelang es mir, auch bei einem Spinaxembryo dieselbe Auflösung des tubulösen Baus nachzuweisen, wie be Myxine. Nicht nur fand ich eine einzelne cytozonale Masche, sondern auch zahlreiche andere, nicht völlig geschlossene. Diese letzteren bin ich geneigt, für nicht völlig entwickelte Formen der vollständigen Maschen anzusehen.

Bei den Knochenfischen finden wir ebenfalls denselben Bau. Nur sind, nach den Golg i - Präparaten zu urteilen, die cytozonalen Maschen hier zahlreicher, ebenso wie sie auch hier sowohl an der Vereinigungstelle von Tubuli vorkommen, wie auch sonst in deren Verlauf. 
Die Anura-Leber zeigt ebenfalls keine grundsitzlich neuen Züge. Ein Unterschied von den niederen Formen liegt jedoch in den spärlich vorkommenden Tubuli mit nur zwei Zellen im Querschnitt. Das veranlasst das Centralgallencapillar, längs der Zellflächen zu verlaufen, während es sich sonst immér längs der Ränder der Zellen hält. Die cytozonalen Maschen sind nun zahlreicher geworden, und nicht selten sieht man zwei, die zusammenhängen.

Bei Triton sind die Verhältnisse verwickelter. Aussar den bereits bekannten Tubuli mit ihren vasozonalen und cytozonalen Maschen finden wir hier ,zweizellige" Tubuli in grösserer Menge als bei Anura, und auch zusammenhängende Zellplatten. In den zweizelligen Tubuli findet man immer, in den Zellplatten meist, Gallencapillaren, die zwischen den zusammenstossenden Flaichen der Leberzellen liegen. Die Zellplatten stellen keine neue Form der Leberstruktur dar, vom grundsätzlichen Gesichtspunkt. Sie bezeichnen bloss eine Änderung im tubulösen Bau. Persönlich nehme ich an, dass sio durch Verschmelzung von "zweizelligen" Tubuli gebildet werden, ein Vorgang, der dadurch erleichtert wird, dass den Tubuli eine Basalmembrane fehlt.

Aus dem Obigen wird man ersehen, dass schon die Grundform eine in der Hauptsache netzförmig-tubulöse Drüse ist, bei der einzelne Anzeichen, die cytozonalen Maschen, eine beginnende Auflösung in dem reinen tubulösen Bau anzeigen. Dieser Auflösungsprozess lïsst sich gradweise aufwärts verfolgen. Bei den $\mathrm{F}$ is $\mathrm{chen}$ ist er nicht besonders ausgeprägt, jedoch wenigstens bei den $\mathrm{Knochenfischen} \mathrm{weiter} \mathrm{vor-}$ geschritten als bei Myxine. Bei Anura ist dieser Vorgang dagegen schon zu weiterer Entwickelung gekommen. Und kommen wir zu Urodela, so sehen wir, wie bereits ziemlich grosse Teile jede Spur des tubulösen Baus verloren habGleichzeitig muss die Leber trotzdem immer noch als 
förmig charakterisiert werden, selbst wenn blind endende Tubuli bei ihr, wie bei allen den niederen Formen, vorkommen.

Über die Struktur des Leberparenchyms liegen von früher zahlreiche Árbeiten vor. Durch meine Studien über die Gefässe der Leber sowie die intrahepatischen Gallengänge habe ich indessen auf jungfräulichen Feldern arbeiten können. Aus früherer Zeit liegen keine systematischen Untersuchungen auf diesem Gebiete vor, nur hier und dort verstreute Bemerkungen. Wie ich in der Einleitung zu meiner Arbeit berührt habe, steht dies damit in Verbindung, dass man bei Leberarbeiten nur der Parenchymstruktur Interesse beigemessen hat.

Nur H y rtl (1864) bildet hier durch seine ausgezeichnete Arbeit über das' Gefässsystem bei Fischen und Amphibien eine Ausnahme; besonders eine Studie über die Gefässe der Amphibienleber ist sehr eingehend.

Oben (S. 674) habe ich hervorgehoben, was mich dazu bewogen hat, meine Untersuchungen auch diese Gegenstände umfassen zu lassen; wie ich nach unserer Bekanntschaft mit den Verhältnissen der Gefässe und Gallengänge in Säugetierlebern eine vergleichende anatomische Studie über diese sowohl naheliegend wie lehrreich fand; und wie ich auch hoffte, dadurch neue Züge zu unserem Bild von der „Wirbeltierleber" hinzuzufügen.

Bei allen untersuchten Lebern geht die Blutversorgung wesentlich durch die V. portae, zu einem unbedeuteńden Teil durch die A. hepatica vor sich. Die letztere läuft zusammen mit der Pfortader und löst sich in die gemeinsamen Blutcapillaren auf. Nur bei Myxine findet man noch ein zuführendes Gefäss. Nachdem das Blut die Blutcapillaren durchlaufen hat, sammelt es sich dann wieder in den Ästen der V. hepatica und wird aus der Leber herausgeführt.

Verfolgt man die grossen Gefässe in den verschiedenen 
Lebern, so wird das Bild nicht immer dasselbe; aber gewisse Züge kommen doch immer wieder.

Bei Myxine liegen die Äste der Lebervene streng peripherisch, unmittelbar unter der Bindegewebekapsel der Leber, während die Äste der Pfortader sich ebenso streng in der Mitte halten. (Jedoch hat die kleine zuführende Vene, die an der caudalen Spitze des hinteren Leberhppens ausmündet, eine peripherische Lage. Der eine ihrer zwei Hauptäste setzt unmittelbar in einem der Hauptäste der Lebervene fort.) -- Bei dem untersuchten $S$ pin ax-Embryo läuft auch die V. portie in den centralen und medialen Teilen der Leber, während die Äste der V. hepatica sich peripherisch in der Nähe der Leberkapsel halten. In der Syngnathus-Leber dringt die Pfortader, begleitet von den Pankreasästen, von der Dorsilseite der Leber aus in die Lebersubstanz ein und reicht insserst selten tiefer als bis zu den Centralteilen. Sie erreichen niemals die ventrale Leberfläche, wo die Äste der Lebervene peripherisch ganz nahe unter der Leberkapsel verliuft. - Bei $\mathrm{B}$ u fo nehmen die Asto sowohl der Pfortader wie der Lebervene anfangs einen centralen Verlauf bei den untersuchten jungen Tieren; aber sie weichen bald nach der Seite aus, so dass wir die Ïste deir $V$. portae in den dorsalen und medialen Teilen der Leber, die Aste der V. hepaticil bei der ventralen und ventro-lateralen Fläche gesammelt finden. Die Äste beider laufen hier im grossen ganzen peripherisch in der Lebersubstanz. - Eitio Sonderstellung nimmt die Triton-Leber ein, insofern, als hier sowohl die Äste der Pfortader wie die der Lebervene peripherisch liegen, und zwar die erstere mitten auf der Dorsal-, die letztere auf der Ventralfläche, teils mitten. auf dieser, teils gegen die Übergangsstelle zwischen der Ventral- und Dorsalfläche hin.

In anderen Organen verlaufen die Äste der zu- und ausführenden Gefässe zusammen. Dies ist nicht der Fall in der 
Leber der niederen .Wirbeltiere. Im Gegenteil, hier münden sie nicht an derselben Stelle in die Leber ein. Und in der Leher selbst liegen sie voneinander entfernt, mit Hauptästen und kleineren $Z$ weigen in begrenzten Teilen gesammelt, liegen z. B. die Äste des einen Gefässes central, so sieht man die des anderen peripherisch verlaufen. Der ganze dazwischenliegende T'eil, $d$. h. das ganze Leberparenchym, weist im grossen ganzen nur Blutcapillaren auf und so gut wie überhaupt keine grösseren Stämme.

In einem Einzelfalle, bei Triton, liegen sowohl die $V$. portae wie die $V$. hepatica peripherisch. Aber selbst da liegen sie also vollständig roneinander getrennt, ebenso wie auch die Pfortader hier.an der hinteren Spitze der Leber in diese eintritt, wïhrend die Lehervene an der vorderen Spitze heraus. bricht.

Ich meine, dass durch den , Nachweis dieser gesetzmössigen Verhältnisse zwischen zu- und ausführenden Gefässen, sowie durch das Verhältnis zwischen Gefässen und Leberparenchym wesentlich neue Züge im Bau , der, Wirbeltierleber" selbst nachgewiesen sind, Züge, die in hohem Grade zu dem eigentümlichen und fremdartigen Gepräge beitragen, das die Leber schon vom ersten Augenblick an aufweist, wenn man sie mit allen anderen Drüsen vergleicht. Und studiert man den Bau der intrahepatischen Gefässe, so wird dieses Gepräge. verstïrkt. Teils kommen die Gefüsse als mit Endothel bekleidete Röhren vor, teils mit einem mehr oder weniger reichlichen Bindegewebe aussen auf dem Endothel. Muskulatur habe ich in der Regel vergebens zu finden gesucht. Nur in den allergrössten Ästen der V. hepatica bei Syngnathus rostellatus und denen der V. portac bei Bufo kamen überaus spärliche : Muskelfasern vor.

Früher ist crwähnt worden (S. 674), dass S h or e u. J on es bisweilen sich auch mit Gefässen und Gallenwegen beschäftigt 
Untersuchungen über den Bau der Leber bei niederen Wirbeltieren. 759

haben, aber nur wenig eingehend, und dabei Arbeitsmethoden. angewandt haben, die ihren Befunden bloss geringen Wert verleihen. Sie sind sich aber doch der Bedeutung eines einzelnen Zuges bei den Gallenwegen bewusst gewesen. Sie sagen nämlich: „In a section of the liver of any of the types we have examined it is remarkable how extremely few small, or even medium sized bile ducts are cut across, and in all. cases whatever ducts are present well marked walls of connective tissue lined by an epithelium quite different in character from the cells composing the liver "tubes"."

Von ihren Beobachtungen verdient erwïhnt zu werden, dass sie bej Petromyzon keinen Gallengang fanden und bei Caecilia "there seems to be only one large main duct running with the portal vein along one side of the organ, and apparently receiving minute communications along its whole course from the liver tubulus".

Irgendwelche eingehende Untersuchung, um die geringe Lntwickelung der Gallengänge festzustellen, haben sie nicht vorgenommen. Sie haben sich mit ihrem Eindruck genügen lassen, dass , it is remarkable how extremely few . . bile ducts are cut across .....

Im übrigen findet man in der Literatur nur verstreute $\mathrm{Be}$ merkungen über die Gallengünge, meistens im Anschluss an die Besprechung der Gefässe oder bei der Klarlegung des Aussehens ihrer Verbindung mit den Gallencapillaren.

Wie der Leser bemerkt haben wird, habe ich versucht, das Verhältnis der Gallengänge eingehend zu untersuchen.

Um die Ergebnisse hier zusammenzufassen, wiederhole ich kurz die Untersuchungen: Bei sämtlichen untersuchten Arten folgen die Gallengänge der Pfortader und deren Verästelungen in der Lebersubstanz. Nur Syngnathus bildet eine Ausnahme insofern, als die Äste der Pforlader und die Gallengänge hier jedes für sich in die Dorsalflüche der Leber einmünden, 
bzw. aus ihr wieder hervorbrechen, wobei die Pfortader hier in den Pankreasästen drin auftritt. Bei Pleuronectes dagegen finden wir das' gewöhnliche Verhältnis. - Bei Myxine zeigten die Serien, dass nur geringe Teile der Leber Gallengänge hatten, und zwar nur in den mittleren Teilen der Schnitte. Line ähnliche Armut an Gallengängen zeigte die Serie durch einen $41 \mathrm{~mm}$ langen $\mathrm{Sp}$ in axe mbryo. - Bei Sy $n \mathrm{gnath}$ us brechen die Gallengänge an verschiedenen Stellen der dorsalen Leberflaiche aus ihr hervor, jedoch finden wir hier nur eine geringe Entwickelung der Gallengänge im Vergleich zu der Menge des Parenchyms. Dasselbe kam auch beim Studium von Serien durch die Leber von Bufo und Triton zum Vorschein.

Bei allen Tierformen haben wir denselben Bau der Gallengänge gefunden. $Z u$ innerst sieht man ein einschichtiges Epithel auf einer dünnen Basalmembrane sitzen. Es wechselt in der Höhe mit der Weite des Lumen. Oft sind sie von Bindegewebe begleitet.

Wie man sieht, zeigen die Gallengänge in der „Wirbeltierleber" viele gemeinsame Züge in ihrem Bau, durch ihre nahe Verbindung mit der $V$. portae und deren Ästen, sowie durch ihre ausserordentlich geringe Entwickelung im Vergleich zu der Menge des Parenchyms. In einer Leber nach der anderen ist es gelungen, diese letztere Erscheinung nachzuweisen. Nicht nur zeigen die Serien, dass den peripherischen Teilen, der Längsachse nach gerechnet, in grosser Ausdehnung die Gallengänge fehlen, sondern ferner erhalten diese auch durch ihre Verbindung mit der Pfortader eine bestimmte, meist centrale oder : peripherische Lage. Und wie die Querschnitte zeigen, halten sie sich hier gesammelt und verästeln sich nicht in das Parenchym. Hierdurch wird eine innigere Verbindung zwischen dem Parenchym und den Gallengängen verhindert. In einem einzelnen Falle (bei Myxine) konnte ich ferner unmittelbar durch 
Untersuchungen über den Bau der Leber bei niederen Wirbeltieren. 76!

Zählen feststellen, wie selten Iubuli in die Gallengänge ausmündeten.

Alles dies, alle diese Einzelheiten, die jede für sich beweisend ist, lassen keinen Zweifel übrig. Ich meine, als einen charakteristischen Zug in den niederen Wirbeltierlebern nachgewiesen zu haben, dass der gröbere Teil des Ausführungssystẹns, die Callengänge, verhältnismässig wenig entwickelt. sind. Wie ich öfters hervorgehoben habe, entsteht hierdurch anscheinend ein Missverhältnis zwischen dem mächtigen Parenchym des Drüsenorgans und dem Ausführungssystem. Bei der Besprechung der Myxineleber habe ich.ein Moment berührt, das, wie ich meine, Bedeutung: für unser Verständnis dieses Verhältnisses haben kann. Denkt man sich nämlich die secernierenden Tubuli, so wie sie in der Leber der niederen Wirbel. tiere auftreten, als gewundene und gedrehte, verzweigte Röhren, so haben die Erzengnisse der am meisten peripherisch liegen. den Zellen einen sehr. langen Weg zurückzulegen, bis sie die grösseren Sammelröhren erreichen. Wohl zu merken, wenn diese in centralen oder peripheren Teilen der Drüse gesammelt liegen. Dadurch würden sehr unzweckmässige Ausscheidungsverhältnisse für grosse Teile des Drüsengewebes entstehen. Könnten die Zellerzeugnisse die schlimmsten Windungen vermeiden, kämen also Anastomosen zwischen die 'I'ubuli an zweckentsprechenden Stellen, dann könnte das Sekret sich oinen kürzeren Weg nach den Simmelröhren aussuchen. -. Nach dieser. Hypothese sollte also eine Verbindung bestehen zwischen den vasozonalen Maschen und der geringen Entwickeluug der Gallengïnge in der Weise, dass eine vom anderen bedingt wäre. Und wenn nun beide diesie Erscheinungen in der Wirbeltierleber zusammen auftreten und nur dort, so scheint mir das nicht unwahrscheinlich. Jedenfalls eröffnet sich hierdurch eine Möglichkeit zum Verständnis des Entstehens der vasozonalen 
Maschen, eine Frage, die man früher nicht einmal zu lösen versucht hat.

Eine andere Sache ist es, dass man selbstverständlich darüber streiten kann, was das Ursprüngliche ist, die Anastomosen der 'Tubuli oder die geringe Entwickelung der Gallengänge. Eine Lösung kann hier wohl nur auf ontogenetischem Wege ger funden werden.

Mit dem Nachweis des grundsätzlich gleichen Leberbaus bei den niederen Wirbeltieren fällt es natürlich, wieder die alte Bezeichnung "Wirbeltierleber" aufzunehmen. Ein Name, den ich jedoch mit dem selbstverständlichen Vorbiehalt aufnehme, dass ich damit nichts über den Bau der Reptilienlqber gesagt haben will. Diese gehört nämlich auch mit zu dem klassischen Begriff ,Wirbeltierlę̧er".

Wollte ich nach Abschluss meiner Arbeit versuchen, eina kurze Beschreibung der „Wirbeltierleber" zu geben, so würde diese folgendermassen lauten:

Die "Wirbeltierleber" ist eine Drüse, die sowohl durch ihre, Parenchymstruktur, ihre Gefässe, wie auch don gröberen Teil ihres Ausführungssystems viele eigentümliche Züge aufweist, die bei anderen Drüsenorganen unbekannt sind. 'Sie zeigt meist keine Spur von Lappenteilung. Das Parenchym ist, in der Hauptsache netzförmig' und tubulös angeordnet; jedoch finden sich bei allen niederen Wirbeltierklassen blind endende Tubuli. Die Maschen des Parenchyms werden von einem anderen Netzwerk; das aus Blutcapillaren besteht, ausgefüllt. In den Tubuli drin liegt ein centrales Gallencapillar. Dieses sendet intercelluläre, błind endende Äste aus, die niemals die Peripherie der Tubuli erreichen. Bei allen niederen Wirbeltierklassen finden sich cytozonale Maschen, und zwar sowoh! uni- wie pluricelluläre Sie nehmen an Häufigkeit zu, je höher man in der Tierreihe hinaúfkommt, bis sie biei Urodela teilweise den tubulösen Bau zum Verschwinden bringen. 
Die Blutversorgung geht durch die Pfortader und teilweise durch die unbedeutende A. hepatica vor sich, die Blutabführung erfolgt durch eine oder mehrere Venae hepaticae. Die Leberarterie und die Pfortader folgen einander. Die $z \mathbf{u}$ - und $a b$ führenden. Gefässe brechen nicht an derselben Stelle der Oberfläche der Leber herein oder herausi; ebensowenig wie sie drin im Leberparenchym einen gemeinsamen Verlauf nehmen. Im Gegenteil, ihre Äste laufen im grossen ganzen in zwei Gruppen in verschiedenen Teilen des Organs. Zwischen den Hauptästen beider liegt das Leberparenchym, in dem man so gut wie ausschliesslich Blutcapillaren beobachtet und keine grossen Gefässstämme. - Der in der Leber liegende Teil des Gefässsystems zeigt keinen gewöhnlichen Gefässbau, insofern als ein so wesentlicher Bestandteil, wie die Muskulatur, sehr häufig fehlt.

Die Gallengänge folgen den Stämmen der Pfortader und ihren Ästen. Sie bauen sich aus einem Epithel auf, das in der Höhe proportional zu der Weite des Gallenganges wechselt und auf einer dünnen Basalmembrane aufsitzt. Häufig sind sie von Bindegewebe begleitet. Verglichen mit dem Ausführungssystem anderer Drüsen zeigen die Gallengänge eine auffallend geringe Entwickelung im Verhältnis zur Menge des Parenchyms.

Diese Arbeit wurde auf Veranlassung meines damaligen Chefs, Herrn Prof. Dr. med. K. E. Schreiber begonnen. Es ist mir eine angenehme Pflicht ihm auch an dieser Stelle für das lebhafte Interesse, das er derselben stets gezeigt und für die Liebenswürdigkeit, mit der er mir die Hilfsmittel des Anatomischen Instituts zur Verfügung stellte, meinen verbindlichsten Dank auszusprechen. 


\section{Inhaltsverzeichnis.}

Kapitel 1. Seite

a) Einleitung und historische Ubersicht . . . . . . . . 667

b) Untersuchungsmaterial . . . . . . . . . . . . . . . . 672

c) Technik . . . . . . . . . . . . . . . . . . . . . 676

Kapitel 2.

Beschreibung der Befunde . . . . . . . . . . . . . . . . 678

a) Cyclostomen . . . . . . . . . . . . . . . . . . . . . 678

b) Selachien ... . . . . . . . . . . . . . . 705

c) Teleostien . . . . . . . . . . . . . . . . . . . . 717

d) Amphibien . . . . . . . . . . . . . . . . . . . . 725

a) Anura . . . . . . . . . . . . . . . . . . . . 729

в) Urodela . . . . . . . . . . . . . . . . . . . 735

Kapitol 3.

Gesamte Ergebnisse der Untersuchung . . . . . . . . . . 752

Literaturverzeichnis . . . . . . . . . . . . . . . . 765

Tafelerklarung . . . . . . . . . . . . . . . . 767 


\section{Literaturverzeichnis.}

Bluntschli, H. (1903), Der feinere Bau der Leber von Ceratodus Forsteri, zugleich ein Beitrag zur vergleichenden Histologie der Fischleber. Se mons zoologische Forschungsreisen. Bd. 1, Lief. 4, S. 1. Jena, G. Fischer. 1903.

Brachet, A. (1896), Die Entwickelung und Histogenese der Leber. und des Pankreas. Ergebn. d. Anat. u. Entwickelungsgesch. Bd.6. 1896.

Braus, H. (1896), Untersuchungen zur vergleichenden Histologie der Leber der Wirbeltiere. Habilitationsschrift und in Semons zoologische Forschungsreisen Bd. 2. Jena, G. Fiseher. 1896.

Cole, F. J. (1913), A monograph on the general morphology of the myxinoid fishes, based on a study of Myxine. Part V. the gut and its appendnges. Transactions of the Royal Society of Edinburgh. Vol. 49. Part. II. 1913.

Eberth, C. J. (1866), Über den feineren Bau der Leber. Med. Zentralbl. 1866. Nंr. 57. S. 897.

Derselbe $(1867, a)$, Untersuchungen über die Leber-der Wirbeltiere. Areh. f. mikr. Anat. Bd. 3, S. 423.1867.

Derselbe $(1867, b)$, Untersuchungen über die normale und pathologische Leber. Arch. f. path. Anat. u. Physiol. Bd. 39, H. 1, S. 70.1867.

Enzyklopädie der mikroskopischen Technik. Urban und Schwarzen. berg. 1910.

Frey, v. H. (1859), Histologie und Histochemie des Menschen. Leipzig. W. Engelmann. 185?.

Gegenbaur, C. (1901), Vergleichende Anatomie der Wirbeltiere mit Berücksichtigung der Wirbellosen. Bd. 2. Leipzig 1901.

Haller, B. (1904), Lehrbuch der vergleichenden Anatomie. Jena, G. Fischer. 1904.

Herịng, E. (1866, a und b), Über den Bau der Wirbeltierleber. 1, u. 2. Mitt. Wien. Sitzungsber. Bd. 54. Abt. 1. 1866 und in Arch. f. mikr. Anat. Bd. 3, S. 88.1867.

Derselbe (1871), Von der Leber. Stricker, Handbuoh der Gewebelehre. 1871. S. 429.

Hol m, J. F. (1897): Über den feineren Bau der Leber bei den niederen Wirbeltieren. Zool. Jahrb. Abt. f. Anat. Bd. 10, S. 277. 1897.

Hy t tl, J. (1864), Über das Verhalten der Leberarterie zur Pfortader bei Amphibien und Fischen. Wien. Sitzungsber. Bd, 49. Abt. 1., S. 167. 1864. 
Klinckowström, A.·(1890), Beiträge zur Kenntnis des Verlaufes der Darmund Lebervenen bei Myxine glutinosa. Biologiska föreningens förhandlingar in Stockholm. Bd. 3, S. 62. 1889-1890.

Mall, Franklin P., A study of the structure unit of the liver. Amer. Journ. of Anat. Vol. 5, p. 227. Nr. 3.

Müller, Joh. (1839), Vergleichende Anatomie der Myxinoiden. Abhandl, Akad. Berlin 1V. Gefässsystem. 1839.

Oppel, A. (1900), Lehrbuch der vergleichenden mikroskopisohen Anatomie der Wirbeltiere. Jena, G. Fischer. 1900.

Retzius, G. (1892, a), Über die Gallenkapillaren und den Drüsenbau der Leber. Biol. Untersuch. N. F. Bd. 3, H. 10, s. 65. 1892.

Derselbe $(1892, b)$, Weiteres über die Gallenkapillaren und den Drüsenbau der Leber. Biol. Untersuch: N. F. BA. 4, H. 9, S. 67. 1892.

Derselbe (1898), Utber die Gallenkapillaren. Biol. Untersuch. N. F. Bd. 8, S. 98.1898 .

Scammon, Richard E., The development of the Elasmobranch liver. 1. The early development of the liver. 2. The development of the liver ducts and gall bladder. Amer. Journ. of Anat. Vol. 14, Nr. 3, S. 333.

Derselbe (1915), The histogenesis of the selachian liver. Amer. Journ. of Anat. Vol. 17, Nr. 3, 1915,

Segerstraale, Eva (1910), Zur Kenntnis der Teleostierleber. Anat. Hefte Bd. 41. Abt. 1. 1910.

Shore, Th. W. und Jones, H. L. (1889), On the structure of the vertebrate liver. Journ. of Physiol. Vol. 10, S. 408. 1889.

Stöhr, Ph. (1910), Lehrbuch der Histologie und der mikroskopisehen Anatomic des Menschen. 14. Aufl. Jena, G. Fischer. 1910. 


\section{Erklärungen zu den Textabbildungen.}

Fig. $b_{1}-b_{7}$. Leber. Myxine gl. Golgi-Imprägnation.

$b_{1}-b_{5}=$ vasozonale Gallencapillarmaschen. Grenzen der Tubuli und die geschwärzten Gallencapillarmaschen. Vergrösserung: 525 .

$b_{6}-b_{7}$; oytozonale Gallencapillarmaschen. Auf Fig. $b_{7}$ sind auch dio Kerne eingezeichnet; die eine Masche ist uni-, die andere pluricellulär. Vergrösserung 675 .

Fig. e. Myxine gl. Schema. Die Verbindung der Tubuli, durch 51 Schnitte verfolgt. Je 2,5 mm in der Höhe entspricht ein Schnitt à $10 \mu$.

Fig. $d_{1}-d_{2}$. Myxine gl. Wachsrekonstruktion (vgl. den Text).

Fig. e. Myxine gl. Schema. Querschnitt eines Tubulus, der zwischen einem Gefäss ( $v$. h.) und der Leberkapsel liegt. (l).

Fig. $f_{1}-f_{2}$. Myxine gl. Schema. Bildung einer cytozonalen Masche durch Vereinigung zweier Tubuli.

Fig. $g_{1}-g_{3}$. Myxine gl. Schema. Bildung einer .oytozonalen Masche im Verlauf eines Tubulus (vgl. den Text).

Fig. h. Spinax. Schema. Die Verteilung der Lebergefässe bei einem $41 \mathrm{~mm}$ langen Embry.o. v. p. = Pfortader, v. h. = Lebervene. Die Leberarterie nicht gezeichnet.

Fig. i. Spinax. Querschnitt eines $41 \mathrm{~mm}$ langen Embryos. Leberparenchym und Blutcapillare sind durch eine graue Farbe angedeutet, nur die Gefässe sind eingezeichnet.

$$
\begin{aligned}
& \text { v. p. }=\text { Zweige der Pfortader. } \\
& \text { v. h. }=\text { Zweige der Lebervene. } \\
& \text { g. = grosser Gallengang. }
\end{aligned}
$$

Die Flüssigkeit von Zenker. Hämatoxylin-Eosin. Vergrösserung:16.

Fig. k. Syngnathus rost. Querschnitt von Leber und Darm. Leberparenchym und Blutcapillare sind durch eine graue Farbe angedeutet. Der Pankreasstamm mit einem Zweig hinein in die Leber. Im Stamm selbst ein Pfortaderzweig; durch die Spitze des Pankreas-Pfortaderzweigs steht die Pfortader in Verbindung mit einem der Blutcapillaren der Leber. Dorsal in der Lebersubstanz ein Gallengang (Querschnitt).

$$
\text { v. h. = Zweige der Lebervene. }
$$

Die Flìssigkeit von Zenker. Hämatoxylin-Eosin. Vergrösserung: 35. 
Fig. $l_{1}-l_{2}$. Leber. Syngnathus rost. Golgi-Imprägnation.

$l_{1}$ eine vasozonale, $l_{2}$ eine cytozonale Gallencapillarmasche. Vergrösserung: $1_{1}: 335,1_{2}: 700$.

Fig. $\mathrm{m}_{1}-\mathrm{m}_{2}$. Bufo cinereus.

$\mathrm{m}_{1}$ halbschematischer Längensehnitt, $\mathrm{m}_{2}$ schematischer Querschnitt durch die Leber bei einem jungen $-2,5 \mathrm{~cm}$ langen - Individuum. Verlauf der Lebergefässe. Die Leberarterie nicht gezeichnet. V. p. $=$ Pfortader, v. h. = Lebervene, D. = Darm.

Fig. $n_{1}-n_{2}$. Leber. Bufo cinereus. Golgi-Imprägnation.

$\mathrm{n}_{1}$ : acht, zusammenhängende vasozonale Gallencapillarmaschen. $\mathrm{n}_{2}$ : zwei zusammenhängende cytozonale an 'der Vereinigungsstelle zweier Tubuli; auch pilzförmige intracelluläre Seitenzweige sind sichtbar. Vergrösserung: 335.

Fig. o. Leber. Triton punct. Querschnitt durch den kranialen Teil der Leber. Leberparenchym und Blutcapillare sind dureh eine graue Farbe angedeutet.

$$
\text { v. p: }=\text { Pfortaderzweig. }
$$

g. = Gallengang. Die übrigen Gefässe sind Lebervenenzweige.

Die Flüssigkeit von Zenker. Hämatoxylin-Eosin. Vergrösserung: 16.

Fig. p. Leber. Triton punct. Das Leberparenchym ist teilweise in einreihigen Zellreihen (a), teils in Tubuli angeordnet. Sowohl ,"zweizelliger“ Tubulus mit Gallencapillaren zwischen den Flächen der Zellen (b), wie gewöhnlicher „mehrzelliger" Tubulus (c). In dem letzteren sieht man den Querschnitt des Gallencapillars, indem er eine cytozonale Masche bildet. Unmittelbar innerhalb der Leberkapsel liegt eine schmale Zone: von leukocytähnlichen Zellen.

Die Flüssigkeit von Zenker. Hämatoxylin-Eosin. Vergrösserung: 200.

Fig. q. Leber. Triton punet. Zellplatte, Flächenschnitt. Die „kanten“und ,flächenständigen". Gallencapillaren.

Die Flüssigkeit von Zenker. Hämatoxylin-Eosin. Vergrösserung: 590.

Fig. r. Leber, Triton punct: Die Flüssigkeit von Zenker. HämatoxylinEosin. Vergrösserung: 590.

Fig. s. Leber, Triton punct. Golgi-Imprägnation.

Vasozonale Masche in Verbindung mit cytozonaler. (Fine kleine Zellplatte.) Vergrösserung: 430.

Fig. $t_{1}-t_{2}$. Leber, Triton punct. Golgi-Imprägnation.

Zusammenhängende cytozonale Gallencapillarmaschen, in $t_{2}$ mit Kernfärbung (Grenachere Alaunkarmin). Vergrösserung: 430.

Fig. $u_{i}-u_{2}$. Triton Schema. Bildung einer Zellplatte aus ,zweizelligen" Tubuli.

Fig. v. Leber, Triton punct. Mehrere Zellplatten stossen zusammen und scheinen dadurch an der Bildung einer neuen Zellplatte teilzunehmen. $\mathbf{p}^{\prime}=$ pigmenthaltige Leukocyten.

Die Flüssigkeit von Zenker. Hämatoxylin-Eosin. Vergrösserung: 590. 


\section{Erklärungen zu den Tafelabbildungen.}

Fig. 1. Leber, Myxine gl. Querschnitt durch den hinteren Leberlappen. In der mittleren Zone des Schnittes sind vier durchgeschnittene Pfortaderzweige sichtbar, begleitet von.Gallengängen. Peripherisch Zweige der Lebervene.

Die Flüssigkeit von Zenker. Hämatoxylin-Eosin. Vergrösserung: 175.

Fig. 2. Leber, Myxine gl. Querschnitt durch den hinteren Leberlappen eines $10 \mathrm{~cm}$ langen Individuums. In der-mittleren Zone drei kleine Pfortaderzweige, peripherisch Lebervenenzweige. $G=$ Gallengang, der ausserhalb der Leber den Pfortaderstamm folgt. Bl. s. = Überbleibsel des Blutsinus.

Die Flüssigkeit von Zenker. Delafields Hämatoxylin-BoraxkarminOrange. Vergrösserung: 72.

Fig. 3. Leber, Myxine gl. Von einem Schnitt durch den hinteren Leberlappen eines $27 \mathrm{~cm}$ langen Individuums. Ein grosser Pfortaderzweig, umgeben von Bindegewebe und Gallengängen von wechselnder Grösse.

Die Flüssigkeit von Zenker. Weigerts Hämatoxylin-van Gieson. Vergrösserung: 200 .

Fig. 4, 5 und 6. Leber, Myxine gl.

Fig. 4: eine unicelluläre Gallencapillarmasche im Verlauf cines Tubulus. Fig. 5: eine pluricelluläre Masche (zwei Zellen) an der Vereinigungsstelle von 4 Tubuli. Fig. 6: unicelluläre Masche an der Vereinigungsstelle von 3 Tubuli.

Die Flüssigkeit von Zenker. Hämatoxylin-Eosin. Vergrösserung: 590.

Fig. 7. Leber, Spinax. Von einem Querschnitt durch ein $39 \mathrm{~mm}$ langes Individuum. Beide oberen und medialen Gefässe sind Pfortaderzweige, das eine ist von einem Gallengang begleitet. Das laterale Gefäss ist der Hauptzweig der Lebervene.

Die Flüssigkeit von Zenker. Hämatoxylin-Eosin. Vergrösserung: 122.

Fig. 8. Spinax. Von einem Schnitt aus einem $41 \mathrm{~mm}$ langen Embryo. - Eine nicht völlig geschlossene cytozonale Masche.

Die Flüssigkeit von Zenker. Hämatoxylin-Eosin. Vergrösserung: 335.

Fig. 9. Spinax. Von einem Schnitt aus einem $39 \mathrm{~mm}$ langen Embryo. Am weitesten rechts bildet das Gallencapillar eine kleine Masche; auch mehrere unvollständige Maschen sieht man im Schnitt.

Die Flüssigkeit von Zenker. Hämatoxylin-Eosin. Vergrösserung: 590.

Fig. 10. Bufo cinereus. Von einem jungen Individuum (etwa $3,5 \mathrm{~cm}$ lang). Tubuli, Pfortaderzweige und Gallengänge, die letzteren begleitet von leukocytähnlichen Zellen.

Die Flüssigkeit von Zenker. Hämatoxylin-Eosin. Vergrösserung: 210. 

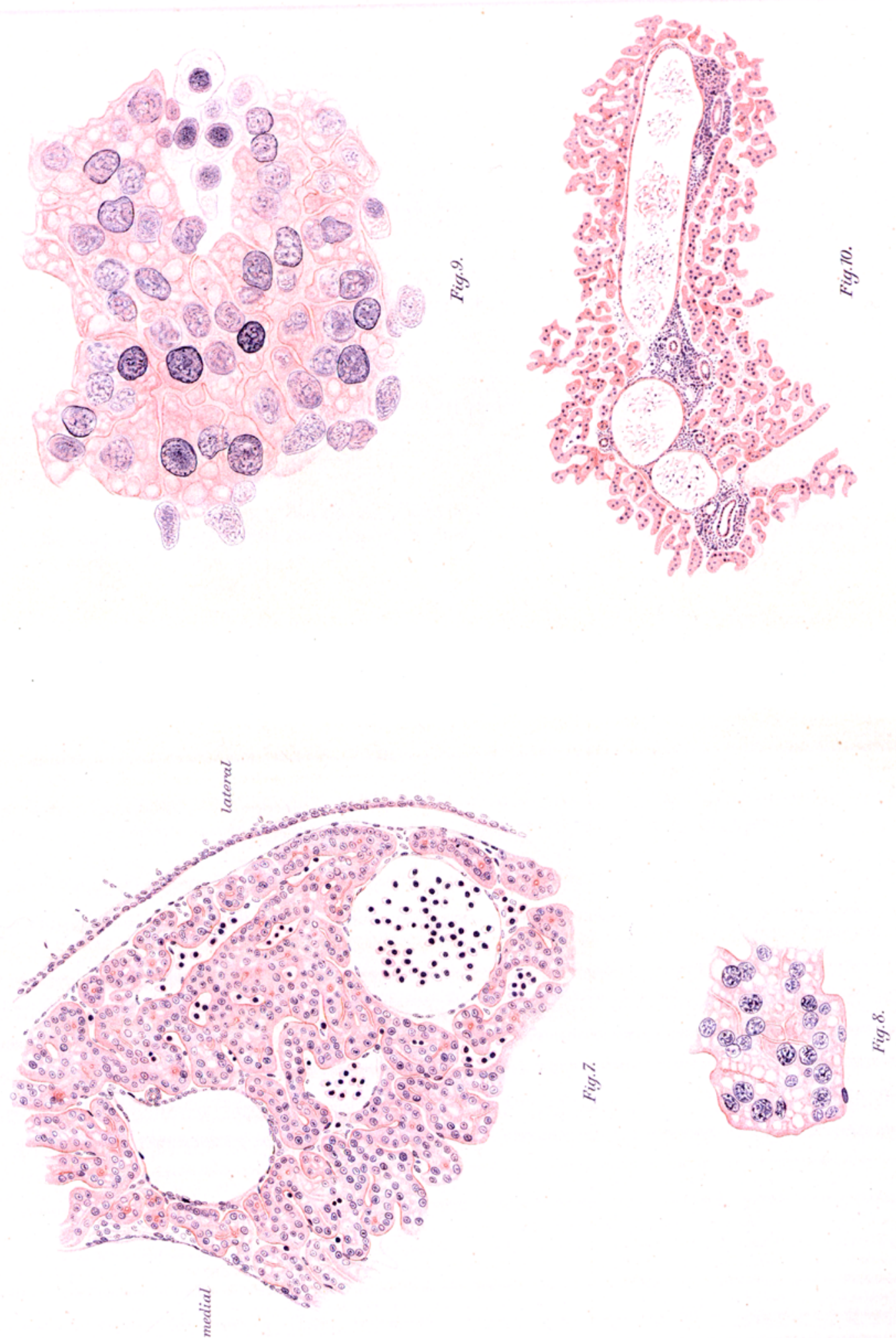